University of Louisville

ThinkIR: The University of Louisville's Institutional Repository

8-2009

\title{
Workplace incivility : relationship with conflict management styles and impact on perceived job performance, organizational commitment and turnover.
}

Jeannie Trudel 1964-

University of Louisville

Follow this and additional works at: https://ir.library.louisville.edu/etd

\section{Recommended Citation}

Trudel, Jeannie 1964-, "Workplace incivility : relationship with conflict management styles and impact on perceived job performance, organizational commitment and turnover." (2009). Electronic Theses and Dissertations. Paper 1460.

https://doi.org/10.18297/etd/1460

This Doctoral Dissertation is brought to you for free and open access by ThinkIR: The University of Louisville's Institutional Repository. It has been accepted for inclusion in Electronic Theses and Dissertations by an authorized administrator of ThinkIR: The University of Louisville's Institutional Repository. This title appears here courtesy of the author, who has retained all other copyrights. For more information, please contact thinkir@louisville.edu. 
WORKPLACE INCIVILITY: RELATIONSHIP WITH CONFLICT MANAGEMENT

STYLES AND IMPACT ON PERCEIVED JOB PERFORMANCE, ORGANIZATIONAL COMMITMENT AND TURNOVER

\author{
By \\ Jeannie Trudel \\ B.Ec., Monash University, Australia, 1987 \\ L.L.B, Monash University, Australia, 1989 \\ M.A., California State University, Dominguez Hills, 2002

\begin{abstract}
A Dissertation
Submitted to the Faculty of the

Graduate School of the University of Louisville in Partial Fulfillment of the Requirements

for the Degree of
\end{abstract} \\ Doctor of Philosophy \\ College of Education and Human Development \\ Department of Leadership, Foundations and Human Resource Education \\ University of Louisville \\ Louisville, KY
}

August 2009 

Copyright 2009 by Jeannie Trudel

All rights reserved 
WORKPLACE INCIVILITY: RELATIONSHIP WITH CONFLICT MANAGEMENT STYLES AND IMPACT ON PERCEIVED JOB PERFORMANCE, ORGANIZATIONAL COMMITMENT AND TURNOVER.

By

Jeannie Trudel

B.Ec., Monash University, Australia, 1987

L.L.B, Monash University, Australia, 1989

M.A., California State University, Dominguez Hills, 2002

A Dissertation Approved on

July 9,2009

by the following Dissertation Committee:

Dissertation Director 


\section{ACKNOWLEDGEMENTS}

My sincere thanks and deepest gratitude to Dr. Joe Petrosko and Dr. Thomas

Reio, Jr., who both served as co-chairs of my dissertation, and were my advisors at different times in the doctoral program. I also extend my warmest thanks to Dr. Patricia Leitsch, Dr. Carolyn Rude-Parkins and Dr. Lyle Sussman, for their invaluable assistance and advice as members of my committee.

I thank my friends and colleagues for their encouragement and support throughout this journey. A special thank you to my husband, Grant, and our children, Jared and Alisa, for their support and sacrifice. This work is dedicated to them. I am also grateful to God for His sustenance and grace in my life. 


\section{ABSTRACT \\ WORKPLACE INCIVILITY: RELATIONSHIP WITH CONFLICT MANAGEMENT \\ STYLES AND IMPACT ON PERCEIVED JOB PERFORMANCE, ORGANIZATIONAL COMMITMENT AND TURNOVER INTENTIONS}

Jeannie Trudel

July 9,2009

This cross-sectional, correlational study $(N=289)$ explored the relationships among workplace incivility, conflict management styles and their influence on perceived job performance, organizational commitment and turnover intentions. Differences between incivility target and instigator perspectives were also examined. Data were collected through a self- report survey questionnaire consisting of a battery of six scales. Research questions were tested through corrclational and hierarchical regression analytic procedures. Findings revealed that incivility and conflict management styles influenced perceived job performance, organizational commitment and turnover intentions to varying degrees. Results remained significant even after controlling for organizational differences and demographic variables.

For the job performance model, the use of an integrating conflict style positively contributed to perceived job performance, while the dominating style negatively contributed to the dependent variable. As for the organizational commitment model, an integrating conflict style and less incivility positively predicted organizational commitment, whereas a dominating conflict style and incivility made negative 
contributions to the regression equation. The turnover intent model indicated that the dominating conflict style and incivility positively predicted turnover, while the integrative style and lower level of incivility negatively predicted turnover intent. The influence of instigator and target incivility perspectives were similar on the dependent variables, with slight variations only in magnitude. Generally, findings reveal that individuals who used an integrating conflict style had higher perceived job performance, tended to be more civil and less inclined to engage in uncivil behaviors, as well as having a higher level of commitment to the organization and less likely to turnover. In contrast, individuals with a dominating conflict style were more likely to instigate incivility as well as be a target of incivility; scoring lower on organizational commitment along with a higher level of intent to quit. Instigators of incivility reported being targets of incivility, confirming a spiral effect where incivilities are exchanged. Findings support theoretical and empirical research on the deleterious effects of incivility on organizational outcomes. HRD interventions are highlighted as possible means for managing or curbing workplace incivility and improving organizational performance. 


\section{LIST OF TABLES}

TABLE

PAGE

1. Big Five Factors, Deviant Behaviors and Conflict Styles.

2. Study procedures based on Dillman's (2007) Tailored Design Method and Online

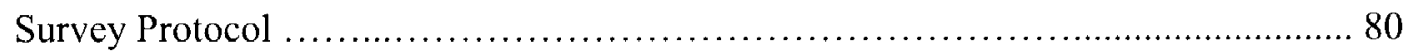

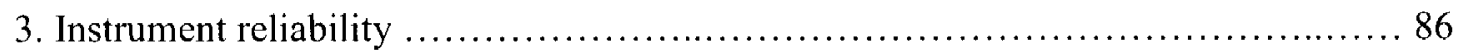

4. Research questions, variables, and proprosed statistical analyses .................... 90

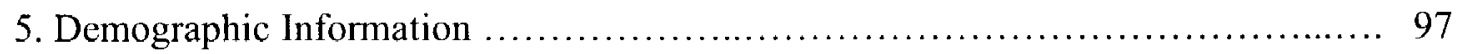

6. Descriptive Statistics ........................................................ 100

7. Cronbach's $\alpha$ Reliability Coefficients for scale measures ........................ 102

8. Correlations between Variables..................................................... 105

9. Summary of Hierarchical Regression Analyses for Organizational Effects, Conflict Management Styles and Target Incivility Predicting Job Performance (Task

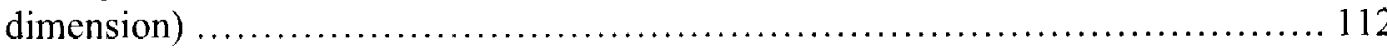

10. Summary of Hierarchical Regression Analyses for Organizational Effects, Conflict Management Styles and Instigator Incivility Predicting Job Performance (Task dimension)

11. Summary of Hierarchical Regression Analyses for Organizational Effects, Conflict Management Styles and Target Incivility Predicting Job Performance (contextual)

12. Summary of Hierarchical Regression Analyses for Organizational Effects, Conflict Management Styles and Instigated Incivility Predicting Job Performance (contextual)

13. Summary of Hierarchical Regression Analyses for Organizational Effects, Conflict Management Styles and Target Incivility Predicting Organizational Commitment 
14. Summary of Hierarchical Regression Analyses for Organizational Effects, Conflict Management Styles and Instigated Incivility Predicting Organizational Commitment

15. Summary of Hierarchical Regression Analyses for Organizational Effects, Conflict Management Styles and Target Incivility Predicting Turnover Intent 125

16. Summary of Hierarchical Regression Analyses for Organizational Effects, Conflict Management Styles and Instigated Incivility Predicting Turnover Intent

17. Summary of Hicrarchical Regression Analyses for Organizational Effects, Demographic variables (Gender, Tenure, Hierarchical Rank, Age), Conflict Management Styles and Target Incivility Predicting Job Performance (Task)

18. Summary of Hierarchical Regression Analyses for Organizational Effects, Demographic variables (Gender, Tenure, Hierarchical Rank, Age), Conflict Management Styles and Instigated Incivility Predicting Job Performance (Task)

19. Summary of Hierarchical Regression Analyses for Organizational Effects, Demographic variables (Gender, Tenure, Hierarchical Rank, Age), Conflict Management Styles and Target Incivility Predicting Job Performance (Contextual)

20. Summary of Hierarchical Regression Analyses for Organizational Effects, Demographic variables (Gender, Tenure, Hierarchical Rank, Age), Conflict Management Styles and Instigated Incivility Predicting Job Performance (Contextual)

21. Summary of Hierarchical Regression Analyses for Organizational Effects, Demographic variables (Gender, Tenure, Hierarchical Rank, Age), Conflict Management Styles and Target Incivility Predicting Organizational Commitment

22. Summary of Hicrarchical Regression Analyses for Organizational Effects, Demographic variables (Gender, Tenure, Hierarchical Rank, Age), Conflict Management Styles and Instigated Incivility Predicting Organizational Commitment

23. Summary of Hierarchical Regression Analyses for Organizational Effects, Demographic variables (Gender, Tenure, Hierarchical Rank, Age), Conflict Management Styles and Target Incivility Predicting Turnover Intent 
24. Summary of Hicrarchical Regression Analyses for Organizational Effects, Demographic variables (Gender, Tenure, Hierarchical Rank, Age), Conflict Management Styles and Instigated Incivility Predicting Turnover Intent

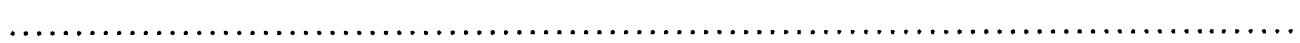




\section{TABLE OF CONTENTS}

PAGE

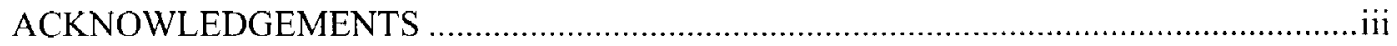

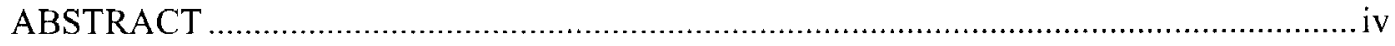

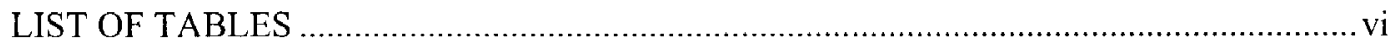

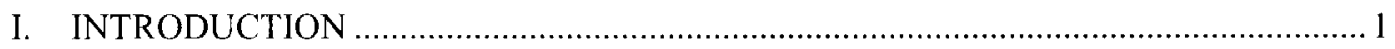

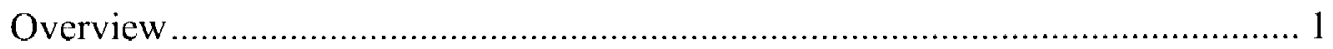

Statement of the Problem................................................................................ 8

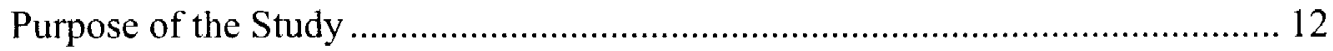

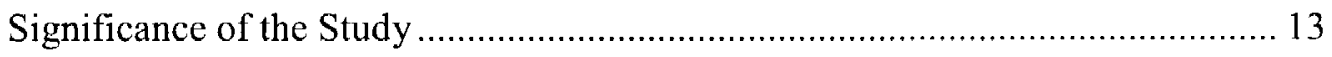

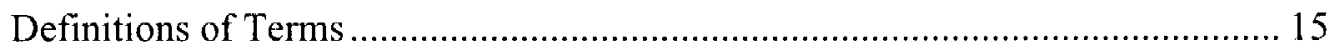

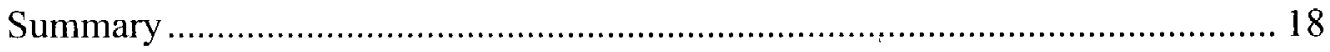

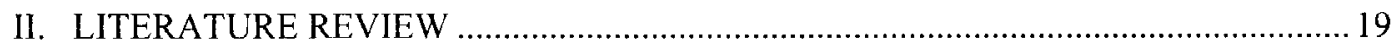

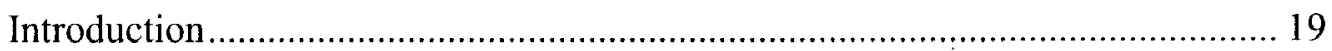

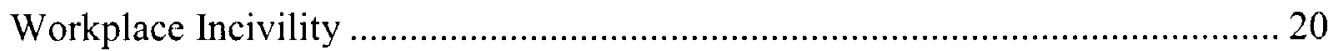

Conflict Management Styles................................................................................ 44

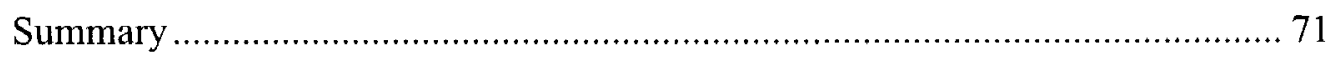

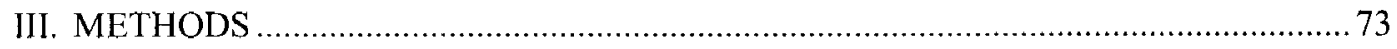

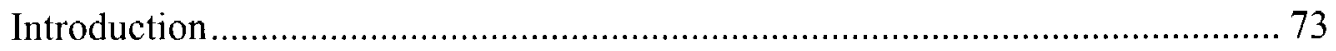

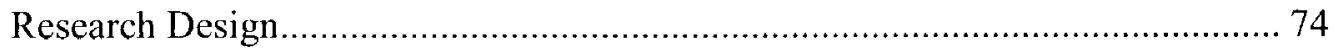

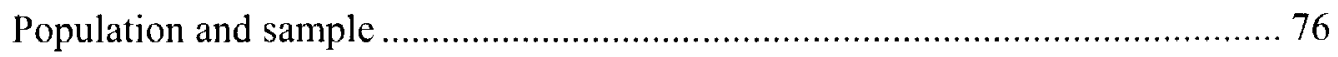


Data Collection Procedures............................................................... 77

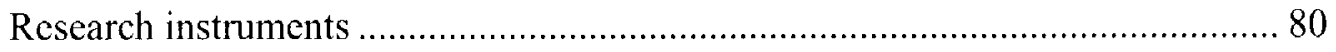

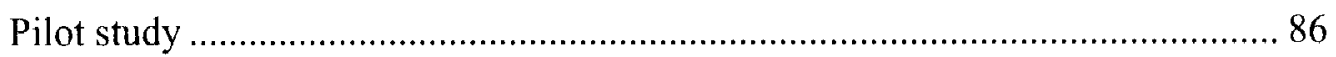

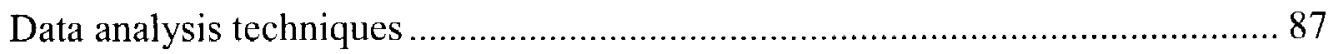

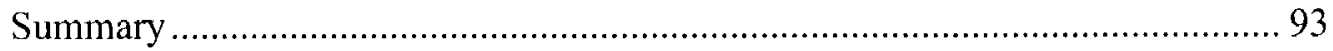

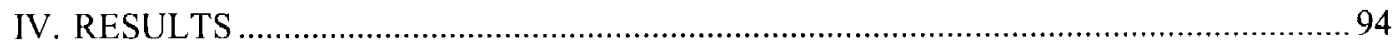

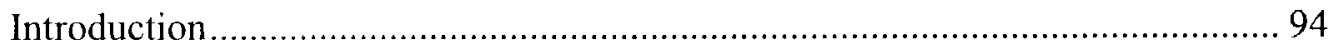

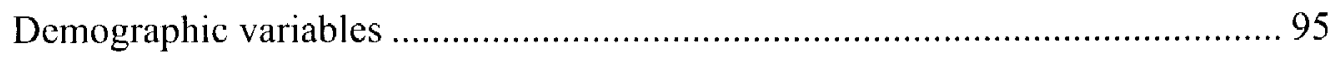

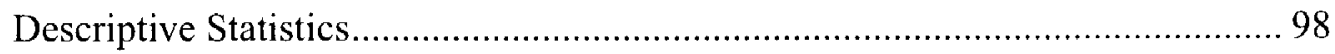

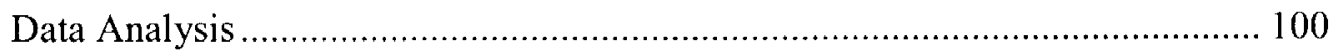

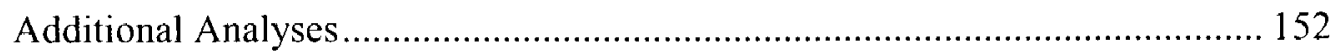

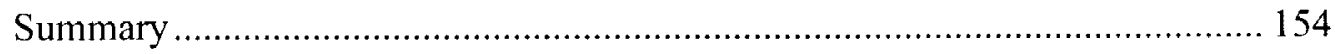

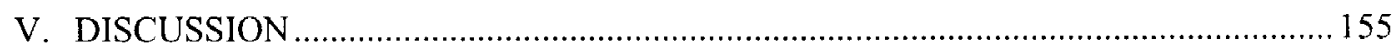

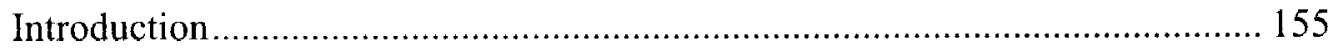

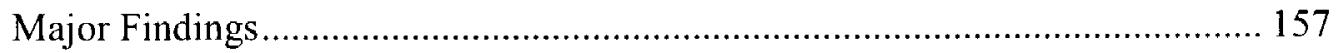

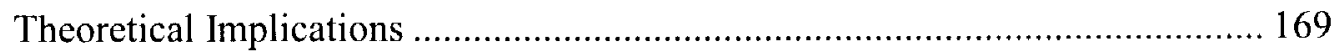

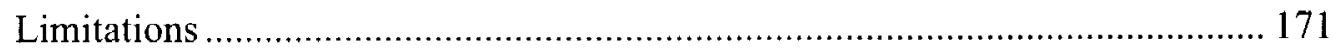

Recommendations for further research ................................................... 173

Implications for Human Resource Development........................................ 176

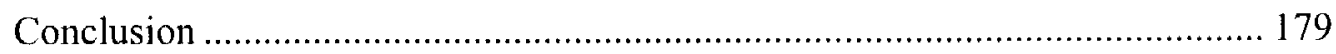

REFERENCES 
APPENDICES

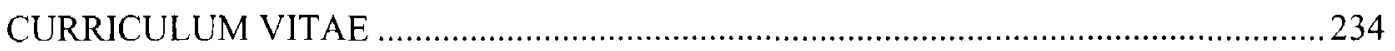




\section{CHAPTER I \\ INTRODUCTION}

Overview

The workforce of the twenty-first century is dealing with rapid changes and increased competition across industries. Organizational change is a constant and businesses are required to adapt and maintain flexibility to remain viable. The workplace itself has been transformed as a result of the convergent forces of globalization, technology and corporate capitalism resulting in new organizational structures and operational models (O'Toole \& Lawler, 2006). The changing structures of organizations from the vertical (hierarchical) to horizontal (collaborative) have resulted in connectivity to the workplace as never before: employees may be accessible to their organizations $24 / 7$ via technology. Consequently, boundaries between work and personal time are blurred. Expectations of work performance have increased and employees are working longer and harder (O'Toole \& Lawler, 2006). All of these changes place stress on management and workers alike, increasing the potential for workplace conflict and deviant workplace behavior.

These profound changes in organizations and work processes have led to a plethora of organizational issues, one of which is workplace incivility. Another issue is that of effective conflict management in the workplace, which although related to workplace incivility, has not been previously linked in the literature. Further, both workplace incivility and conflict management styles may have an impact on how 
workers' perform their jobs (job performance), their commitment to their organization and their intent to leave their jobs. These issues, which are relevant to organizational effectiveness, is of interest to researchers and Human Resource Development practitioners alike. Human Resource Development (HRD) is concerned about the development and maintenance of a high performing and adaptable workforce that forms the foundation for organizational effectiveness. The study of both of these issues and their related constructs will yield pertinent information on the effective management of cmployees' conflict and curbing workplace incivility.

Workplace incivility has garnered much attention in the research and popular literature over the last decade. It is recognized as a growing problem (Andersson \& Pearson, 1999; Pearson, Andersson, \& Porath, 2000) as employees attempt to do more with less. Civility requires time as well as effort and employees are constantly under time constraints, which then promulgate uncivil behaviors (Pearson \& Porath, 2005). Workplace collegiality and interpersonal relationships enabling collaboration and communication are foundational to an organization. Interpersonal relationships are critical determinants of organizational effectiveness - how it functions, how effectively it performs its central tasks, and how it reacts to its external environment (Duffy, Ganster, \& Pagon, 2002). Behaviors that erode the fabric of interpersonal relationships in the workplace can be detrimental to organizational effectiveness.

Although uncivil behaviors do not usually merit organizational or legal sanctions, their negative impact has far-reaching effects on organizations. Incivility can affect the bottom line of organizations. Pearson, Andersson and Porath (2000) found that in a sample of over 1400 employees across industries, $50 \%$ of respondents who experienced 
incivility, reported lost work time due to worry, while $25 \%$ wasted work time trying to avoid instigators in the workplace. Targets of incivility are more likely to turnover (Pearson et al., 2000; Lim \& Cortina, 2005; Lim, Cortina, \& Magley, 2008). Further, studies have shown that workplace incivility negatively affects other organizational members who are witness to, or work with either the instigator or the target (Pearson et al., 2000; Spreitzer, 1995).

Various factors, both individual and organizational, affect the promulgation of workplace incivility. Situational factors have been established as significant predictors of individuals who are predisposed to deviant behaviors. When an organization experiences pressures to change such as reduction in budgets, increasing diversity in its workforce including increasing part-time workers, management changes, and the implementation of technology to monitor worker productivity, employees are more likely to engage in deviant behaviors targeted at the organization and/ or its members (Baron \& Neuman, 1996; Neuman \& Baron, 1998; Neuman \& Baron, 1997). Informal organizational climates are also more likely to encourage uncivil exchanges (Andersson \& Pearson, 1999). Some researchers contend that technology facilitates uncivil and antisocial behaviors in the workplace (Pearson, Andersson, \& Porath, 2000). The prolific use of email and voicemail appear to facilitate uncivil behaviors. However, Neuman and Baron (1997) recognized that individual characteristics such as Type A personality, selfmonitoring and hostile attributional style may be important factors as well. Andersson and Pearson (1999) substantiated that employees who are more emotionally reactive, take offense easily, and are rebellious are more prone to uncivil behaviors. 
In sum, workplace incivility is a complex issue that needs to be examined at both the macro-external and micro-internal levels since organizational and individual factors play a role in its proliferation. Examination of such factors may help HRD practitioners in exploring methods of dealing with this growing problem in organizations.

\section{Workplace Incivility}

Workplace incivility is defined as a form of organizational deviance, on an interpersonal level (Robinson \& Bennett, 1995) and is characterized by low-intensity behaviors that violate respectful workplace norms, appearing vague as to intent to harm (Andersson \& Pcarson, 1999). Workplace incivility presents a unique challenge as it is "more insidious, taking hold in such an ambiguous and stealthy manner that it is difficult to identify, manage, and prevent" (Cortina, 2008, p. 71).

There are a number of similar constructs that overlap workplace incivility including aggression, petty tyranny, deviant and antisocial behaviors (Andersson \& Porath, 1999). Earlier, Giacalone \& Greenberg (1997) classified workplace incivility as a subset of antisocial employee behavior. Counterproductive workplace behavior is similar in concept to workplace incivility in that specific intent to harm need not be a requisite. Counterproductive workplace bchavior is defined as purposeful employee actions that result in harm to an organization or its members (Spector \& Fox, 2005). Workplace incivility may be considered as a subset of counterproductive workplace behavior. If viewed on a continuum of abusive behaviors in the workplace, workplace incivility would place at the lower end of the continuum (Johnson \& Indvik, 2001a). Further, workplace incivility was identified as a precursor to aggression and violent behaviors (Glendinning, 2001; Pearson et al., 2000; Pearson, Andersson, \& Wegner, 2001). In spite 
of the overlap between the various types of workplace deviance, workplace incivility is accepted as a separate construct consisting of a mild form of interpersonal deviant workplace behavior.

\section{Workplace Incivility and Conflict Management}

Workplace incivility may be considered a cause or trigger of conflict as well as the consequential behaviors arising from conflict. Consistent with the concept of incivility being both an antecedent and outcome of conflict, conflict is defined as a "process that begins when one party perceives that the other has negatively affected, or is about to negatively affect, something that he or she cares about" (Thomas, 1992, p. 653). Various reasons have been posited for the genesis of organizational conflict. Rahim (2002) attributes differences in attitudes, values, level of skills and behaviors for conflict between co-workers or between employees and their organization.

Workplace conflict, if not managed effectively, leads to increased stress, reduced workplace performance and negatively impacts health and wellbeing of employees (McKenzie, 2002). Other negative effects of such conflict include dysfunctional behavior, lowered productivity and even the demise of an organization (Khun \& Poole, 2000; Nicotera, 1997). Further, Meyer (2004) asserts that unresolved workplace conflict may lead to antisocial behaviors, covert retaliation, and even violence. Conflict at the lower levels is akin to workplace incivility, lower in intensity but over time, has the potential to escalate.

The negative consequences of badly managed conflict in the workplace are evident. Consequently, effective management of conflict is essential for individuals, groups and organizations to function successfully (Rahim, 2000). If managed effectively, 
conflict can be a positive force in organizations (Jameson, 1999; Pelled, Eisenhardt \& Xin, 1999; Rahim, 2001, 2002; Song, Dyer, \& Thieme, 2006). The perception that conflict has a negative impact at the workplace is substantiated in the literature. Conflict stress is associated with emotional exhaustion, absenteeism, and turnover intentions (Giebels \& Janssen, 2005). Research has established that poorly managed conflict affects the level and frequency of future conflict and has a negative effect on productivity and work performance (Meyer, 2004). Similarly, there is a negative association between destructive conflict and innovation performance in organizations (Song et. al., 2006).

Often, in a conflict situation, it is the differences in conflict management styles, rather that the conflict issue itself, that creates the most tension (Ting-Toomey, Gau, Trubisky, Yang, Kim, Lin, \& Nishida, 1991). It stands to reason that how a conflict is handled impacts the process and outcomes of that conflict. Various scholars have posited models of conflict management styles: that fundamentally there are certain groupings or styles of conflict behaviors manifested by individuals (Blake \& Mouton, 1970; Rahim, 1983; Thomas, 1992). Conflict management styles are indicative of an individual's general tendency to engage repeatedly in a certain type of conflict behavior across situations (Cupach \& Canary, 1997). Consequently, these styles are considered as relatively stable personal dispositions even though individuals do utilize varying approaches to conflict depending on the situation (Ruble \& Schneer, 1994).

Rahim (1985) proposed a model consisting of five conflict management styles: dominating, integrating, compromising, accommodating, and avoiding. These styles are aligned according to two dimensions reflecting the degree to which a person is concerned about satisfying his or her own goals and the extent to which the person is supportive of 
the other person's goals. The integrating, also known as problem-solving or collaboration style is considered the most constructive of the five conflict management styles (Blake \& Mouton, 1970, 1981; Rahim, 1983). There is some research to substantiate this perspective. Styles of conflict and levels of conflict were found to be significantly related to individual job satisfaction, with the integrating and compromising styles being positively related to interpersonal outcomes, while dominating and avoiding styles were negatively related to interpersonal outcomes (Weider-Hatfield \& Hatfield, 1995). Workplace Incivility, Conflict Management Styles and Personality Traits

Studies have established that separately, both workplace incivility and conflict management styles are related to personality traits. Four of the Big Five personality traits: Conscientiousness, Agreeableness, Extraversion and Neuroticism, do influence individuals' propensity toward deviant workplace behaviors. For instance, individuals who are low in conscientiousness are more likely to engage in interpersonal deviant behaviors in the workplace ( Berry, Ones, \& Sackett, 2007; Judge, LePine, \& Rich, 2006). Further, agreeableness, is negatively correlated to interpersonal deviance (Berry, Ones, \& Sackett, 2007). In another study, Extraversion and Agreeableness were related to interpersonal anti-social behaviors (Lee, Ashton, \& Shin, 2005). However, the Big Five personality trait of Openness to Experience has not been found to be significantly related to deviant workplace behaviors although it was positively correlated to turnover (Salgado, 2002).

Similarly, previous research found that the Big Five personality traits predicted the use of certain conflict management styles (Antonioni, 1998; Moberg, 1998). These studies found that both extraversion and conscientiousness significantly predicted an 
integrating style of conflict management; while conscientiousness was negatively related to the avoiding style. In contrast, managers who were low in agreeableness were more likely to use the dominating style to manage conflict. Agrecableness and neuroticism were found to be negatively related to the dominating style of managing conflict (Antonioni, 1998).

Given that both workplace incivility and conflict management styles are constructs related to personality traits, it is reasonable to deduce that there is a need to explore the relationship between them. Both of these constructs are linked to organizational disengagement and lowered productivity. This suggests an intersection between workplace incivility and conflict management styles, which may lead to the expansion of research in new directions contributing to understanding and application of strategies to manage these workplace issues.

\section{Statement of the Problem}

Workplace incivility is a persistent and growing problem in organizations. Deetz (1992) posited that corporations have "significant effects on the quality of life, political and conceptual activity, and the contemporary production of meaning" (p.9). Consequently, workplace incivility is an issue that has social, organizational and legal ramifications. Although empirical studies have demonstrated that workplace incivility is prevalent, statistics are unavailable as to its direct costs. Conceptually, sexual harassment overlaps with workplace incivility (Lim \& Cortina, 2005) and workplace violence is theorized as being on the opposite end of workplace incivility along a continuum for workplace deviance (Namic, 2003), therefore statistics associated with such related concepts are useful in considering the costs of workplace incivility. In 1998, a study 
estimated that the costs associated with workplace violence are between $\$ 6.4$ and $\$ 36$ billion in lost productivity, diminished public image, insurance expenses, increased security, and other related factors (Speer, 1998). According to the Bureau of Labor Statistics, in 2005, about five percent, or 355,000, out of 7.1 million U.S. private industry businesses had an incident of workplace violence within the 12 months prior to the workplace violence prevention survey ("Survey," 2006). The Equal Employment Opportunities Commission reported that in 2007, 12,510 sexual harassment charges were filed and that $\$ 49.9$ million were awarded, not including compensation obtained through litigation ("Sexual harassment," 2008). These statistics indicate that deviant workplace behaviors exact tremendous costs on organizations and explicate the need for further research, in particular, workplace incivility, since it is a mild form of deviant workplace behavior. This study explores the effects of workplace incivility and conflict management styles, to expand knowledge of workplace incivility and provide insights on how it can be managed in organizations.

Although there is a growing body of research on workplace incivility, it has concentrated on individual and organizational antecedents, as well as individual outcomes such as turnover intention and job satisfaction. There is a dearth of empirical research on the effects of workplace incivility on an organizational outcome such as job performance.

Research to date has established various individual and organizational antecedents to workplace incivility as well as individual and some organizational outcomes of workplace incivility. Individual characteristics such as Type A personality, selfmonitoring and hostile attributional style (Neuman \& Baron, 1998), certain Big Five 
personality traits (Berry, Ones, \& Sackett, 2007), and high avoidance motivation (Diefendorff \& Mehta, 2007) are linked to negative behaviors in the workplace. Organizational antecedents to workplace incivility include downsizing (Andersson \& Pearson, 1999; Blau \& Andersson, 2005; Johnson \& Indvik, 2001a; Salin, 2003; Vickers, 2006), organizational justice variables (Diefendorff \& Mehta, 2007), and casual work atmosphere (Johnson \& Indvik, 2001a).

Other studies on workplace incivility found that outcomes of incivility include increased absenteeism, reduced organizational commitment (Pearson et al., 2001), reduced job satisfaction, increased turnover intentions (Cortina, Magley, Williams, \& Langhout, 2001; Lim \& Cortina, 2005; Lim, Cortina, \& Magley, 2008), affected mental health, well-being (Lim, Cortina, \& Magley, 2008; Martin \& Hine, 2005), career salience (Cortina et al., 2001) and withdrawal behaviors and distress (Cortina et al., 2001). Further, witnesses of uncivil behaviors in the workplace also experience significant negative effect (Montgomery, Kane, \& Vance, 2004) including decreased organizational trust and commitment (Spreitzer, 1995).

Scant attention has been paid to variables that may address ways to manage or curb workplace incivility. Responses to uncivil behavior do, in large part, determine if such bchaviors escalate in subsequent exchanges as a conflict spiral (Pearson et al., 2000). This model of an incivility spiral suggests that the manner in which employees manage conflict would have a bearing on further exchanges. Research on conflict management indicates that how conflict is managed in the workplace impacts the process and outcomes of conflict, both for individuals and organizations. Poorly managed workplace or organizational conflict affects the level and frequency of future conflict and 
has a negative effect on productivity and work performance (Meyer, 2004). How conflict is managed or the styles of conflict management reflect individuals' behavioral orientations or preferences. Such behavioral orientations may be modified through cognitive and behavioral trainings. The current study seeks to explore the relationship between conflict management styles and workplace incivility, thus filling a gap in the literature and providing insight on possible interventions to deal with workplace incivility.

There is a lack of research on how incivility and the behavioral construct of conflict management styles are related. Further, research on workplace incivility has primarily focused on the perspective of targets, with limited research conducted on instigators. This study seeks to expand on research by examining workplace incivility from both the target and instigator perspectives through conflict management styles. The proliferation and escalation of workplace incivility in part, is determined by individual responses to negative actions. Consequently, examination of workplace incivility through the lenses of conflict styles is important in understanding and curbing workplace incivility to improve workplace performance and organizational effectiveness.

Workplace incivility and how conflicts are handled may impact job performance. This is an important variable that has not been considered in the research on workplace incivility and conflict management styles although studies have demonstrated that targets of incivility have lost work time through absenteeism (Pearson et al., 2001) and experienced decreased mental and physical well-being (Lim et al., 2008; Martin \& Hine, 2005). Further, an examination of both these constructs and their relationships to 
organizational commitment and intent to tumover would clarify the extent to which incivility and individual's management of uncivil behavior affects organizations.

Purpose of the Study

The purposes of this study were to explore and identify the relationships between workplace incivility and the five conflict management styles, as well as to determine the effects of conflict management styles and workplace incivility as they impact job performance, organizational commitment and turnover intentions.

In light of the purposes of this study, the following research questions were addressed:

1. What is the relationship between workplace incivility and conflict management styles of (a) dominating, (b) integrating, (c) compromising, (d) accommodating, and (e) avoiding?

2. Are there differences between the relationships of conflict management style and workplace incivility from the perspectives of targets versus instigators of incivility? 3. Do conflict management styles affect the impact of workplace incivility on employee's job performance, commitment to their organization and turnover?

4. After controlling for select demographic variables, what is the relationship between workplace incivility, conflict management styles and perceived job performance?

5. After controlling for select demographic variables, what is the relationship of workplace incivility and conflict styles on organizational commitment?

6. After controlling for select demographic variables, what is the impact of workplace incivility and conflict styles on turnover intentions? 


\section{Significance of the Study}

This study is needed because workplace incivility is a prevalent problem and there are gaps in the empirical research on workplace incivility. Firstly, it has not been examined in relation to conflict management styles. The literature suggests that how conflict is managed determines the course and outcomes of that conflict (Rahim, 2001). Conflict management skills can be acquired through human resource interventions, therefore, outcomes of the study could expand knowledge of workplace incivility, as well as present strategies to manage or curb workplace incivility. Secondly, empirical studies established various antecedents to and outcomes of workplace incivility but not any measure of job performance. This variable is relevant because it relates directly to organizational effectiveness and profits. Thirdly, research has focused primarily on perspective of targets of workplace incivility and only a limited extent on the perspective of instigators. The combined perspectives of instigators and targets have not been previously explored.

Research to date has focused on various antecedents and outcomes of workplace incivility based on individual and organizational factors. However, the question of whether workplace incivility influences job performance remains unaddressed. A study on high school students demonstrated that rudeness affected their ability to problem-solve effectively (Chiu \& Khoo, 2003). Further research is needed to determine what if any, impact workplace incivility may have on job performance. This relevant issue will be examined in the current study. Prior studies have not considered job performance, organizational commitment and turnover intention in tandem with workplace incivility. 
This study seeks to extend prior research in examining the effects of incivility on all three work outcomes.

Separately, there has been research on conflict management styles and their relationship to leadership styles, workplace role and hierarchy, conflict level, job satisfaction, and affect level of individuals. There is a paucity of research linking workplace incivility to conflict management styles and their influence on work outcomes. There is reason to explore the link between these two constructs since each is related to the Big Five personality factors in ways that are consistent with theoretical assumptions. For instance, less agrecable individuals are more likely to engage in uncivil behaviors and are also less collaborative in managing conflict, tending to utilize a more forceful or competing style. Conflict management styles reflect individual behavioral orientation or preference; these may be influenced through cognitive and behavioral change strategies such as training. Studies have indicated that conflict management trainings are effective in changing conflict responses and strategies in a positive manner ( $\mathrm{Lau}, \mathrm{Li}, \mathrm{Mak}, \&$ Chung, 2004; Haraway \& Haraway, 2005). The implication is that similarly, workplace incivility may be managed through human resource interventions such as training. Consequently, findings of this study may provide strategies to control and minimize workplace incivility. This in turn, would be relevant to the practice and research of HRD since workplace incivility and conflict management are both workplace issues.

Previous research on workplace incivility focused on either targets (e.g. Cortina et al., 2001; Cortina \& Magley, 2003; Pearson et al., 2001; Pearson \& Porath, 2005) or instigators of incivility (Blau \& Andersson, 2005), but there is a paucity of research on both perspectives in the same study. Pearson et al. (2001) theorized that incivility 
escalates in a "tit for tat" exchange pattern and this study extends previous research by examining the perspectives of both targets and instigators of workplace incivility.

Gender, age, organizational rank and tenure are demographic variables that are controlled in this study because research has linked them to both conflict management styles and workplace incivility. This is to ensure that the relationship between conflict management styles and workplace incivility can more clearly be identified and defined.

This study contributes to previous research on workplace incivility by examining if there are differing relationships between individual personality construct of conflict management styles and workplace incivility. Further, empirical testing was conducted on the impact of established relationships on work outcomes of job performance, organizational commitment and the attitudinal construct of intent to turnover. The findings of this study will inform researchers and HRD practitioners alike on the vicissitudes of workplace incivility as well as strategies or interventions to manage this increasingly prevalent workplace problem.

\section{Definitions of Terms}

The following are terms utilized through this study:

1. Big Five. This is a five factor model of personality dimensions consisting of: Extraversion, Emotional Stability, Agreeableness, Conscientiousness, and Openness to Experience (Digman, 1990). These five relatively independent dimensions "provide a meaningful taxonomy for studying individual differences" (Barrick \& Mount, 1991, p.5).

2. Conflict. Conflict is defined as a process that begins when an individual (or group) pereeives differences and opposition between him or herself and another 
about interests, beliefs, or values (De Dreu, Harinck, \& Van Vianen, 1999; Wall \& Callister, 1995).

3. Conflict Management. Rahim (2002) suggests that conflict management does not necessarily, "imply the avoidance, reduction or termination of conflict but involves designing effective macro-level strategies to minimize the dysfunctions of conflict and enhancing the constructive functions of conflict in order to enhance learning and effectiveness in an organization" (p. 208).

4. Conflict Management Styles. The five conflict management styles adopted by Thomas (1976) and Rahim (1985) is based on a two-dimensional framework reflecting the degree to which a person is concerned about satisfying his or her own goals and the degree to which the person is supportive of the other person's goals. The five conflict management styles are dominating, integrating, compromising, accommodating, and avoiding. Dominating style reflects a competitive win-lose approach that is direct and non-cooperative. It is indicative of high concern for self and low concern for others (Rahim, 2004).

Integrating style is associated with openness, collaboration involving confrontation when appropriate and problem solving orientation. This reflects a high concern for both self and others).

Compromising style is characterized by a "split the difference" approach where there is a moderate level of concern for self and moderate concern for others. Middle ground is the general goal in resolving the conflict. 
Accommodating style is reflected by acquiescing to other's decisions or statements without asserting or expressing own concerns or needs. This indicates a low concern for self and high concern for others.

Avoiding style is characterized by non-confrontational, indirect and uncooperative, withdrawal behaviors. It indicates low concern for self and others.

5. Counterproductive workplace behaviors. These are purposeful actions that harm, or are intended to harm an organization or its members (Spector \& Fox, 2005).

6. Employee deviance is "voluntary behavior that violates significant organizational norms and in so doing threatens the well-being of an organization, its members, or both" (Robinson \& Bennett, 1995, p.555).

7. Job performance. Consists of both task and contextual performance. Motowidlo (2003) clarified that there is a distinction between behavior, which is what people do, and performance, which is the expected organizational value of what people do.

8. Organizational commitment. An employee's psychological state reflecting a need, desire, and obligation to continue being employed in an organization (Meyer \& Allen, 1991).

9. Turnover intent. Thoughts about, and intent to quit one's present job.

10. Workplace Aggression are intentional behaviors by individuals that cause psychological or physical harm to those with whom they work, or have worked, or organizations in which they are currently or previously employed (Neuman \& Baron, 1998). 
11. Workplace bullying is defined as "the repcated actions and practices (of a perpetrator) that are directed to one or more workers, which are unwanted by the victim, which may be done deliberately, or unconsciously, but clearly cause humiliation, offense, distress, may interfere with job performance, and/or cause an unpleasant working environment" (Einarsen, 1999, p. 17).

12. Workplace Incivility is "low-intensity deviant behavior with ambiguous intent to harm the target, in violation of workplace norms for mutual respect. Uncivil behaviors are characteristically rude and discourteous, displaying a lack of regard for others" (Andersson \& Pearson, 1999, p.457).

13. Workplace Deviance is behavior that is voluntary, violates significant organizational norms and threatens well-being of the organization, its members of both (Robinson \& Bennett, 1995).

\section{Summary}

This study examined the relationship between conflict management styles and workplace incivility as evidenced by work outcomes. Workplace incivility is examined from the perspectives of both instigator and target. This study extends previous research in examining if there are differing relationships between individual personality constructs of conflict management styles and workplace incivility on work outcomes of job performance, organizational commitment and the attitudinal construct of intent to turnover. 


\title{
CHAPTER II
}

\section{LITERATURE REVIEW}

\author{
Introduction
}

Organizations are experiencing constant pressure to improve organizational outcomes and operational efficiency at all levels, especially in the current domestic and global economic crises. This drive to remain competitive in the age of globalization has contributed to much change in organizational structures and processes. The adjustments, increased workplace expectations and demands have given rise to workplace deviant behaviors. Over the last ten years, these deviant behaviors have been extensively studied under various guises. Workplace incivility is one such distinct group of behaviors that negatively impacts both individuals and organizations, thus warranting further investigation. Along with workplace incivility, the manner in which issues of conflict are managed by individuals within organizations may also be a factor in the frequency and occurrence of uncivil behaviors.

The purpose of this study was to examine the relationship between workplace incivility, conflict management styles, and workplace outcomes, namely, perceived job performance, organizational commitment and turnover. This chapter provides a review of salient literature on research and theoretical concepts concerning workplace incivility and its related constructs, the antecedents and outcomes of uncivil behaviors for individuals and organizations, conflict management styles, and the relevance of personality factors to both constructs. Further, the importance of job performance, organizational commitment 
and turnover intent are examined while controlling for gender, status and age variables. The chapter concludes with a conceptual framework developed on the basis of this review of the literature. An understanding of the research conducted on workplace incivility and conflict management styles will clarify the gap in the literature and explicate the rationale for linking both constructs.

$$
\text { Workplace Incivility }
$$

\section{What is Workplace Incivility?}

A simple definition of civility is that of being considerate of others in interpersonal relationships (Ferriss, 2002). This definition was expanded to encompass not just treating others with dignity and showing concern for others' feelings, but also preserving social norms of mutual respect (Carter, 1998). Gonthier and Morrissey (2002) asserted that civility is being mindful of the dignity of others in everyday living. Kowalski (2003) argued that civility can be either etiquette (strict adherence of cultural norms) or acts of kindness and consideration of others. The author asserted that unlike etiquette, kindness and consideration of others is a practice or attitude that is difficult to teach or to impose as a standard of behavior.

The social contexts of civil or uncivil behaviors are paramount since such behaviors can only be construed within such contexts, particularly in the workplace. Ferriss (2002) acknowledged that "Roles influenced by gender, social class, and social position affect the canons of proper behavior and hence the folkways that define civility" (p. 378). What is considered acceptable workplace behaviors depends on organizational norms and legal frameworks. For instance, as an organizational norm, name calling may be acceptable in an organizational culture that is informal. Within the legal environment 
of business, the imposition of legal regulations calls organizations to accountability for workplace standards and behaviors. Before sexual harassment laws came into effect, sexual harassment in the workplace did not constitute cause for complaint and legal action. Johnson and Indvik (2001a) suggested that workplace incivility may cause the development of a hostile work environment increasing the likelihood of harassment, intimidation and violence, which may lead to serious legal and economic ramifications.

In a study on civility, Ferriss (2002) developed a scale based on the 1996 General Social Survey data and conducted statistical analysis that indicated age, education, occupation and health were weak but statistically significant predictors of civility. No gender differences were found, and marital status predicted civility (those separated and divorced had lower civility scores). Further, this study suggests that for civility to prevail, there needs to be self-restraint in managing anger and suppressing one's feelings (Ferriss, 2002). Although this study was not focused on civility in the workplace, the findings may be generalizable to the workplace context.

Incivility reflects uncivil behaviors toward others, acting without consideration or concern for others. In the workplace, incivility may be an issue for individuals, teams and the organization as a whole. Andersson and Pearson (1999), in their seminal work, define workplace incivility as "low-intensity deviant behavior with ambiguous intent to harm the target, in violation of workplace norms for mutual respect. Uncivil behaviors are characteristically rude and discourteous, displaying a lack of regard for others" (p.457). This definition of workplace incivility has been widely adopted by researchers (Blau \& Andersson, 2005; Pearson, Andersson, \& Porath, 2000; Caza \& Cortina, 2007; Cortina, Magley, Williams, \& Langhout, 2001; Lim, Cortina, \& Magley, 2008; Penney \& Spector, 
2005). In a similar vein, rudeness, according to Porath and Erez (2007), is "insensitive or disrespectful behavior enacted by a person that displays a lack of regard for others" (p.1181).

Workplace incivility is a form of interpersonal deviance subsumed under the domain of workplace deviance (Robinson \& Bennett, 1995). The authors characterized low-intensity and interpersonal deviant behaviors as harmful "political deviance" (p.566). Johnson and Indvik (2001a) assert that incivility is at the lower end of a proposed continuum of workplace abuse. Similarly, others have classified incivility as behaviors that place at the lower end of a continuum of workplace deviant behavior. For instance, Namie (2003) ranked incivility as one to three points on a ten point continuum of organizationally disruptive bchaviors, with homicide placing as 10 on the opposite end, and workplace bullying falling in between. Giacalone and Greenberg (1997) frame workplace incivility as a subset of antisocial employee behavior. As previously established, workplace incivility overlaps with, and in some aspects, is similar to other constructs such as aggression, petty tyranny, deviant and antisocial behaviors (Andersson \& Pearson, 1999) as well as bullying.

\section{Constructs related to workplace incivility}

The literature documents numerous concepts related to deviant or bad behaviors in the workplace. Various terms applying to such negative behaviors include: employee or workplace deviance, counterproductive work behaviors, antisocial behaviors, workplace aggression, bullying, emotional abuse, interpersonal deviance, abusive supervision, interpersonal mistreatment, rudeness, and workplace incivility. Attempts have been made to place these constructs into an inclusive conceptualization of negative 
workplace behaviors since there is some degree of overlap amongst them (see Pearson, Andersson, \& Porath, 2005; Namic, 2003).

Robinson and Bennett (1995) presented one of the first attempts of conceptualizing a model of deviant workplace behaviors; and defined employee deviance as "voluntary behavior that violates significant organizational norms and in so doing threatens the well-being of an organization, its members, or both" (p.555). Further, employee deviance is categorized into two distinct groups of behaviors: interpersonal deviance and organizational deviance (Robinson \& Bennett, 1995; Bennett \& Robinson, 2000; Gruys \& Sackett, 2003). Interpersonal deviance consisted of two categories; political deviance which involves interaction that disadvantages other individuals either personally or politically, and personal aggression which is aggressive behaviors that causes harm to others (Robinson \& Bennett, 1995). Interpersonal deviant behaviors include cursing or criticizing others, blaming, taking credit for others' work, and saying hurtful things to others (Jelinek \& Ahearne, 2006). These behaviors are consistent with those associated with workplace incivility. Reio and Ghosh (in press) redefined employee deviance as incivility directed at others and incivility that is directed at the organization on the basis that neither includes physical aggression nor violence.

In contrast, counterproductive workplace behaviors are purposeful actions that harm, or are intended to harm an organization, its members or its stakeholders, including clients and customers (Spector \& Fox, 2005). This extends Sackett's (2002) definition of counterproductive workplace behaviors as actions that run counter to an organization's legitimate interests. Although counterproductive workplace behaviors are similar to employee deviance as conceptualized by Robinson and Bennett (1995), the targets of 
these behaviors now include members outside of an organization. Spector and Fox (2005) suggested that abusive behaviors, verbal and physical aggression, sabotage, theft, purposely doing work incorrectly are all examples of counterproductive workplace behaviors. The requisite intent to harm and actual harm distinguishes this construct from workplace incivility.

Aggression involves deliberate actions with a clear intent to harm someone psychologically and/ or physically (Neuman \& Baron, 1997). Robinson and Bennett (1995) characterized personal aggression as "scrious and interpersonally harmful deviant behavior" (p.566). Neuman and Baron (1998) conceptualize workplace aggression as intentional behaviors by individuals that causes psychological or physical harm to those with whom they work, or have worked, or organizations in which they are currently or previously employed. The authors defined three workplace aggression factors: verbal aggression (behaviors primarily verbal in nature such as belittling someone's opinion, talking behind someone's back, dirty looks, and the "silent" treatment); obstruction (behaviors that reduce a target's ability to perform required duties to an optimum level such as failure to deliver messages, showing up late for a meeting); and workplace violence (physical attacks, theft, destruction of property, stealing - primarily overt actions). Schat and Kelloway (2005) extended the concept of workplace aggression to "behavior by an individual or individuals within or outside an organization that is intended to physically or psychologically harm a worker or workers and occurs in a work-related context" (p. 191).

Earlier, Buss (1991) developed a typology of aggression characterized by three dichotomies: verbal vs. physical, direct vs. indirect, and active vs. passive. Intentionality 
is a requisite for each dichotomy. Although overlaps exist in terms of some of the behaviors, the ambiguity of intent and intensity of the behaviors or actions distinguish workplace incivility from aggression. However, some of the effects or outcomes of either uncivil or aggressive acts are difficult to differentiate. The similarity between counterproductive workplace behaviors (CWB) to workplace aggression are noted (Baron \& Neuman, 1998; Neuman \& Baron, 2005), except that CWB do not require specific intent to harm.

Bullying, another overlapping construct with workplace incivility, is defined as "the repeated actions and practices (of a perpetrator) that are directed to one or more workers, which are unwanted by the victim, which may be done deliberately, or unconsciously, but clearly cause humiliation, offense, distress, may interfere with job performance, and/or cause an unpleasant working environment" (Einarsen, 1999, p. 17). A one time incident does not constitute bullying. Over a period of time, depending on circumstances and frequency, routine or unintended behavior may be perceived differently by the recipient (Rayner, Hoel, \& Cooper, 2002). In contrast, Mayhew, McCarthy, Chappell, Quinlan, Barker, and Sheehan (2004) contend that bullying consists of recurring behaviors that are offensive to the reasonable person. These definitions of bullying behaviors differ as to either the target's perception or the standard according to the "reasonable person". Bullying behaviors include the withholding of needed information, opinions and views being ignored, spreading gossip, being humiliated or ridiculed about work, being shouted at, being ordered to do work below one's competence, exposure to unmanageable workload, and being given unreasonable or impossible datelines for tasks (Hoel \& Cooper, 2000). The effects of workplace bullying 
at more serious levels on the victim are akin to post-traumatic stress disorder (Leymann, 1996). Glendinning's (2001) study documented other effects of workplace bullying which include higher turnover, reduced productivity, and counterproductive workplace behaviors. Further, the author asserts that bullying may also create hostile work environments that can lead to violence as well as increase legal liabilities in the form of law suits. On the individual level, employees' health are negatively impacted and increased job stress, depression, anxiety were reported (Glendinning, 2001). Lee and Brotheridge (2006) recognize that bullying behaviors overlap with incivility and aggression. The effects and outcomes of incivility, aggression and bullying are similar, if not undifferentiated.

Keashly (1998) assert that behaviors such as name-calling, silent treatment, withholding necessary information, yelling at someone, making aggressive eye contact and explosive angry outbursts constitute emotional abuse. Such behaviors are common to both bullying and workplace incivility. Abusive supervision, another subset of negative workplace behaviors, includes behaviors such as public ridicule, rudeness, invasion of privacy, taking undue credit, and inappropriately assigning blame (Tepper, Duffy, Henle, \& Lambert, 2006). Again, such behaviors are similar to those categorized under workplace incivility, aggression and bullying.

Cortina and Magley (2003) further used the term "interpersonal mistreatment" and define it as a "specific, antisocial variety of organizational deviance, involving a situation in which at least one organizational member takes counter normative negative actions - or terminates normative positive actions—against another member" (p. 247). In their study involving a sample of 1167 public sector employees, they examined the 
strategies used in response to interpersonal mistreatment in the workplace and found that those who spoke up (use of voice) experienced retaliation victimization and their professional well-being suffered. Interpersonal mistreatment is difficult to distinguish from workplace incivility. No further studies on the development of this theoretical model have been found.

Although the constructs presented have some degree of overlap with each other, they all have separate bodies of literature examining varying antecedents, processes and outcomes. A detailed examination of workplace incivility is required to define and verify the need for this as a distinct construct of negative workplace behaviors. Low intensity deviant behaviors

Workplace incivility is defined in part by deviant behaviors that are low in intensity (Andersson \& Pearson, 1999). Low intensity, however, does not mean that incivility is of minor consequence and should be overlooked in organizations. Andersson \& Pearson (1999) theorize that uncivil experiences in the workplace are like an accumulation of minor stresses. These may be more damaging than a single, major stressful event and spiral to a point where incivility transitions to overt aggression (Andersson \& Pearson, 1999; Cortina, Langhout, Magley, \& Williams, 2001). Andersson and Pearson's (1999) model of a conflict spiral from incivility to coercive behaviors that lead to workplace aggression is consistent with the "popcorn" model of aggression where repeated minor offenses or injustices eventually lead to an explosion of aggression (Folger \& Skarlicki, 1998; Schat \& Kelloway, 2005). Research provides some support for this model in that aggressiveness is related to interpersonal deviance (Aquino, Galperin \& Bennett, 2004). Further, others assert that incivility is a precursor to aggression and 
violent behaviors (Glendinning, 2001; Pearson, Andersson, \& Porath, 2000; Pearson, Andersson, \& Wegner, 2001). Given the potential gravity of its consequences, workplace incivility is not a trivial issue for organizations and should be taken seriously.

Examples of uncivil behaviors include writing nasty and demeaning notes or emails, undermining a colleague's credibility, treating another like a child, berating one for an action in which they played no part, giving people the silent treatment, publicly reprimanding someone, making unfounded accusations, and spreading gossip (Johnson \& Indvik, 2001a; Pearson, Andersson, \& Porath, 2000). Being uncivil also includes excluding someone from a meeting, neglecting to greet someone, cutting people off while they are speaking, not turning mobile phones off during meetings, leaving a jammed photocopier or printer for another to fix, leaving mess and untidiness in the kitchen; listening in on another's phone call, ignoring a colleague's request, using demeaning language or voice tone, making inflammatory remarks; and writing rude or unnecessarily incendiary emails (Johnson \& Indvik, 2001b; Pearson, Andersson, \& Wegner, 2001).

Most of the above described behaviors present as low intensity rude behaviors that may be overlooked on occasion but with frequency and over a period of time, could have detrimental effects at individual, group and organizational levels. Cortina et al. (2001) likened the ongoing and possibly escalating uncivil behaviors to the everyday, routine hassles inducing stressors that impair individuals' well-being over time.

Norms

Sherif (1936) defined norms as acceptable or desirable prescribed behaviors and attitudes within a given social unit. Consequently, anyone whose behaviors fall outside of such prescribed boundaries will be perceived as violating behavioral norms. Workplace 
norms are shared behavioral standards developed from traditions, policies and culture of a workplace (Pearson, Andersson, \& Porath, 2000). Every organization has a universal set of norms for mutual respect enabling cooperation between organizational members (Andersson \& Pearson, 1999). Although norms do differ between organizations, there is a common understanding of what constitutes incivility across all organizations (Lim, Cortina, \& Magley, 2008). It follows then, that uncivil acts violate workplace norms for appropriate behavior (Pearson, Andersson, \& Wegner, 2001). Uncivil behaviors are recognized by organizational members as falling outside the realm of common practice, causing offense and unwanted consequences.

Pearson et al. (2000) asserted that organizational norms of civility may be eroded over time if uncivil behaviors are left unchecked. This assertion appears to be supported by Skarlicki, Folger and Tesluk (1999) who suggested that retaliatory behaviors may be representative of an organizational norm: retaliation is related to individuals' perception of what constitutes common practice in an organization.

\section{Ambiguous intent}

Low intensity deviant behaviors are identifiable in two categories: those where there is intent to harm but are ambiguous to the target and those without intent to harm that also appear ambiguous to the target (Robinson \& Bennett, 1995; Blau \& Andersson, 2005). Workplace incivility overlaps with psychological aggression (Cortina, 2008; Lim, Cortina, \& Magley, 2008) and counterproductive workplace behaviors (Penney \& Spector, 2005), where there is clear intent to harm a target. However, with workplace incivility, the intent to harm may or may not be present; any harmful intent may be easily denied or dismissed. Indeed, the intent to offend or harm may not be immediately 
apparent and can be difficult to prove. Most instigators of aggressive behaviors tend to act in ways that help them conceal any hostile intentions (Einarsen, Matthiesen, \& Skogstad, 1998). Further, even when there is a clear intent to harm, the instigator may claim that his or her behavior was unintentional and due to oversight, ignorance, or attributed to personality (Andersson \& Pearson, 1999; Pearson, Andersson, \& Wegner, 2001). Regardless of intent, targets of incivility can still perceive uncivil acts as offensive and harmful.

\section{Prevalence of incivility}

Workplace incivility is a widespread problem impacting work processes and workplace performance (Pearson, Andersson, \& Porath, 2000). A number of studies document a high percentage of responses indicating that workplace incivility is a prevalent problem with some claiming that it is a worsening condition. In a 2001 study, researchers found that of the 1,167 public sector employees in the study sample, $71 \%$ reported having been targets of workplace incivility within the last five years (Cortina, Magley, Williams, \& Langhout, 2001). Pearson, Andersson, and Porath (2000) surveyed 775 workers claiming to have been targets of workplace incivility from widely diverse organizations across the United States. They found that $78 \%$ felt that incivility had worsened over the last ten years. In 2004, Cortina, Lonsway and Magley reported that $79 \%$ of a law enforcement sample indicated that they experienced workplace incivility. A similar result is found in the ficld of healthcare: $72 \%$ of nurses reported witnessing a range of inappropriate behaviors including verbal abuse and confrontation by their peers (Rosenstein \& O’Daniel, 2005). A more recent study of a university employee sample by 
Cortina and Magley (2007) revealed that $75 \%$ of those employees experienced uncivil behaviors.

A study on civility using a sample of employees across four industries reported that $31 \%$ of workers experienced incivility within the last year (Forni, Buccino, Greene, Freedman, Stevens, \& Stack, 2003). $83 \%$ of the sample respondents indicated that a civil workplace was very important and $67 \%$ believed that society has become less civil in the past year. Bennett and Robinson (2000) assert that workplace deviance, in general, is prevalent and poses an economic threat to organizations.

As previously stated in Chapter I, the Bureau of Labor Statistics reported that close to five percent of 7.1 million U.S. private industry businesses had an incident of workplace violence in 2005 within the 12 months prior to a workplace violence prevention survey ("Survey," 2006). Workplace violence is a serious problem impacting many organizations. It is considered as the extreme on a continuum of deviant workplace behaviors while workplace incivility, at the opposite end of the continuum, presents as the mildest form (Namie, 2003). If left unchecked, workplace incivility may escalate and spiral into workplace aggression, or worse, workplace violence.

The costs of workplace deviant behaviors can be very high. For instance, the costs of workplace violence were conservatively estimated at $\$ 4.2$ billion a year in a U.S. Department of Justice report (Duhart, 2001). An earlier study estimated the cost of workplace violence at between $\$ 6.4$ and $\$ 36$ billion in lost productivity and other associated factors (Speer, 1998).

The Equal Employment Opportunities Commission reported that in 2007, 12,510 sexual harassment charges were filed and that $\$ 49.9$ million were awarded, not including 
compensation obtained through litigation ("Sexual harassment," 2008). Such information is relevant given that research established that general incivility and sexual harassment are related constructs that tended to occur at the same time in organizations (Lim \& Cortina, 2005). These statistics indicate that deviant workplace behaviors exact tremendous costs on organizations and explicate the need for further research, in particular, on workplace incivility, since it is a mild form of deviant workplace behaviors. Antecedents to incivility: Work Outcomes, Individual Outcomes

Responses to incivility appear to vary across individuals and organizations. Ferriss (2002), in a study on civility, reported that responses to incivility varied amongst respondents' high and low scores on a civility scale. Individuals who scored higher on civility responded more constructively in comparison to low scorers who tended to react by yelling or hitting something to vent, confronting the source, or think about how to exact revenge. Hierarchical and relational status is another factor that determines individuals' responses to mistreatment (Aquino, Tripp \& Bies, 2001, 2006). Porath, Overbeck and Pearson (2008) determined that hierarchical status as well as gender significantly influenced reactions to incivility. They found that employees with higher status and those that are men were more reactive and tended to retaliate overtly to incivility. On an organizational level, organizational sanctions or acceptance of uncivil behaviors determine the level of incivility in the workplace (Andersson \& Pearson, 1999).

These studies imply that both individual and organizational factors need to be considered when investigating the antecedents and effects of workplace incivility. There is a proliferation of research on interpersonal deviant behaviors. However, the topic of 
workplace incivility has only been defined and garnered interest within the last 10 years and therefore research is still limited. However, the similarity between the constructs of workplace deviance does enable an examination of common antecedents and outcomes. Impact of incivility on the individual

A number of empirical studies established that incivility is related to negative individual outcomes. These outcomes relate to job satisfaction, organizational commitment, job withdrawal, career salience, mental and physical health, lower satisfaction with coworkers, absentecism, morale, stress, lowered productivity and cognitive ability.

Job satisfaction is a variable widely studied and associated with workplace incivility (Andersson \& Pearson, 1999; Blau \& Andersson, 2005; Cortina et al., 2001; Lim, Cortina, \& Magley, 2008; Pearson \& Porath, 2005). Studies have also reported that workplace incivility correlated with increased absenteeism, reduced organizational commitment (Pearson et al., 2001), increased turnover intentions, and affected mental health (Lim, Cortina, \& Magley, 2008). In a study of female court employees and female attorneys, Lim and Cortina (2005) reported that targets of incivility suffered reduced job satisfaction, increased job stress and turnover intentions (job withdrawal). The researchers also found that gender harassment strongly correlated with both general incivility and sexual harassment. Lim, Cortina and Magley (2008) conducted two studies on two different samples, applying the theories of affective events, and chronic stress: they found that incivility had a direct negative impact on mental health, which then affected physical health, although there were no gender differences in outcomes. They 
also reported that job satisfaction mediates the impact of incivility on mental health and turnover intentions.

Job satisfaction, career salience, and turnover intentions are negatively associated with incivility (Cortina et al., 2001). Individuals who are targets of incivility experience lower levels of satisfaction with coworkers and supervisors, psychological well-being and health (Martin \& Hine, 2005). Further, targets also are more likely to withdraw from work. Withdrawal behaviors and distress are positively related to incivility (Cortina et al., 2001). It stands to reason that incivility leads to employees' alienation and detachment from the workplace, and lowers morale (Hornstein, 1996; Pearson, Andersson, \& Wegner, 2001).

The experience of incivility from supervisors has a negative impact on employees. Tepper (2000) found that targets of abusive supervisors experienced negative consequences such as anxiety, emotional exhaustion, and depression. Further, perceptions of uncivil supervisors had a greater impact on work and health outcomes than perceptions of uncivil coworkers (Lim et al., 2008). The detrimental impact of incivility on workplace relationships with coworkers and supervisors may have implications for organizational performance especially given the increasing reliance on team structures and teamwork in organizations.

Porath and Erez (2007) found in a randomized design experimental study on a sample of college students that rude behaviors negatively impacted task performance through the disruption of cognitive processes. Further, rudeness also reduced helpfulness in both targets and third party observers. Although this study may have limited application since the study sample consisted of college students, the authors contend that 
there is support for the generalizability of contrived study findings across numerous psychological domains. Earlier, in another experimental study, Chiu and Khoo (2003) found that rudeness negatively affected the ability of groups of high school students to problem-solve effectively, resulting in less likelihood of arriving at a correct solution. They reported that rudeness reduced the cognitive ability of students to evaluate and correctly solve a problem. Again, these results may have limited generalizability due to the young sample groups and more research need to be conducted in organizational settings. However, the implication that rudeness and incivility may have direct influence on job performance and cognitive ability is one that needs further consideration.

Consequently, the current study seeks to address the impact of incivility on self perceived job performance.

The negative effects of workplace incivility on the individual level are welldocumented. These outcomes impact organizations in insidious ways that makes it challenging to manage or control.

Impact of incivility on organizations

Incivility hurts the bottom line of organizations. Uncivil organizational climates are linked to problems such as lowered productivity and morale, tardiness, absenteeism, work slowdowns and sabotage as well as turnover (Neuman \& Baron, 1997; Pearson, Andersson, \& Wegner, 2001). Empirically, there is much support for workplace incivility being linked to increased intentions to quit and even actual turnover (Andersson \& Pearson, 1999; Cortina et al., 2001; Glendinning, 2001; Pearson et al., 2000; Pearson \& Porath, 2005). 
Lost work time is also another documented consequence of workplace incivility. Gardner and Johnson (2001) reported that $30 \%$ of targets lost work time trying to avoid the workplace bully. In a study based on data collected from over 1400 employees across industries, Pearson et al. (2000) found that $50 \%$ of sample respondents lost work time due to worry while $25 \%$ reported wasting work time avoiding instigators by working around them. They also found that targets were less committed to the organization, disengaged or reduced organizational and helping activities, as well as reduced work efforts and even engaged in organizational theft. Further, over $50 \%$ of respondents indicated intention to turnover and $12 \%$ actually quit (Pearson et al., 2000).

Previously, it was established that rudeness impacted not just targets but also observers or witnesses by reducing helpful behaviors and disrupted cognitive processes, reducing problem-solving abilities (Chiu \& Khoo, 2003; Porath \& Erez, 2007). Organizational climate and productivity may then be affected if employees are not as collaborative or effective at their tasks. Researchers reported that the negative impact of uncivil behaviors extend beyond the immediate target to observers or witnesses as well as others in the organization (Montgomery, Kane, \& Vance, 2004; Lim et al., 2008; MinerRubino \& Cortina, 2007). Such witnesses experienced declines in psychological wellbeing and job satisfaction, thus resulting in lowered physical wellbeing, higher burnout, and increased turnover intentions (Miner-Rubino \& Cortina, 2007). Robinson and O'Leary-Kelly (1998) posit that since aggressive behaviors of individuals are related to aggressive behaviors of their coworkers, perceived organizational climate could perpetrate or discourage workplace aggression including verbal aggression. 
Andersson and Pearson (1999) presented a model of a spiral effect of incivility where reciprocating uncivil acts lead to increasing incivility that then permeates the organizational climate. They explain that even witnesses to incivility are themselves likely to engage in uncivil behaviors as a result. Others theorize that deviant behaviors are products of an individual's causal reasoning about the workplace environment and expected outcomes (Martinko, Gundlach, \& Douglas, 2002). Sackett and DeVore's (2001) reason that individual's attitudes toward the organization and workplace influence counterproductive behaviors. There is support for the spiral effect model: in a study on workplace bullying, Lee and Brotheridge (2006) found that aggressive or bullying behaviors toward others lead to counteraggressive actions by the targets. Other studies on workgroups established that there is a contagious pattern to negative behaviors (Robinson \& O’Leary-Kelly, 1998; Glomb \& Liao, 2003). Individuals who have been targets of negative behavior are more likely to engage in those behaviors themselves. In fact, Robinson \& O'Leary-Kelly (1998) reported that repeated exposure to deviant behaviors is one of the strongest predictors of aggression.

The escalation of incivility is attributed to retaliatory behavior tendencies of individuals against negative behaviors targeted at them (Bies \& Tripp, 2001; Greenberg \& Barling, 1999; Skarlicki \& Folger, 2004). Retaliatory behaviors in turn, tend to be at a higher level of intensity than the original negative action. Empirical evidence support the reciprocal nature of workplace aggression (Glomb \& Liao, 2003), and the inference may be drawn that similarly, workplace incivility would have the same reciprocal tendencies. Further, workplace incivility may lead to disrupted work patterns and changes in social 
interactions that spiral into higher levels of workplace aggression (Ncuman \& Baron, 2005; Pearson et al., 2000; Porath \& Erez, 2007).

Penney and Spector (2005) found that workplace incivility is positively related to counterproductive workplace behaviors and negatively related to job satisfaction. Results from their study also indicated that negative affect moderated the effects of workplace incivility and other job stressors on counterproductive workplace behaviors.

Counterproductive behaviors are costly to the organization in that they involve both interpersonal and organizational deviance.

Antecedents to workplace incivility

There are two categories of factors that facilitate workplace incivility. They consist of both organizational and individual variables. A proliferation of studies has been conducted on antecedents of workplace aggression, counterproductive workplace behaviors and workplace deviance as compared to workplace incivility. The similarity and overlap between all these constructs indicate that they share similar antecedents.

\section{Organizational antecedents}

The primary antecedents to workplace deviance are workplace experiences of frustration, injustices, and perceived threats to self (Bennett \& Robinson, 2003). Specifically, interpersonal mistreatment is a predominant factor in deviant behaviors (Robinson \& Greenberg, 1999). Andersson and Pearson (1999) assert that incivility can define an organization's climate and become ingrained in its culture if it is left unchecked. According to Cortina (2008), the organizational environment may perpetuate or inhibit incivility. To that end, organizational leaders model acceptable behaviors that set the standard for other members. For instance, Pearson, Andersson, \& Porath (2000) 
found that employees go along with supervisors' and managers' jokes. Organizationally accepted practices, like norms, may dictate employees' responses to negative behaviors. Consequently, uncivil behaviors, if consistently unsanctioned in an organization, can have a cumulative effect. Andersson and Pearson (1999) conceptualized workplace incivility as an interactive occurrence whereby incivility is a "dynamic interchange" (p. 457) which becomes an interpersonal conflict spiral. They asserted that this spiral may then lead to a tipping point, changing the ambiguous nature of incivility into a more tangible intent to harm which then may lead to acts of aggression. As other members of an organization observe or hear about such interpersonal conflicts, and find tacit acceptance of uncivil behaviors, a culture of incivility can promulgate.

Passive and verbal forms of workplace aggression increase when organizational changes occur - these include budget reductions, increased diversity of the workforce, changes in management, increased use of part-time workers, and wage cuts or wage freezes (Baron \& Neuman, 1996). Further, Henle (2005) proposed that certain factors such as job stressors, weak sanctions for work violations, lack of control over the work environment, and downsizing, create an organizational environment for workplace deviance, irrespective of individual characteristics. Combined with personality traits, Henle's (2005) study revealed that workplace deviance is related to organizational justice.

Organizational climate prescribes acceptable behaviors. Informal climates characterized by informal attire, free expression of emotions and lack of formality in interpersonal relationships may lead to increased frequency and intensity of deviant behaviors (Tedeschi \& Felson, 1994). Organizational members have less clearly defined 
behavioral boundaries that may encourage rude and uncivil bchaviors (Andersson \& Pearson, 1999). More formal organizational climates in contrast, have clearer boundaries about what constitutes acceptable standards of behaviors including how members are to interact with one another, dress attire, and other professional work requirements. However, high organizational constraints along with personal trait of high avoidance motivation, were found to be positively related to interpersonal deviance (Diefendorff $\&$ Mehta, 2007). Empirically, Jelinek and Ahearne (2006) showed that bureaucracy (degree to which an organization is bound by rules and hierarchy) is negatively related to both organizational and interpersonal deviant behaviors. In their mixed-method study of salespersons, organizational and management antecedents to employee deviance were investigated. Future orientation, defined as "the extent to which a firm encourages a longterm view with respect to planning, strategizing, and managing operations", was found to be negatively correlated to interpersonal deviance (Jelinek \& Ahearne, 2006, p.332). Interestingly, managerial role modeling is related to organizational deviance but not related to interpersonal deviance. The study also demonstrated that intrafirm competition amongst the sales force encouraged interpersonal deviance.

Organizational conditions and practices such as leadership are associated with workplace dysfunctional behaviors including bullying and harassment (Einarsen, 1999). In organizations where there is stratification in a social system and some individuals have access to informal sources of power, a culture of victimization may persist among those who do not have equal access to those sources (Lamertz \& Aquino, 2004). This may result in a higher level of incivility, perceived or actual. 
It is clcar that organizational factors play an important role in encouraging or curbing workplace incivility. However, these do not detract from personal factors such as the expected accountability of individuals' behaviors and the influence of individual personality traits in workplace interactions.

\section{Individual characteristics}

Numerous studies document individual characteristics that predispose an employee to deviant behaviors in the workplace. Douglas \& Martinko (2001) established a link between trait anger and workplace aggression: individuals high in trait anger may be more easily provoked to aggression as they tend to perceive situations as frustrating. They also found that workers with high negative affectivity are more reactive to negative events. Further, negative attribution style and attitudes toward revenge are related to workplace aggression. These findings are consistent with Hepworth and Towler's (2004) study indicating that trait anger and negative affectivity predicted workplace aggression. They also reported that self control is linked to workplace aggression. However, their study, unlike Douglas and Martinko (2001), did not find a relationship between negative attribution style and attitude towards revenge, and revenge. Individuals who are more aggressive in disposition are more likely to engage in interpersonal deviant behaviors although this tendency is moderated by high formal status in the organization (Aquino, Galperin \& Bennett, 2004). These studies indicate that individuals who, by nature or disposition are angry, are more prone to deviant behaviors in the workplace, including uncivil behaviors. Big Five personality traits and organizational justice variables are antecedents of deviance (Berry, Ones, \& Sackett, 2007). 
Empirically, Miles, Borman, Spector, and Fox (2002) determined that perceptions of workplace environment, such as interpersonal conflict, relate to negative emotions, which in turn is positively correlated with counterproductive workplace behaviors. Further, the researchers also found that trait anger predicted counterproductive workplace behaviors. Other researchers established that positive perceptions of work situations are negatively related to workplace deviance (Colbert, Mount, Harter, Witt, \& Barrick, 2004). These researchers found that personality traits of conscientiousness, emotional stability, and agreeableness moderated this relationship. Specifically, the relationship between perceptions of the developmental environment and organizational deviance was stronger for employees low in conscientiousness or emotional stability, and the relationship between perceived organizational support and interpersonal deviance was stronger for employees low in agreeableness. In a study of workplace incivility and Big Five traits, Milam, Spitzmucller and Penney (2009) found that individuals low in agreeableness are more likely to be targets of incivility, as were those who were low in emotional stability. Further, meditational analyses conducted in the study revealed that individuals low in agreeableness are perceived by their coworkers as inviting uncivil behaviors, thus implying that coworkers may be engaging in low level retaliatory behaviors in response to disagreeable individuals.

In a meta-analytic study on workplace aggression, Hershcovis, Turner, Barling, Arnold, Dupre, Innes, LeBlanc, and Sivanathan (2007) reported that trait anger and interpersonal conflict were the strongest predictors of interpersonal aggression, confirming that individual factors are antecedents. Interpersonal aggression is a construct that overlaps with workplace incivility. Other findings include poor leadership and 
interpersonal injustice being strong predictors of supervisor-targeted aggression (Hershcovis et al., 2007). Gender differences were also revealed: men are more aggressive than women.

The profile of an instigator of incivility tends to be someone who is temperamental, emotionally reactive to problems, rebellious, easily offended, disrespectful of subordinates and rude to peers (Andersson \& Pearson, 1999; Pearson et al., 2000). This profile is substantiated by a study establishing negative affect and low adaptation (degree of establishing relationships with coworkers and supervisors) as predictors of incivility (Reio \& Ghosh, in press). In a study of applicants for police jobs, Dilchert, Ones, Davis, and Rostow (2007) investigated and found that cognitive ability of individuals were linked to observable counterproductive workplace behaviors, which in turn, predicted their tendency to engage in interpersonal counterproductive behaviors. They propose that cognitive ability has an inhibitory effect on behaviors due to the consideration of possible outcomes of engaging in deviant behaviors. Andersson and Pearson (1999) suggest that individuals who are less able to regulate their own behaviors are more likely to engage in uncivil behaviors.

Another variable associated with workplace deviant behavior is an individual's ethical ideology. In a study on a sample of employed MBA students, Henle, Giacolone and Jurkiewicz (2005) established that idealism (the degree that individuals adhere to universal moral code that there is an intrinsic rightness of behavior) is a significant predictor of interpersonal deviance. Those who scored higher on relativism (the degree that individuals reject universal moral rules and believe that morality depends on the situation and individuals involved) were more likely to engage in workplace deviant 
behaviors. This implies that personal values or ideals may be a factor in workplace deviance.

The range of studies indicates that individual factors do play a role in predicting workplace incivility. However, it is imperative to examine workplace incivility in the context of workplace conflict since uncivil behaviors can be considered a cause, trigger or outcome of a conflict episode. A conflict is defined as a process in which an individual perceives that another person has negatively affected something that matters to him or her (Thomas, 1992). If an individual perceives that he or she has been the target of rude behavior and is offended, a conflict arises. Alternatively, if there is a conflict at work, parties may react by engaging in uncivil behaviors towards each other. Ting-Toomey et al. (1991) assert that it is the differences in how conflict is managed that creates the most tension in a conflict situation, instead of the conflict issue itself. The manner in which a conflict is handled impacts the process as well as outcomes of that conflict.

The retaliatory tendencies of individuals in response to incivility as clarified earlier in this chapter, indicate that how incivility is managed on an individual level, will impact the level and frequency of an escalating spiral of incivility. Individual behavioral preferences for managing conflict needs to be examined, since such preferences for conflict bchavior may have an effect on the prevalence of incivility in the workplace.

\section{Conflict Management Styles}

\section{Overview}

Conflict is an integral part of daily life, whether within or outside of the work context. It is pervasive in organizations. Workplace incivility.may be either an antecedent or outcome of conflict. Employees who are uncivil cause conflict amongst those who are 
the targets or those who are observers. Likewise, in conflict situations, individuals are more likely to behave uncivilly toward instigators and others around them. In an organizational context, Putnam and Poole's (1987) definition of conflict as "the interaction of interdependent people who perceive the opposition of goals, aims, and values, and who see the other party as potentially interfering with the realization of these goals," (p.552) is particularly apt. Another view of conflict is that it is a process that begins when an individual (or group) perceives differences and opposition between him or herself and another about interests, beliefs, or values (De Dreu et al., 1999; Wall \& Callister, 1995). Earlier, Pondy (1967) conceptualized conflict as a process encompassing antecedent conditions, emotions, perceptions as well as behaviors. Wall and Callister (1995) emphasized that conflict is a process involving at least two parties where the perceptions of the parties involved play a prominent role. In this way, it is related to workplace incivility where perception plays a prominent role: the ambiguity of intent to harm distinguishes workplace incivility from other forms of interpersonal deviance.

Various factors contribute to the experience of conflict in organizations. Rahim (2002) posited that differences in attitudes, values, level of skills and behaviors lead to conflict in the workplace. Similarly, Wall and Callister (1995) viewed the interpersonal relationship issues of trust, communication, behavior and relationship structure as key factors to any conflict. Further, competition for resources, coordination of systems, work distribution, and participation in decision making in the organization can also lead to conflict (Putnam \& Poole, 1987). Generally, "Disagreement exists when parties think that a divergence of values, needs, interests, opinions, goals, or objectives exists" (Barki \& Hartwick, 2001, p. 198). 
According to Pondy (1967) and Nicotera (1997), conflict is neutral. It is the management of conflict that is a key factor for outcomes. The carlier literature indicated that scholars and researchers assumed that conflict in organizations is dysfunctional and negatively associated with work performance, job satisfaction (Blake \& Mouton, 1964; Pondy, 1967) and organizational commitment (Thomas, Bliese, \& Jex, 2005). That perspective has changed as empirical research established that conflict could be constructive or destructive (Song, Dyer, \& Thieme, 2006). Some scholars and researchers advocate encouraging or stimulating conflict as it can improve organizational performance if managed carefully (George \& Jones, 2005; Pondy, 1992; Van de Vliert \& De Dreu, 1994). However, De Dreu (2008) cautioned that the positive nature of conflict is only found in the narrowest of circumstances, the negative effects may far outweigh the positive and that cooperative management of conflicts is required.

Effective management of conflict is essential for individuals, groups and organizations to function successfully (Rahim, 2000). Work environments charged with conflict may have far reaching negative effects on individuals and their organizations. Meyer (2004) asserted that there is a need for organizations to encourage use of conflict management behaviors and skills that are more collaborative to effectively manage conflict. Individuals with collaborative skills have few conflicts in the workplace (Meyer, 2004). Rahim (2002) advocated the need for macro-level strategies to manage conflict in order to maximize organizational learning and effectiveness. On a micro-level, Friedman, Tidd, Currall and Tsai (2000) asserted that the ways in which an employee manages conflicts shapes his or her work environment. This implies that a positive work environment can result from employees handling conflict productively. 
Many argue that if managed effectively, conflict can be a positive force in organizations (Jameson, 1999; Pelled, Eisenhardt \& Xin, 1999; Rahim 2001, 2002; Song, Dyer, \& Thicme, 2006). A curvilinear relationship between conflict and work-team innovations indicates that at certain levels, conflict can be beneficial to the organization (Song et al, 2006). Other studies revealed that conflict in work teams, can increase individual and work-team effectiveness and productivity (De Dreu et al., 1999; Thomas, 1992; Tjosvold, 1998). A strong positive association between constructive conflict and innovation performance has been established (Song et al, 2006).

Previous research indicates that poorly managed workplace or organizational conflict affects the level and frequency of future conflict and has a negative effect on productivity and work performance (Mcyer, 2004). Morris-Conley and Kern (2003) noted that with the advancement of technology, work environments foster a sense of disenfranchisement and isolation that together with ineffective conflict resolution, may lead to incidents of workplace violence. The need for effective workplace conflict management strategies is evident. Gross and Guerrero (2000) demonstrated the utility of appropriate conflict management strategies; they reported that employees who manage conflict effectively are perceived as more skilled in communication and better suited for leadership roles. In contrast, ineffective or inappropriate conflict management exact costs on organizations. Such costs of poor conflict outcomes include litigation, replacement and training of replacements, overall lowered morale and productivity as well as possible workplace violence.

Conceptual Framework: Conflict management styles 
Van de Vliert (1997) defined conflict behavior as an intended or displayed outward reaction to an experienced conflict issue. Other terms describing such conflict bchaviors are conflict handling and conflict management and refer to both intentions and actions. Individuals have a tendency to engage consistently in certain types of conflict behavior repeatedly and across situations (Cupach \& Canary, 1997). Such conflict preferences "do not predict how a person will react in a single incident, with its idiosyneratic factors, but rather how a person tends to react across a range of conflict situations" (Barki \& Wood, 2005, p. 250). This is not to imply that there is no variation in behavioral responses when in conflict but in general, the reliance on certain conflict behaviors or intent more than others lead Ruble and Schneer (1994) to the conclusion that conflict styles are relatively stable personal dispositions. Others argue that conflict approaches reflect strategies and intentions (Thomas, 1992) that are adaptable to different situations, rather than related to dispositional traits. However, some researchers, while recognizing that conflict style is influenced by type of conflict and who the parties to the conflict are, found that there is consistency in conflict style across types of conflict (Sternberg \& Soriano, 1984) and that personality traits such as agreeableness do predict conflict styles (Graziano, Jensen-Campbell, \& Hair, 1996).

There are a number of conceptual models to explain and classify individuals' conflict responses. Thomas (1992) described these models as relating to strategic intentions and asserted that conflict behaviors are attributions of intent. He further explained that although there are varied terms (conflict handling modes, orientations, approaches, styles, strategies and behaviors) relating to strategic intentions, they are similar across models. The first such conceptualization was presented by Blake and 
Mouton (1964) who focused on individual differences in managerial conflict situations and developed a dual concern model that consists of two dimensions; concern for people and concern for production. Along these dimensions, five approaches to conflict were proposed: forcing, confronting, withdrawing, smoothing over and compromising (Blake \& Mouton, 1964). Later, Thomas $(1976,1979)$ redefined the two dimensions as assertiveness (attempt to satisfy own concerns) and cooperativeness (attempt to satisfy other's concerns). He classified conflict resolution into five strategic intentions: competing, collaborating, avoiding, accommodating and compromise (Thomas, 1979). Similarly, Rahim and Bonoma (1979) conceptualized a dual dimensional model (the degree to which a person wants to satisfy his or her own concerns; and the degree to which a person wants to satisfy the concerns of others) resulting in five conflict handling modes or styles consisting of dominating, integrating, avoiding, accommodating and compromising. The two dimensions reflect behavioral dispositions (Deutch, 1994) or motivational orientations (Rahim, Buntzman, \& White, 1999) of individuals in conflict. Empirically, there is support for this dual dimensional concept (Ruble \& Thomas, 1976; Van de Vliert \& Kabanoff, 1990; Volkema \& Bergmann, 1995). Volkema and Bergmann (1995) reported that individuals' preferences for assertiveness defined their prime choices of strategic and tactical behaviors, while cooperativeness is associated with behaviors of last-choice.

The five part typology of conflict management styles advanced by Thomas (1979) initially, and then Rahim and Bonoma (1979), consists of collaborating (integrating), competing (forcing), accommodating, avoiding and compromising (See Figure 1). A collaborative or integrating style is indicative of a high level of concern for both one's 
goals and others' goals in conflict. This style involves a problem-solving orientation and a willingness to explore and work with the other person to find options that will be mutually acceptable and maximize joint gains. Openness, exchange of information and confrontation characterize the style. The dominating style reflects a high concern for one's goals along with a low concern for others' goals. This style is evidenced by a winlose orientation with attempts to accomplish objectives without account of the other person's needs. The dominating style is uncooperative and direct (Blake \& Mouton, 1964). Confrontational or critical remarks, accusations, and rejection of other person's points are representative of this style (Hocker \& Wilmot, 1998).

The accommodating or obliging style involves a low level of concern for one's goals but a high concern for others' goals. This style is manifested by someone who attempts to minimize differences by giving in to the other person, not expressing concerns. The avoiding style is associated with having low concern for both one's goals and others' goals. It is characterized by attempts to withdraw, deny and disengage from a conflict situation. Changing the topic or making irrelevant remarks are efforts to avoid the conflict (Hocker \& Wilmot, 1998). Compromising indicates a moderate concern for one's goals and others' goals. This is evidenced by a give and take approach, secking middle ground through each person giving up something to reach a solution. 
Figure 1. Rahim's (1983) Styles of handling interpersonal conflict.

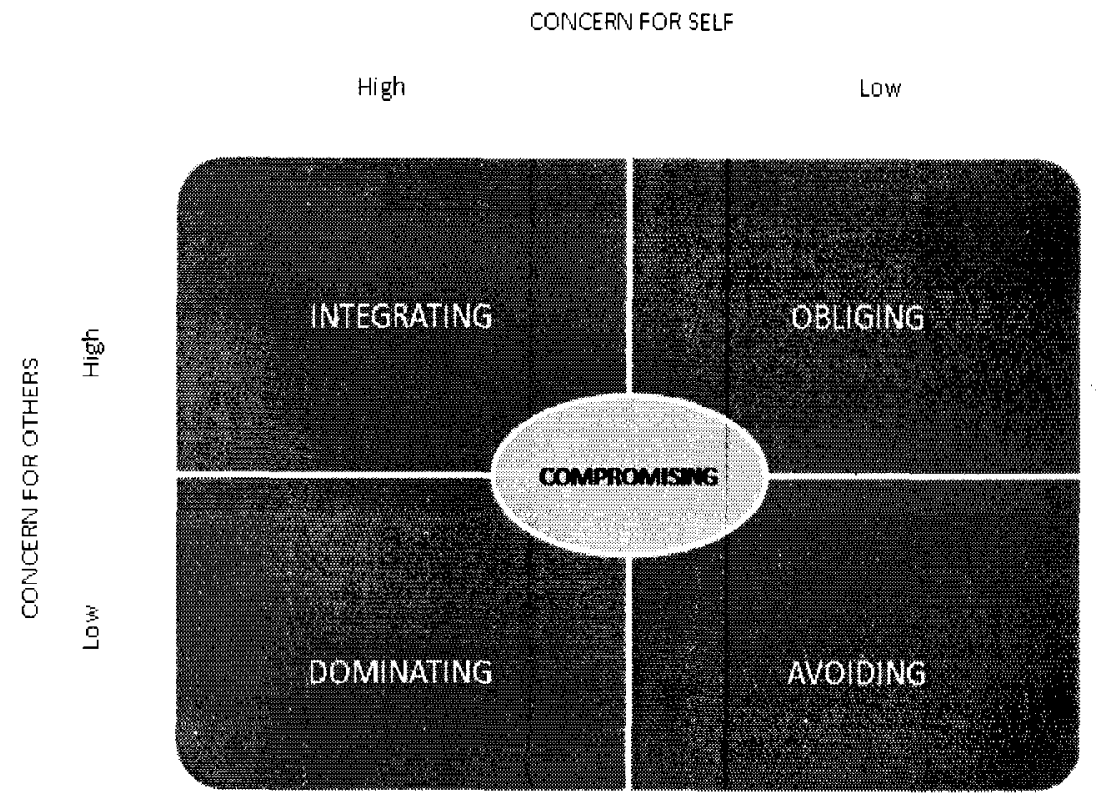

Various other scholars and researchers developed two, three and four factor typologies of conflict management styles. For instance, Hammock, Richardson, Pilkington, \& Utley (1990) reported that in a sample of college students, integrating and compromising were undifferentiated components that were collapsed to a single cooperation factor. However, Rahim \& Magner (1995) assert that the five factor ROC-II model has a better fit with data than models of two, three and four conflict-handling style orientations. Other studies support the five factor structure of the conflict management strategies (De Dreu, Evers, Beersma, Kluwer, \& Nauta, 2001; Euwema \& Van Emmerik, 2007; DeChurch, Haas, \& Hamilton, 2007).

While this dual concern, five factor typology model has gained wide acceptance, some have critiqued the instruments developed based on this model as lacking. Volkema and Bergmann (1989) point out that the five factor model do not account for affective responses occurring during conflict episodes. They further assert that the instruments do 
not necessarily measure conflict behaviors, but merely intentions, which are more abstract.

\section{Which styles work best?}

There are three major perspectives on conflict management in the literature: the one-best-way perspective (Lewicki, Weiss, \& Lewin, 1992), the contingency perspective (Rahim, 2000), and the complexity perspective (Van de Vliert, Nauta, Giebels, and Janssen, 1999). The one-best-way perspective focuses on problem-solving (collaboration) as the most constructive of five conflict management styles consisting of avoidance, accommodation, compromise, forcing and collaboration (Blake \& Mouton, 1970, 1981; Fisher, Ury, \& Patton, 1991; Rahim, 1983). Burke (1970) assert that forcing (dominating) and avoiding (withdrawing) styles are related to ineffective conflict management while a confrontation (integrating/ collaboration) style is related to the effective management of conflict. There is research to substantiate this perspective. Some scholars and researchers suggest that collaborative (integrative) conflict management style leads to more effective outcomes since it is based on a win-win orientation with a high concern for both an individual's and the others' goals, and reflects a joint search for mutual gains (Chusmir \& Mills, 1989; Fisher et al., 1991). Within the context of organizations, the use of dominating (competitive) conflict management styles involving a win-lose orientation may create a hostile work environment and negative affect.

Canary and Spitzberg $(1987,1989)$ reported that individuals with integrative strategies were viewed as the most competent while distributive and avoidant strategies correlated negatively with competence. In another study, Gross and Gucrrero (2000) reported that integrating was perceived by respondents as the most effective style, while 
dominating (forcing) was viewed as inappropriate unless used together with the integrating style. Avoiding was perceived as incompetent while accommodating and compromising were viewed as neutral.

Although there is recognition that the integrative (collaborative) style leads to more creative and satisfactory outcomes (Fisher et al., 1991; Thomas, 1992), collaboration takes more time and energy which may not be possible due to limited resources (Marcus, Dorn, Kritek, Miller, \& Wyatt, 1995). In a study conducted by De Dreu, Giebels, and Van de Vliert (1998), cooperative negotiators took an average of $30 \%$ more time to reach integrative agreements than cooperative negotiators who settled on compromises.

A contingency perspective is one reflecting the view that appropriate conflict management "can best be determined in the light of situational realities" (Van de Vliert et al., 1999, p.476; Rahim, 2000). One of these situational realities pertains to organizational constraints such as hierarchical relationships. Rahim's (1986) study of a national random sample of executives using three different forms measuring conflict styles with superiors, subordinates and peers, indicated that referent role, i.e. hicrarchical status served as constraints that influenced conflict styles. He found that respondents were mostly accommodating to superiors, integrative with subordinates, and compromising with peers. In the field of healthcare, various studies based on nursing samples established that compromising and avoidance are the most often used styles to manage conflict (Cavanaugh, 1991; Shell, 2001; Reich, Wagner-Westbrook, \& Kressel, 2007). Researchers attribute this to the nurturing environment of nursing and healthcare. A study by Callanan, Benzing, and Perri (2006) substantiates the contingency approach to 
conflict as they found that when presented with conflict scenarios, individuals were generally responding with contextual appropriate strategies which differed from their assumed predominant conflict style. However, their study utilized written case scenarios where respondents could consider the appropriate strategy to apply as distinct from being in a real life conflict experience. This may be a methodological shortcoming although it is indeed extremely challenging to replicate real life experiences within a laboratory setting.

The complexity perspective is based on the assumption that a reaction to a conflict issue consists of a simultaneous or sequential aggregation of several behavioral responses (Van de Vliert et al., 1999). These behaviors impact both substantive and relational outcomes of the conflict. Van de Vliert et al. (1999) reported that best outcomes result when dominating and integrating styles are used in combination and consecutively, in that order. This perspective appears to be substantiated by Munduate, Ganaza, Peiro, and Euwema (1999), who reported that optimum outcomes resulted when a combination of conflict styles were applied, specifically the integrating, dominating and compromising styles. They concluded that conflict styles are not used separately but that the various combinations of styles are better predictors of perceptions of competence. Conflict management styles should be evaluated in the light of whether the conflict effects are exacerbated or reduced and whether task outcomes are positive or negative (Chusmir \& Mills, 1989). Along similar lines, Medina, Munduate, Dorado, Martinez, and Guerra (2005) emphasized the need to consider conflict styles in the context of desired outcomes while preserving both task and relationship goals.

Conflict Management Styles and associated variables 
Conflict researchers and scholars have studied the relationships between conflict management styles and numerous organizational constructs such as leadership styles, workplace role and hierarchy, conflict level, job satisfaction, and affect level of individuals. Certain conflict styles have been associated with positive outcomes while others were found to be detrimental at both the individual and corporate levels. At the individual level, styles of conflict and levels of conflict were found to be significantly related to individual job satisfaction, with the integrating and compromising styles being positively related to interpersonal outcomes, while dominating and avoiding styles were negatively related to interpersonal outcomes (Weider-Hatfield \& Hatfield, 1995). Barki \& Hartwick's (2001) study determined that problem-solving and compromising styles were correlated to lower frequency and intensity of conflicts while dominating, avoiding, and accommodating were associated with higher levels and frequency of conflict.

Friedman et al. (2000) investigated the effect of conflict styles on workplace conflict and stress. They found that the use of the integrating style reduces the experience of workplace conflict and consequently, associated with lower stress. In contrast, both dominating (forcing) and avoiding increased both workplace conflict and stress. The accommodating style produced interesting results - individuals reported lower levels of conflict but increased levels of stress. In another study, supervisors using the integrating style were more likely to achieve behavioral compliance with their requests (Rahim \& Buntzman, 1990).

Rahim et al. (1999) conducted a study using a sample of collegiate employed business students to assess if conflict management styles are related to moral development in individuals. They found that those who are at the highest stage of moral 
development were more likely to use the integrative (collaborative) style while those at the lowest stage of moral development were more prone to the dominating and avoiding style. The integrative approach is considered to be the most effective for conflict management, therefore, there are two-fold implications for human resource practices: to consider stages of moral development in the selection process and also in organizational training to develop moral reasoning in employees (Rahim et al., 1999).

Conflict management styles do influence the outcomes of conflict. Song, Dyer, and Thieme (2006) examined the relationship between the five conflict styles and conflict outcomes. They determined that avoiding and forcing (dominating), both on the noncooperative dimension, were associated with destructive conflict outcomes. The integrating and accommodating styles were related to constructive conflict outcomes while compromising was linked to destructive outcomes. A strong positive association between constructive conflict and innovation performance was also established (Song et al., 2006).

Conflict management styles in general, may impact more than individuals. On an organizational level, outcomes can be either negative or positive. In a study on work teams in China, Tjosvold, Hui, and Yu (2003) found that a cooperative mode of conflict management is related to team task reflexivity, which in turn impacts team performance. This suggests that effective teamwork requires a cooperative style of managing conflict. Avoiding and competitive approaches to conflict have a pernicious effect on employees: empirically, project managers who applied both competitive and avoiding approaches to conflict were judged as ineffective and therefore reduced employees' trust and commitment (Barker, Tjosvold \& Andrew, 1988). In the same study, project managers 
who combined cooperative and confirming (of employees' competence) approaches were perceived as cffective and inspired employee trust and commitment.

Conflict and conflict management have also been associated with other organizational variables such as leadership effectiveness (Barbuto $\& \mathrm{Xu}, 2006$ ), satisfaction of followers (Gross \& Guerrero, 2000), task performance (Olson-Buchanan, Drasgow, Moberg, Mead, Keenan, \& Donovan, 1998), and contextual performance (Greenberg \& Barling, 1999).

Workplace Incivility, Conflict Management Styles and Personality Factors

Workplace incivility and conflict management styles may be associated through personality factors. Research has established that each of these constructs is related to personality and behavioral traits such as Type A, hostile and angry personalities, negative affect and the Big Five Factors. A revicw on the extant literature will establish a foundation for the current study to investigate the relationship and effect of conflict management styles on workplace incivility.

\section{Big Five and WPI}

Research indicates that personality traits are associated with the propensity to engage in both organizational and interpersonal deviant behaviors, which includes workplace incivility. Some studies examined the influence of personality factors based on the Five Factor personality dimensions (as conceptualized by Digman, 1990), on workplace deviance. These five dimensions are: Conscientiousness, which consists of hard work, orderliness, conformity, and sclf-control (Hogan \& Ones, 1997); Extraversion is evidenced by being sociable, talkative, assertive and active; Agreeableness is associated with being courteous, flexible, trusting, good-natured, cooperative, friendly, 
forgiving, and tolerant. Openness to Experience is described as being imaginative, curious, artistic, intelligent, cultured, open-minded and original; while Neuroticism or Emotional Stability is linked to levels of anxiety, depression, anger, worry and insecurity (Barrick \& Mount, 1991).

Barrick and Mount's (1991) meta-analysis of the Big Five and job performance established that Conscientiousness was a consistent predictor of job performance across all occupational groups. This was substantiated empirically by Fallon, Avis, Kudisch, Gornet, and Frost (2004), who found that Conscientiousness did predict overall performance, as well as supervisors' willingness to rehire employees who score higher on Conscientiousness. Further, the researchers also established that Conscientiousness also predicted employee work attendance. This implies that those who score high on Conscientiousness are less likely to engage in deviant behaviors.

Flaherty and Moss (2007) studied the effects of injustice on counterproductive workplace behaviors and determined that procedural, distributive, and interactional injustice all provoked counterproductive behaviors. However, they found that the pernicious effects of injustice were reduced where team members scored higher on Agreeableness and lower on Neuroticism, in conjunction with higher levels of team commitment and coworker satisfaction. According to Miles, Borman, Spector, and Fox (2002), "Affective dispositions such as state anger and anxiety, neuroticism, and emotional experience are related to emotional response and are therefore related to CWB (counterproductive workplace behaviors)" (p.52). Salgado (2002) determined that both Conscientiousness and Agreeableness were associated with deviant behaviors and turnover, while extraversion, openness, and emotional stability predicted turnover only. 
However, deviant behaviors (theft, admissions, actual theft, disciplinary problems, substance abuse, property damage, organizational rule breaking, and other irresponsible behaviors) in this study appcar to be focused on those that are targeted toward the organization, and not necessarily interpersonal deviance.

In a study by Colbert et al. (2004), three of the Big Five factors, conscientiousness, emotional stability (neuroticism), and agreeableness were found to be moderators of the relationship between perceptions of the work environment and workplace deviance. Specifically, individuals scoring low in conscientiousness or emotional stability were more prone to engage in organizational deviance when they perceive the work environment as negative. They also discovered that interpersonal deviance was more likely for individuals who are low in agreeableness when they perceive a lack of organizational support.

Other personality or dispositional variables such as trait anger and trait anxiety were linked to counterproductive workplace behaviors (Fox \& Spector, 1999; Fox et al., 1999; Miles, Borman, Spector, \& Fox, 2002). Earlier, integrity tests assessing conscientiousness, agreeableness, and emotional stability (Neuroticism), were found to be related to counterproductive workplace behaviors (Ones, Viswesvaran, \& Schmidt, 1993).

Tepper, Duffy and Shaw (2001) investigated whether conscientiousness and agreeableness moderated the relationship between abusive supervision and resistance. Neuroticism and Extraversion were used as control variables. They found that subordinates with lower conscientiousness and lower agreeableness reported greater level of dysfunctional resistance behaviors in response to abusive supervisors. In another 
study, Lee, Ashton and Shin (2005) determined that Extraversion was a significant predictor of interpersonal and organizational antisocial behavior. They also found that Agreeableness was related to interpersonal antisocial behavior, whereas Conscientiousness was related to antisocial behavior towards the organization. Skarlicki et al. (1999) reported that negative affectivity (relating to Neuroticism or Emotional Stability factor) and agrecableness moderated retaliatory behaviors in individuals who perceived organizational injustice. Those who are high on negative affectivity or low in agreeableness had a tendency to engage in retaliatory behaviors.

\section{Big Five and Conflict Management styles}

Conflict management styles are generally linked to stable, dispositional traits in individuals. Empirical research suggests that all Big Five personality traits predict the use of individuals' conflict management styles. Antonioni (1998) and Moberg (2001), in independent studies, both using samples of managers, found that conscientiousness was negatively related to the avoiding style, and positively related to the integrating style. Further, both studies established that extraversion was also positively linked to integrating, and low agreeableness corresponded with the dominating style. Moberg (2001) reported that the avoiding style was positively related to neuroticism, negatively related to extraversion, while integrating was negatively linked to neuroticism, negatively linked to openness. He also confirmed that the compromising style is positively related to openness and agreeableness, and the accommodating style is positively linked to neuroticism.

Dijkstra, Van Dierendonck, Evers, \& De Dreu, (2005) reported that conflict adversely affects well-being, especially when individuals were low in agreeableness, low 
in emotional stability or low in extraversion. Given such dispositional traits, individuals are more likely to experience the negative effects in the workplace. Graziano et al. (1996) found that agrecableness predicted conflict style and individuals who score low on agreeableness are more likely to perceive provocative behaviors as a conflict thereby experiencing higher level of negative affect and aggression. These individuals may more likely perceive incidents of workplace incivility.

Table 1 illustrates the summary of empirically established relationships between Big Five personality traits with conflict management styles and deviant behaviors respectively as previously examined in this chapter. 
Table 1

Big Five Factors, Deviant Behaviors and Conflict Styles

\begin{tabular}{|c|c|c|}
\hline Big Five Factor & Relationship with Deviant Behaviors & $\begin{array}{l}\text { Relationship with Conflict } \\
\text { Styles }\end{array}$ \\
\hline Conscientiousness & $\begin{array}{l}\text { Positive- Fewer deviant } \\
\text { behaviors (Salgado, 2002) } \\
\text { Moderated perceptions of } \\
\text { negative work environment } \\
\text { on workplace deviance } \\
\text { (Colbert et al., 2004). } \\
\text { - Negative- Dysfunctional } \\
\text { resistance behaviors toward } \\
\text { abusive supervisors (Tepper, } \\
\text { Duffy, \& Shaw, 2001) } \\
\text { Negative-Antisocial } \\
\text { behaviors towards } \\
\text { Organization (Lee, Ashton, \& } \\
\text { Shin, 2005). } \\
\text { Negative- interpersonal and } \\
\text { organizational deviance } \\
\text { (Berry et al., 2007). } \\
\text { Turnover }\end{array}$ & $\begin{array}{l}\text { - Negative with } \\
\text { avoiding, positively } \\
\text { with integrating } \\
\text { (Antonioni, 1998; } \\
\text { Moberg, 2001) }\end{array}$ \\
\hline Agreeableness & $\begin{array}{l}\text { Negative - Org justice effect } \\
\text { lower (Flaherty \& Moss, } \\
\text { 2007) } \\
\text { Negative- Deviant behaviors } \\
\text { (Salgado, 2002; Berry et al., } \\
2007 \text { ) } \\
\text { Moderator between } \\
\text { perceptions of work situation } \\
\text { and WPD (Colbert et al., } \\
\text { 2004). } \\
\text { Negative- Dysfunctional } \\
\text { resistance behaviors toward } \\
\text { abusive supervisors (Tepper, } \\
\text { Duffy, \& Shaw, 2001) } \\
\text { Negative- Interpersonal } \\
\text { antisocial behaviors (Lee, } \\
\text { Ashton, \& Shin, 2005). } \\
\text { Negative with Vengefulness } \\
\text { (McCullough, Bellah, } \\
\text { Kilpatrick, \& Johnson, 2001) }\end{array}$ & $\begin{array}{l}\text { Negative } \\
\text { agreeableness with } \\
\text { dominating } \\
\text { (Antonioni, 1998; } \\
\text { Moberg, 2001) } \\
\text { - Positive - } \\
\text { Compromising } \\
\text { (Moberg, 2001). } \\
\text { - Positive- with more } \\
\text { compromising tactics } \\
\text { (Jensen-Campbell \& } \\
\text { Graziano, 2001) } \\
\text { Positive- Problem- } \\
\text { solving and yielding } \\
\text { styles reflect } \\
\text { disposition to forgive } \\
\text { (Rizkalla, Wertheim, } \\
\text { \& Hodgson, 2008). }\end{array}$ \\
\hline
\end{tabular}


Neuroticism

Extraversion

Openness to experience
- Positive- Organizational injustice effect higher, more dysfunctional behaviors toward abusive supervisors (Flaherty \& Moss, 2007).

- Positive- Moderator between perceptions of work situation and WPD (Colbert et al., 2004).

- Positive- Counterproductive workplace behaviors (Spector \& Fox, 2005)

- Positive- interpersonal and organizational deviance (Berry et al., 2007).

- Positive with vengefulness (McCullough et al., 2001)

- Negative- Interpersonal and organizational antisocial behaviors (Lee et al., 2005).
- Positive with avoiding (Moberg, 2001)

- Negative with integrating (Moberg, 2001)

- Positive with accommodating (Moberg, 2001).

- Positive with use of destructive tactics (Jensen-Campbell \& Graziano, 2001).
- Positive with integrating (Antonioni, 1998; Moberg, 2001)

- Negative with avoiding (Antonioni, 1998; Moberg, 2001)
- Negative with integrating (Moberg, 2001)

- Positive with compromising (Moberg, 2001)

Research points to both workplace deviant behaviors and conflict management styles being in part, dispositional as established through their individual associations with the Big Five personality traits. Consequently, research into the possible link between workplace incivility and conflict management styles is warranted. 
WPI and Conflict Management styles on Job performance, Organizational Commitment,

\section{Intent to Turnover}

\section{Job performance}

Employers have a vested investment in the job performance of their employees. Job performance that is sub-standard is detrimental to overall organizational performance and effectiveness. Consequently, this is an important organizational variable that has garnered much attention in the literature. Job performance is defined as the value an organization can expect from discrete behaviors performed by an employee over time (Motowidlo, 2003; Motowidlo, Borman, \& Schmit, 1997). Job performance consists of various components: it relates to behaviors, within a time context, has an evaluative component and is multidimensional (Motowidlo, 2003, Motowidlo, Borman, \& Schmit, 1997). Job performance is more than completion of tasks, which involves knowledge, technical skills and abilities (Van Scotter, Motowidlo, \& Cross, 2000).

Borman and Motowidlo (1993) identified two categories of job performance: task performance and contextual performance. Both contribute differentially to overall job performance and related job performance criteria such as experience and personality variables (Motowidlo \& Van Scotter, 1994). Contextual performance involves "behavior that contributes to organizational effectiveness through its effects on the psychological, social and organizational context of work: (Motowidlo, 2003, p.44). Further, Motowidlo (2003) clarified that there is a distinction between behavior, which is what people do, and performance, which is the expected organizational value of what people do.

Sackett (2002), in analyzing the literature linking counterproductive workplace behaviors and job performance, found that counterproductive workplace behaviors were 
consistently highly correlated to contextual performance (conceptualized as citizenship bchavior). In contrast, the relationship between task performance and counterproductive workplace behaviors varied across studies. He postulated that the inconsistent results may be due to differing conceptualizations of task performance: task proficiency vs. typical task performance.

Rahim et al. (2001) found that conflict management styles, specifically a problem-solving style, were positively related to job performance. They defined a problem-solving style as the difference between one's integrating style and avoiding style. Other variables impacting job performance include Big Five personality factors (Barrick \& Mount, 1991). These personality factors are associated with both workplace deviant behaviors as well as conflict management styles.

\section{Organizational Commitment}

There is a proliferation of research on organizational commitment because it is a key variable that is related to various aspects of organizational behaviors and outcomes. For instance, a decline in organizational commitment has been cited as a precursor to employee turnover (e.g., Angle \& Perry, 1981; Hom \& Griffeth, 1995; Mowday, Porter, \& Steers, 1982; Somers, 1995; Whitener \& Waltz, 1993). Empirically, there is also evidence that organizational commitment is a predictor of job performance (Organ \& Ryan, 1995; Riketta, 2002).

Meyer and Allen (1991) propose a three component model of organizational commitment. These components are affective commitment, continuance commitment, and normative commitment. Affective commitment is defined as an employee's "emotional attachment to, identification with, and involvement in the organization" 
whereas continuance commitment refers to an employee's "awareness that costs are associated with leaving the organization" (Meyer \& Allen, 1991, p. 11). Normative commitment refers to a "feeling of obligation to continue employment ... or a feeling that an employee ought to remain with the organization" (Meyer \& Allen, 1997, p. 11). Thus, they describe commitment as a "psychological state that (a) characterizes the employee's relationship with the organization, and (b) has implications for the decision to continue or discontinue membership in the organization" (Meyer \& Allen, 1991, p. 67). Individuals who have a sense of attachment to institutions and conform to social norms are less likely to engage in deviant behaviors (Bennett \& Robinson, 2000). This is supported by Thau, Crossley, Bennett, \& Sczesny (2007) who showed that trust, as operationalized by feclings of attachment to an organization and its members, relates to antisocial behaviors.

Thomas et al. (2005) determined that interpersonal conflict in common forms such as rudeness, disagreement and shouting, has a detrimental effect on organizational commitment, specifically both affect and continuance commitment. Further, there is also some evidence to suggest that workplace violence, a form of interpersonal conflict is related negatively to commitment (Leather, Lawrence, Beale, Cox, \& Dickson, 1998). Workplace incivility has been negatively associated with organizational commitment (Pearson et al., 2001). These studies indicate that organizational commitment is a pertinent variable that needs further study in relation to incivility and conflict management styles.

Intent to Turnover 
Turnover is widely researched since it is an important issue for both organizations and researchers. Within the contexts of both workplace incivility and conflict, intent to turnover has been determined as one of the dominant outcomes. One of the major concerns about turnover is its associated costs for both the individual and the organization (Mobley, 1997). Turnover is associated with lowered morality and productivity among employees who remain in the organization (Sheehan, 1993). Cascio's (1991) turnover costing model considers three major categories of expenses: separation costs (exit interview, administrative and severance pay), replacement costs and training costs. Another computational framework presented by Tziner and Birati (1996) calculates direct costs (replacement process), indirect costs and losses related to interruptions of processes and financial value of decreased performance due to drop in employee morale. These costs are relevant in considering the issue of turnover in any organization and draws attention to the pernicious and expensive problem of voluntary turnover.

Price (1977) defines turnover as "the degree of individual movement across the membership boundary of a social system" (p.4). This implies that turnover is a process and not an instant occurrence. Although researchers theorize that there are two types of turnover, voluntary and involuntary, the current focus is on voluntary turnover. Shaw, Duffy, Johnson, and Lockhart (2005) refer to employee turnover as the incidents of employees voluntarily leaving an organization. They suggest that organizational performance may be reduced as a consequence of high turnover since it requires the diversion of organizational resources from other core areas of activities.

Mobley (1977) found intermediate linkages between job satisfaction and turnover that substantiates theoretically that turnover is a process. An employee thinks about 
leaving his or her job in the context of job satisfaction, which may then translate to withdrawal behaviors at work. He or she continues to analyze the costs of quitting and seeking a new position. It is a deliberative process that involves thought and analysis as opposed to a sudden impulsive decision to quit (Mobley, 1977). The intent to quit is a strong predictor of actual turnover (Mobley, Horner, \& Hollingsworth, 1978).

Previous studies indicated that workplace incivility predicts turnover (Cortina et al., 2001; Lim \& Cortina, 2005). Certain conflict management styles such dominating and avoiding is associated with higher levels of experienced conflict and stress (Friedman et al., 2000). Increased job stress as a result of dealing with workplace conflict was associated with intent to turnover (Giebels \& Janssen, 2005).

Control variables: Gender, Age, Organizational rank, Tenure.

Gender, age, organizational rank and tenure are demographic variables that were assessed because of their potential relationship to both conflict management styles and workplace deviance, which includes workplace incivility. This is to ensure that the relationship between conflict management styles and workplace incivility was not confounded. Ostensibly, these are variables that have had a demonstrated effect on each of the constructs.

Gender. Research concerning the relationship of gender to workplace incivility and conflict management styles reveals mixed results. In a study of Federal Court employees, Cortina et al. (2001) reported that women were more likely than men to experience workplace incivility. This finding is supported by a subsequent study using a sample of 4068 practicing attorneys: it was more common for female attorneys to be targets of incivility than male attorneys (Cortina, Lonsway, Magley, Freeman, Collinsworth, 
Hunter, \& Fitzgerald, 2002). More recently, gender reportedly impacted workplace incivility in terms of the perceived threshold level of what are considered rude or offensive behaviors (Young, Vance, \& Harris, 2007). Women in general, are more likely than men, to perceive certain behaviors as inappropriate or uncivil. In contrast, according to Porath and Pearson (2000), both men and women were just as likely to be targets of incivility. However, men of higher status were seven times more likely to be instigators of workplace incivility (Pearson et al., 2001).

In studies on conflict management styles, no definitive answers have emerged regarding gender differences. There are some studies indicating that in gencral, women are more cooperative in conflict by utilizing integrating, compromising, accommodating and avoiding styles while men appear to prefer the dominating and avoiding styles (Brahnam, Margavio, Hignite, Barrier, \& Chin, 2005; Klenke, 2003; Portello \& Long, 1994). Others have not found any gender differences (Chan, Monroe, $\mathrm{Ng}$, \& Tan, 2006; Ting-Toomey, Oetzel, \& Yee-Jung, 2001), particularly in the use of integrating, accommodating and compromising although women were more likely to avoid and men tended to be more dominating (Chan et al., 2006).

Age. Research indicates that employees' approaches to conflict and also behaviors at work are influenced by their age. For instance, in a study of nurses and their conflict management styles, Marriner (1982) found that nurses over the age of 55 are significantly less inclined to compromise as compared to nurses who were under than 35 . In contrast, another study on staff nurses revealed that although age was a significant predictor of conflict management styles, compromising was the most often used, with collaborating coming in second, and avoiding, third (Thomas, 1992). Rhodes (1983) suggested that 
older workers actually have lower absenteeism, turnover, illness, and accident rates, higher job satisfaction, and more positive work values than younger workers.

Organizational rank or status. Relative or hierarchical status within an organization influences employees' responses to personal offenses. In a study by Aquino, Tripp, and Bies (2001), employees were more likely to seek revenge against less powerful people. Interestingly, those who are of higher status were less likely to exact revenge than those of lower status. Further, incivility is perpetrated more often by someone of higher status than the target: according to one study as mentioned previously, the instigator is seven times more likely to be a male of higher status (Pearson et al., 2000). This is supported by Gonthier and Morrissey (2002) and Rayner (1997) whose studies reported that incivility usually goes down hierarchically through the organization. Likewise, in a study on conflict management styles, Brewer, Mitchell, and Weber (2002) determined that individuals who are higher on organizational status tend to use the integrating style, while lower ranking individuals were more likely to use the avoiding and accommodating styles.

Tenure. The literature suggests that tenure has an effect both on conflict management and workplace incivility separately. In a study of over 700 executives and middle managers in the Australian Public Service (APS), experience in senior management, job and organization tenure were most likely to predict conflict management style (KoracKakabadse, Korac-Kakabadse, \& Myers, 1998). A more recent study of school teachers' conflict preferences supported previous findings that years of experience on the job is associated with conflict management style (Morris-Rothschild, 2003). Pearson et al. (2000) reported that instigators of incivility tended to be older males with longer tenure in 
the organization. Their study was based on a sample of 1400 employees across different industries. Hollinger, Slora, \& Terris (1992) indicated that employees with less tenure are more likely to engage in workplace deviant behaviors, in particular, organizational deviance.

Ostensibly, these are variables that have a demonstrated effect on both workplace incivility and conflict management styles. In this study, they served as controls so the relationships between workplace incivility and conflict management styles on job performance, organizational commitment and turnover may be examined.

\section{Summary}

The literature has revealed a plethora of research on the major constructs of this study as well as the proposed associated organizational variables. Workplace incivility and conflict management styles have each been assessed with many individual and organizational variables. However, empirical research exploring workplace incivility and conflict management styles is sparse to non-existent. Further, there is also scant study of the relationship between workplace incivility and job performance although the literature indicated that job satisfaction is associated with workplace incivility. The purpose of this research is to address the gap in the literature and explore the relationships between workplace incivility, management styles and selected organizational variables. A conceptual model, Figure 2, has been developed to explain the relationship between workplace incivility and workplace outcomes of job performance, turnover and organizational commitment as moderated by conflict management styles.

Chapter III will detail the methods utilized and present the appropriate context in which this study was conducted. 


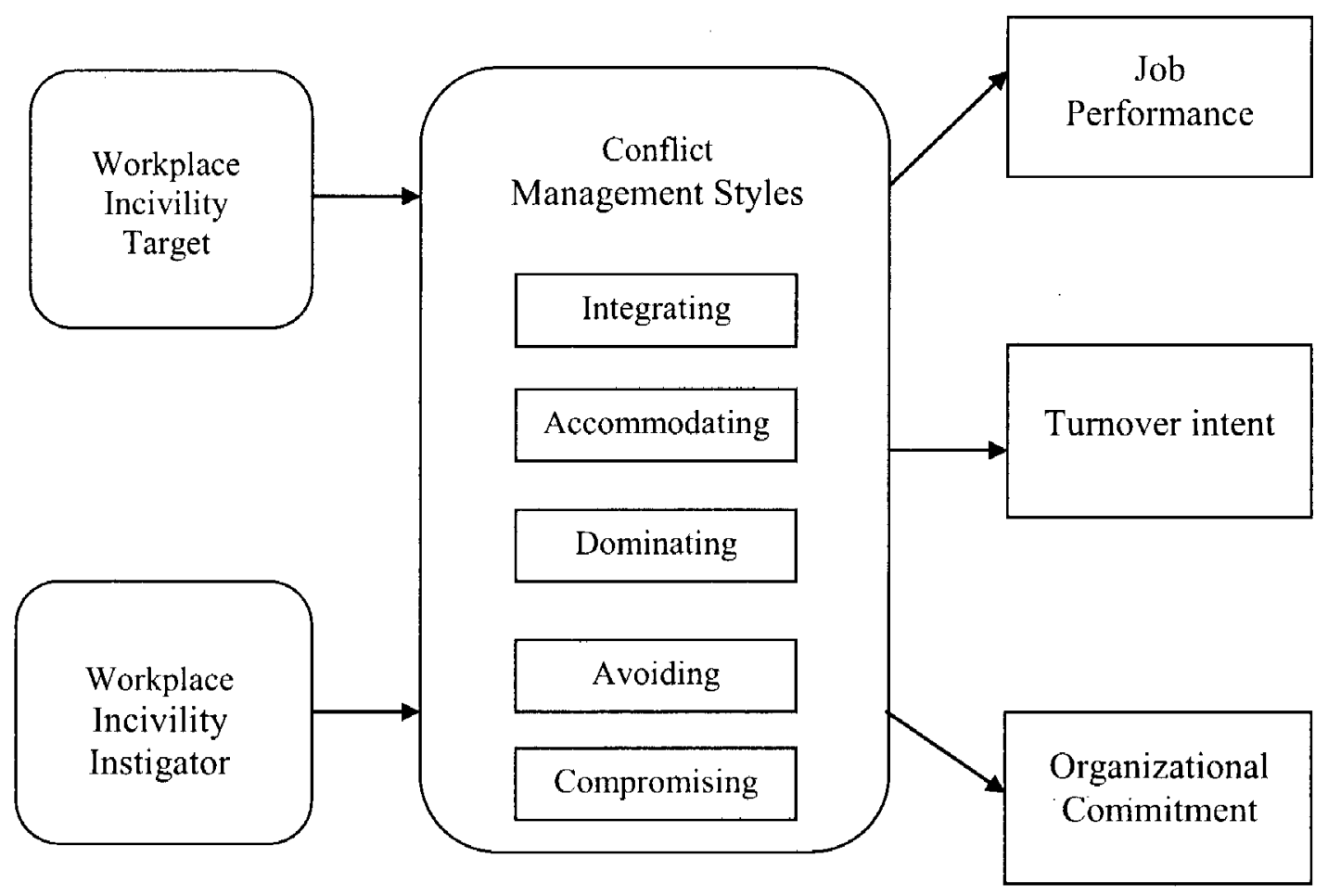

Figure 2. Conceptual model of the relationship between workplace incivility, conflict management styles and workplace outcomes study 


\section{CHAPTER III}

\section{METHODS \\ Introduction}

The purpose of this study was to explore the relationships between workplace incivility, conflict management styles and their effects on job performance, organizational commitment and intent to turnover. This chapter presents pertinent information relating to the methods and procedures of data collection and analyses used in conducting this study. The research design, population and sample will be discussed, along with descriptions of the research instruments, the pilot study, and a chapter summary.

The proposed research questions to investigate these relationships are:

1. What is the relationship between workplace incivility and conflict management styles of (a) dominating, (b) integrating, (c) compromising, (d) accommodating, and (e) avoiding?

2. Are there differences between the relationships of conflict management style and workplace incivility from the perspectives of targets versus instigators of incivility?

3. Do conflict management styles affect the impact of workplace incivility on employee's job performance, commitment to their organization and turnover? 
4. After controlling for select demographic variables, what is the relationship between workplace incivility, conflict management styles and perceived job performance?

5. After controlling for select demographic variables, what is the relationship of workplace incivility and conflict styles on organizational commitment?

6. After controlling for select demographic variables, what is the impact of workplace incivility and conflict styles on turnover intentions?

\section{Research Design}

This study applied a non-experimental correlational design to address the above research questions. A correlational design allows for the consideration of relationships between a number of variables in a single study (Gall, Borg, \& Gall, 1996) as well as the strength of relationships among such variables (Pagano, 1998). The characteristics of corrclational designs include: the use of two or more variables, data is collected at one point in time, participants are analyzed as a single group (as compared to an experimental design where multiple groups are involved), at least two scores (one for each variable under study) are obtained from each participant, the data analysis includes correlational statistical tests and the results are interpreted (Creswell, 2005).

A correlational design involves statistical procedures that provide for multiple variable analyses such as partial correlations and multiple regression as well as correlational analysis to determine associations between variables. The researcher used multiple regression analyses to examine the unique variance and effect of workplace incivility and conflict management styles in predicting separately job performance, organizational commitment and turnover intent. 
A cross-sectional survey methodology was utilized to gather self-report data from workers in three organizations to study the relationship between the research variables. Such a cross-sectional survey design is used to "collect data about current attitudes, opinions or beliefs" (Creswell, 2005, p.355). It involves collecting data at one point in time as opposed to several points in time as in longitudinal survey research. Survey research are useful for addressing questions, solving problems that have been identified, assessing needs, goal setting, determining if objectives have been met, establishing baselines for future comparisons, analyzing trends over time, and provide information as to current conditions and context (Isaac \& Michael, 1997). Dillman (1991) noted that surveys are a common method of data collection for research because of efficacy and cost efficiency. Larger samples can be used and more accurate information may be gathered since respondents are less apt to provide more socially desirable responses when completing a survey anonymously than telephone or in-person interviews (Dillman, 1991, 2002). Fowler (2002) noted that surveys can help ensure an unbiased sample and in estimating the accuracy of data fit in representing the larger population under study. Further, surveys provide a means of standardized measurement across respondents to obtain comparable information (Fowler, 2002).

This study utilizes a self report survey questionnaire on employees' experiences (both as targets and instigators) of workplace incivility, their preferred conflict management style, job performance as well as their commitment toward their organizations and turnover intent. The same questionnaire was offered in both electronic and hard copy modes. 
Following Tabachnick and Fidell's (2001) guidelines $(N \geq 50+8 m$, where $m$ is the number of independent variables), the recommended number of survey responses necessary for testing multiple correlations between 11 independent variables (two for workplace incivility (target and instigator), five conflict management styles, age, sex, tenure and organizational rank) and the dependent variables of job performance, organizational commitment and turnover intentions is 138. Further, Tabachnick and Fidell (2001) also recommended $N \geq 104+m$ responses for testing individual predictors. This would entail a sample size of at least 115 responses. However, the researcher will strive for a minimum of 165 responses. This is consistent with the advice of Stevens (2002) who suggested a minimum of 15 subjects per predictor variable in social science applications of regression.

\section{Population and sample}

The population of interest in this study was employees from private sector organizations in the Midwest. The first is from the manufacturing sector with 201 members consisting of hourly, salaried and corporate salaried employees; the second organization, with 400 employees, is from the healthcare sector, providing independent and assisted living services and facilities with locations in five states. The third and smallest sample was from another manufacturing organization consisting of only the corporate employees who had computer access. The Human Resource Directors of each organization were contacted prior to the administration of the survey questionnaire to secure agreement for their organization's participation and later, to enable them to review the contents of the survey. Participants from both organizations completed the same survey on hard copy due to the challenges that most of them did not have access to work 
computers. The support of the presidents or human resource directors of each of the companies was sought and a memorandum composed by the researcher but sent from them was forwarded to all their respective employees to invite participation. The third organization completed the survey online.

\section{Data Collection Procedures}

This study employed a mixed mode survey methodology to collect data: both electronic survey and hard copy pen and paper survey were used. The majority of employees in the first and second organizations did not have online access so hard copy surveys were necessary. Only the third sample had computer access to complete the survey. Dillman (2007) noted that mixed-mode surveys provide a means to compensate for the weaknesses of each method even though he acknowledged that there may be a possibility that participants' answers may differ according to mode.

Dillman's (2007) online survey protocol was followed in the administration of the electronic survey to maximize responses. To that end, a pre-notification email explaining the research study was sent to the Human Resource Director requesting her to forward an email invitation resembling a cover letter (that includes a Web-link) to the employees. Two days following the pre-notification email, the email invitation with the Web-link was sent to the Human Resources Directors for forwarding to all potential participants. The email invitation explained the purpose of the study, sought cooperation from the participants, and assured confidentiality of their responses. Instructions were provided to access the electronic survey through the internet link.

To increase the response rates, the HR Director was emailed a reminder to be forwarded to participants following similar procedures as the previous email invitation. 
Five days later, a "thank you" email was sent to the HR Director additionally requesting them to remind once more the employees to complete the survey. Again, this final email was designed to maximize the response rate. Contrary to Dillman's (2000) recommendation of sending surveys directly to participants, there was no direct access to the participants in this study. All communication was through each organization's respective Human Resource Department.

The online survey questionnaire was administered through a web-based survey tool, Zoomerang. Zoomerang allows for surveys to be completed on a secure server, and the resulting data collected were then downloaded in a database format and imported into SPSS for analysis. The online survey method was used in this study because it offers numerous advantages such as cost and time efficiency (Mehta \& Sivadas, 1995); higher likelihood of response from participants who only have to point and click through the web-link (Shannon \& Bradshaw, 2002); design flexibility and interactivity, anonymity, ability to reach large numbers of people, and less time-consuming than mail surveys (Simsek \& Veiga, 2001). The time efficiency aspect of electronic surveys was a positive consideration since an average of 3.21 days for return was reported as compared to 9.13 days for mail survey return (Shannon \& Bradshaw, 2002). However, one of the limitations associated with electronic surveys is the variability of response rates, which may range from $6 \%$ to $68 \%$ (Schonlau, Fricker \& Elliot, 2002). In the current study, variability of response rates was controlled by working directly with the Human Resource Directors and garnering the support of the company presidents in encouraging full participation and cooperation from cmployee participants. Further, Dillman (2000) noted that multiple contacts with potential participants are helpful in guarding against low 
response rates. Kaplowitz, Hadlock, and Levine (2004) confirmed that with advance notification to participants, a Web-based survey questionnaire achieved a comparable response rate to mailed hard copy survey questionnaire.

The web-link forwarded to the organizations as part of the email invitation led directly to the survey questionnaire on Zoomerang. Participants could complete the survey at his or her convenience, including unlimited access to unsubmitted sections of the survey until the final page is submitted. However, once completed, participants will no longer have access to the survey. To ensure that each employee will only submit one survey per person, they were assigned a corresponding number with the assistance of the HR departments. This also ensures anonymity and controls for researcher bias.

The hard copy survey was administered according to Dillman's (2007) Tailored Design Method with some modifications. Hard copies of the survey, along with a cover letter and preaddressed stamped envelope for survey return, were sent to the Human Resource Directors of the first two organizational samples for distribution. The employees were advised to complete the survey during their breaks or on their own time. Reminders were emailed to the HR Directors to urge their employees to complete the survey. The hard copy survey administration process, along with that of the Online Survey Protocol (Dillman, 2007) are summarized in Table 2. 
Table 2

Study procedures based on Dillman's (2007) Tailored Design Method and Online Survey

Protocol

\begin{tabular}{|c|c|c|}
\hline Step & Week & Activity description \\
\hline & 1 & $\begin{array}{l}\text { Pilot study conducted with } 10 \text { participants from a } \\
\text { university's adult degree programs - } 5 \text { for online survey } \\
\text { and } 5 \text { for hard copy }\end{array}$ \\
\hline 2. & 2 & $\begin{array}{l}\text { Mailed or emailed prenotification memo to HR managers } \\
\text { for distribution to all employees }\end{array}$ \\
\hline 3. & 3 & $\begin{array}{l}\text { Provided hard copy suryeys to HR manager of sample } \\
\text { organizations } 1 \text { and } 2 \text { for distribution to employees. } \\
\text { Emailed HR manager of Sample } 3 \text { the cover email with link } \\
\text { to online survey }\end{array}$ \\
\hline 4. & 4 & $\begin{array}{l}\text { Emailed all HR managers a reminder memo for distribution } \\
\text { to employees. }\end{array}$ \\
\hline 3 & 5 & $\begin{array}{l}\text { Thank you ernail sent to all HR managers along with } \\
\text { reminder for any other employees to complete survey. }\end{array}$ \\
\hline
\end{tabular}

Research instruments

The survey instrument that was mailed to the organizational members comprised of demographic data, workplace incivility, conflict management, job performance, organizational commitment and turnover measures. Permission to use the various scales 
that comprised the survey was obtained from the relevant authors or creators of the original instruments.

Demographic variables. The demographic information questions were developed by the researcher and included personal and organizational information related to the participant. The demographic information served two purposes: identifying characteristics of the population under study as well as to control the effects of these factors on the key variables. Demographic information pertained to age, sex, ethnicity, tenure and organizational rank. Examples of questions with checkboxes for categorical answers include "how long have you been working at this company", and "what is your position in the company". Age, sex, tenure and organizational rank were controlled in this study since previous research indicated that each of these influenced workplace incivility, conflict management styles, organization commitment and job performance to varying extents.

Workplace Incivility. Workplace incivility was measured using the Workplace Incivility Scale (WIS) developed by Cortina, Magley, Williams and Langhout (2001). These seven survey items was designed to measure frequency of experienced rude, disrespectful or condescending behaviors from superiors or coworkers within the previous five years. However, the time frame for this scale was altered to one year to make it easier for respondents to recall (Johns, 1994, Blau \& Andersson, 2005). This seven-item measure, which asked them, inter alia, whether they had been in a situation where any of their superiors or coworkers "made demeaning or derogatory remarks about you," "addressed you in unprofessional terms," and "paid little attention to your statements or showed little interest in your opinion," were rated on frequency using a Likert type scale from 1 - 5 ( 1 
= never; $2=$ rarely $3=$ sometimes $; 4=$ often; $5=$ most of the time $)$. Results from the WIS were calculated by summing the responses to the items. Cortina et al. (2001) demonstrated the content and discriminant validity of this reliable measure. Confirmatory factor analysis on the seven items of the scale indicated that they loaded onto one factor, with an alpha coefficient of 89 . Convergent validity was measured by correlating the WIS with Donovan, Drasgow and Munson's (1998) PFIT scale which assessed perceptions of interpersonally fair or civil treatment in the workplace.

Two versions of the WIS were used: the original, which measures experiences of incivility (target); the second version measures incidences of instigated incivility. The second version merely reverses the perspective with the general content of the seven-item WIS scale being replicated (Blau \& Andersson, 2005). The lead-in phrase for the instigator perspective was "How often have you exhibited the following bchaviors in the past year to someone at work (e.g. co-worker, supervisor, other employee)?" as opposed to the original WIS target perspective's "During the past year while employed at your current organization, have you been in a situation where any of your superiors or coworkers..." Blau and Andersson (2005) established the original WIS scale's reliability as. 88 , and the instigated version of the WIS had a scale reliability of .89 .

Conflict Management Styles. The 20-item DUTCH Test for Conflict Handling (De Dreu, Evers, Beersma, Kluwer, \& Nauta, 2001) is a scale measuring each of the five styles, or preferences of managing conflict: problem-solving, yielding, avoiding, compromising and forcing. It was selected because it is a shorter instrument (with 20 survey items), than the Rahim Organizational Conflict Inventory - II (ROCI-II) (with 28 items). A shorter measure is a consideration when conflict management is part of a large organizational 
survey (De Dreu et al., 2001). The 20 items assess the frequency of conflict behaviors on a Likert scale from 1 to $5(1=$ Never; 2 =rarely; $3=$ sometimes, $4=$ often; $5=$ always $)$. Examples include "I give in to the wishes of the other party," (yiclding), "I avoid a confrontation about our differences," (avoiding), "I work out a mutually beneficial solution," (problem-solving), "I try to obtain a middle-of-the-road solution," (compromising), and "I fight for a good outcome for myself," (forcing). Confirmatory factor analyses revealed good to excellent psychometric qualities of the DUTCH instrument (De Dreu et al., 2001) with the original study reporting internal reliability alpha coefficients of $.65, .68,66, .70$, and .73 for accommodating, collaborating, compromising, competing, and avoiding, respectively. Further, discriminant validity of the subscales were assessed and found satisfactory.

In a recent study by Euwema and Van Emmerik (2007), the DUTCH instrument's alpha reliability coefficients for accommodating (yielding) was .80 , collaborating (problem solving) was .84 , compromising was .87 , competing (forcing) was .83 , and avoiding was .84 . In a recent United States sample (DeChurch et al., 2007), the DUTCH instrument was modified from a self report to an observer's perspective where the observer completed the scale on the basis of frequency of each conflict management style observed. The alpha reliability coefficients for accommodating, collaborating (problemsolving), compromising, competing (forcing), and avoiding were $.86, .82, .92, .89$, and .92 respectively.

Job Performance. Borman and Motowidlo (1993) posited that job performance consisted of both task performance and contextual performance. Task performance pertains to the technical components of the job; the execution of technical processes (conversion of raw 
materials into output) or maintenance and service of its technical requirements (Motowidlo \& Van Scotter, 1994). In contrast, contextual performance relate to the broader social and psychological environment of the technical framework. These two dimensions were supported by Motowidlo and Van Scotter's (1994) study where task performance was measured on a 14-item scale $(\alpha=.95)$ while contextual performance was measured with 16 items $(\alpha=.95)$. In a modified 6 -item scale measuring task (technical) performance, contextual (interpersonal) performance and overall job performancc, Reio and Callahan (2004) established a reliability of .95 for the scale. The current study utilized a modified 11 item scale measuring job performance. Each of the 11 items was scored on a five-point Likert scale from $1=$ Not at all likely, to $5=$ Extremely likely, with questions 1 through 5 measuring task performance and questions 6 through 11 measuring contextual performance. Questions begin with general instructions: In comparison to other individuals in your organization, how likely is it that you followed by specific focus on performance such as use problem-solving skills, have a good overall technical performance, and cooperate with others in a team. Organizational Commitment. Meyer and Allen (1997) operationally defined organizational commitment as a three component model: the desire to remain with an organization (affective commitment), perceived need to remain with the organization (continuance commitment), and obligation to stay with the organization (normative commitment). Only two of these dimensions, affective and continuance commitment, will be measured in this study. The reliability coefficients for the affective and continuance commitment scales were .85 and .83 respectively (Meyer, Allen, \& Smith, 1993). This scale has performed well in past research in terms of its reliability and confirming the 
factor structure for the affective commitment and continuance commitment factors (Allen, 2003). Four of the scale items measured affective commitment, and four of the items measured continuance commitment. Responses were scored on a 5-point scale ranging from 1 (strongly disagree) to 5 (strongly agree). High scores represent high commitment on both commitment dimensions. Cronbach's alpha was .89 for affective commitment and .89 for continuance commitment.

Turnover. Intention to turnover was used as one of the outcome measures in this study. The three-item Intention to Turnover Scale is a subscale from the Michigan Organizational Assessment Questionnaire (MOAQ) (Seashore, Lawler III, Mirvis, \& Camman, 1983). This three-item subscale was designed to measure the perceptions of organizational members about their psychological state relevant to the quality of work life issues in the workplace. Internal consistency reliability of $.83(N>460, r=.13, p<$ .01 ), with individual factor loadings of $.79, .41$ and .75 were reported for the scale (Seashore, Lawler III, Mirvis, \& Cammann, 1983).

The responses to the three items were summed based on five-point Likert-type scales. "How likely is it that you will actively look for a new job in the next year?" was from $1-5$ (not likely $=1 ;$ somewhat likely $=2 ;$ quite likely $=3 ;$ very likely $=4$; extremely likely $=5$ ). Responses to the second item "I often think of quitting", and third item, "I will probably look for a new job in the next year" used slightly different descriptors of frequency (strongly disagree $=1 ;$ disagree $=2$, neither disagree or agree $=3$; agree $=$ 4; and strongly agree $=5$ ).

Reliability of the various scales used in this study in presented in Table 3. 
Table 3

Instrument reliability

\begin{tabular}{|c|c|c|}
\hline 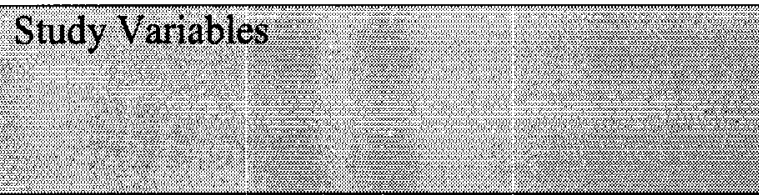 & No. of items & $\begin{array}{l}\text { Reliability from } \\
\text { original study } \\
(\text { Crombach's } \mathrm{q} \text { ) }\end{array}$ \\
\hline $\begin{array}{l}\text { Incivility (Workplace incivility Scale, Cortina } \\
\text { et al, 2001) } \\
\begin{array}{l}-\quad \text { Target (Experienced incivility) } \\
\text { (Blau \& Andersson, 2005) }\end{array}\end{array}$ & 7 & $\begin{array}{l}.89 \\
.89\end{array}$ \\
\hline $\begin{array}{l}\text { Conflict Management Styles (The DUTCH, } \\
\text { De Dreu et al., 2001) } \\
\text { - } \quad \text { Accommodating } \\
\text { - } \quad \text { Collaborating } \\
\text { - } \quad \text { Compromising } \\
\text { - } \quad \text { Competing } \\
\text { Avoiding }\end{array}$ & $\begin{array}{l}4 \\
4 \\
4 \\
4 \\
4\end{array}$ & $\begin{array}{l}.65 \\
.68 \\
.66 \\
.70 \\
.73\end{array}$ \\
\hline $\begin{array}{l}\text { Job Performance (Motowidlo \& Van Scotter, } \\
\text { 1993) } \\
\text { • } \quad \text { Task performance } \\
\text { - Contextual performance }\end{array}$ & $\begin{array}{l}5 \\
6\end{array}$ & $\begin{array}{l}.95 \\
.95\end{array}$ \\
\hline $\begin{array}{l}\text { Organizational Commitment (Meyer, Allen \& } \\
\text { Smith, } 1995 \\
\begin{array}{cl}- & \text { Affective } \\
\bullet & \text { Continuance }\end{array}\end{array}$ & $\begin{array}{l}4 \\
4\end{array}$ & $\begin{array}{l}.85 \\
.83\end{array}$ \\
\hline $\begin{array}{l}\text { Intent to turnover (MOAQ, Scashore et al., } \\
\text { 1983) }\end{array}$ & 3 & .83 \\
\hline
\end{tabular}

Pilot study

Prior to the administration of the online surveys, a pilot study was conducted on 10 associates, baccalaureate and masters degree business students (who are working adults). Five of the participants completed the online survey questionnaire and the other five, the hardcopy pen and paper version. A pilot study is a useful means to determine if 
procedures and instructions in administration of the survey are effective in achieving the desired response (Dillman, 2002).

In the current study, the pilot study served to provide feedback on the clarity of the survey questions and response categories, as well as the time required to complete the survey. The students were approached either in person or via email about participating in the pilot study. Those selected for the online survey were then sent the email invitation with the web-link to the survey. No other instructions were provided. Participants who completed the hardcopy survey did so during class. Participation in this pilot study was voluntary. No statistical analysis was performed on the anonymous pilot questionnaires. Feedback from the students was incorporated into the survey and the final product was administered to the actual study participants.

\section{Data analysis techniques}

Once data was collected and downloaded in a database format, SPSS was used for analysis of the survey results. This includes examining the data for any missing data. Reverse scoring on selected items were then carefully computed and the data was examined for outliers. Cronbach's $\alpha$ values for all the research instruments measuring the dependent and independent variables were computed. Data relating to descriptive and inferential statistics including the means and standard deviations were presented and tabulated.

To address the first research question, Pearson's correlations were computed to examine the strength and direction of relationships between the study variables, workplace incivility (target perspective) and the five conflict management styles, and workplace incivility (instigator perspective) and the five conflict management styles. A 
significant positive or positive relationship would indicate that the conflict management style has a direct effect on the level of workplace incivility, either from the perspective of instigator or target. The second research question was addressed through examining and comparing sets of correlations for workplace incivility from both target and instigator perspectives to determine any similarities or differences in choices of conflict management styles.

Hierarchical regression analyses were conducted following the order guided by previously cstablished theoretical and empirical rescarch to address research questions three, four, five and six. The independent variables consisted of the five conflict management styles and workplace incivility (target and instigator) while job performance (task and contextual), organizational commitment and turnover intentions were the dependent variables. Further, research questions four, five and six controlled for demographic variables of age, gender, tenure and organizational rank to determine the effects of workplace incivility (target and instigator) and conflict management styles on job performance (task and contextual), organizational commitment and turnover intention separately. Consequently, those demographic variables were entered first into each of the hierarchical linear regressions, followed by conflict management styles and then workplace incivility (target or instigator) to determine the effects on each of the dependent variable.

These statistical procedures determined the degree to which the independent variables (workplace incivility and conflict management styles), predict the dependent variables (job performance, organizational commitment and turnover intentions). Multiple correlation coefficients $(R)$ and the proportion of variance explained by the 
Table 4

Research Questions, Variables and Statistical Analyses

\begin{tabular}{|c|c|}
\hline Research Question & Variables Used and Analyses \\
\hline $\begin{array}{l}\text { 1. What is the relationship between } \\
\text { workplace incivility (WI) and conflict } \\
\text { management styles (CMS) of: (a) } \\
\text { dominating, (b) integrating, (c) } \\
\text { compromising, (d) accommodating, } \\
\text { and (e) avoiding? }\end{array}$ & $\begin{array}{l}\text { Ten correlation coefficients. } \\
\text { WI-target correlated with each of } 5 \text { CMS } \\
\text { scores. } \\
\text { WI-instigator correlated with each of } 5 \text { CMS } \\
\text { scores. }\end{array}$ \\
\hline $\begin{array}{l}\text { 2. Are there differences between the } \\
\text { relationships of conflict management } \\
\text { style and workplace incivility from the } \\
\text { perspectives of targets versus } \\
\text { instigators of incivility? }\end{array}$ & $\begin{array}{l}\text { Compare the } 5 \text { correlations from WI-target with } \\
\text { CMS scores with the } 5 \text { correlations from WI- } \\
\text { instigator with CMS scores and note similarities } \\
\text { and differences. }\end{array}$ \\
\hline $\begin{array}{l}\text { 3. Do conflict management styles } \\
\text { affect the impact of workplace } \\
\text { incivility on employee's job } \\
\text { performance, commitment to their } \\
\text { organization and turnover? }\end{array}$ & $\begin{array}{l}\text { Hierarchical regression } 1 \text {. } \\
\text { Dependent variable is job performance (task } \\
\text { performance) } \\
\text { Independent variables are entered in this order. } \\
\text { 1. } 5 \text { CMS variables } \\
\text { 2. WI scores (target) } \\
\text { Hierarchical regression } 2 . \\
\text { Dependent variable is job performance (task } \\
\text { performance) } \\
\text { Independent variables are entered in this order. } \\
\text { 1. } 5 \text { CMS variables } \\
\text { 2. WI scores (instigator) } \\
\text { Hierarchical regression } 3 \text {. } \\
\text { Dependent variable is job performance } \\
\text { (contextual) } \\
\text { Independent variables are entered in this order. } \\
\text { 1. } 5 \text { CMS variables } \\
2 . \text { WI scores (target) } \\
\text { Hierarchical regression } 4 . \\
\text { Dependent variable is job performance } \\
\text { (contextual) } \\
\text { Independent variables are entered in this order. } \\
\text { 1. } 5 \text { CMS variables } \\
2 . \text { WI scores (instigator) }\end{array}$ \\
\hline
\end{tabular}




\begin{tabular}{|c|c|}
\hline & $\begin{array}{l}\text { Hierarchical regression } 5 . \\
\text { Dependent variable is organizational } \\
\text { commitment (affective and continuance } \\
\text { composite score) } \\
\text { Independent variables are entered in this order. } \\
\text { 1. } 5 \text { CMS variables } \\
\text { 2. WI scores (target) } \\
\text { Hierarchical regression } 6 . \\
\text { Dependent variable is organizational } \\
\text { commitment (affective and continuance } \\
\text { composite score) } \\
\text { Independent variables are entered in this order. } \\
\text { 1. } 5 \text { CMS variables } \\
\text { 2. WI scores (instigator) } \\
\text { Hierarchical regression } 7 . \\
\text { Dependent variable is intent to turnover } \\
\text { Independent variables are entered in this order. } \\
\text { 1. } 5 \text { CMS variables } \\
\text { 2. WI scores (target) } \\
\text { Hierarchical regression } 8 \text {. } \\
\text { Dependent variable is intent to turnover } \\
\text { Independent variables are entered in this order. } \\
\text { 1. } 5 \text { CMS variables } \\
\text { 2. WI scores (instigator) }\end{array}$ \\
\hline $\begin{array}{l}\text { 5. After controlling for select } \\
\text { demographic variables, what is the } \\
\text { relationship between workplace } \\
\text { incivility, conflict management styles } \\
\text { and perceived job performance? }\end{array}$ & $\begin{array}{l}\text { Hierarchical regression } 1 . \\
\text { Dependent variable is job performance (task } \\
\text { performance) } \\
\text { Independent variables are entered in this order. } \\
\text { 1. Age, sex, tenure, and } \\
\text { organizational rank } \\
\text { 2. } 5 \text { CMS variables } \\
\text { 3. WI scores (target) } \\
\text { Hierarchical regression } 2 \text {. } \\
\text { Dependent variable is job performance } \\
\text { (contextual performance) } \\
\text { Independent variables are entered in this order. } \\
\text { 1. Age, sex, tenure, and } \\
\text { organizational rank } \\
\text { 2. } 5 \text { CMS variables } \\
\text { 3. WI scores (instigator) }\end{array}$ \\
\hline
\end{tabular}




\begin{tabular}{|c|c|}
\hline $\begin{array}{l}\text { 6. After controlling for select } \\
\text { demographic variables, what is the } \\
\text { relationship of workplace incivility } \\
\text { and conflict styles on organizational } \\
\text { commitment? }\end{array}$ & $\begin{array}{l}\text { Hierarchical regression } 1 \text {. } \\
\text { Dependent variable is organizational } \\
\text { commitment (affective and continuance } \\
\text { composite score) } \\
\text { Independent variables are entered in this order. } \\
\text { 1. Age, sex, tenure, and } \\
\text { organizational rank } \\
\text { 2. } 5 \text { CMS variables } \\
\text { 3. WI scores (target) } \\
\text { Hierarchical regression } 2 . \\
\text { Dependent variable is organizational } \\
\text { commitment (affective and continuance } \\
\text { composite score) } \\
\text { Independent variables are entered in this order. } \\
\text { 1. Age, sex, tenure, and } \\
\text { organizational rank } \\
\text { 2. } 5 \text { CMS variables } \\
\text { 3. WI scores (instigator) }\end{array}$ \\
\hline $\begin{array}{l}\text { 7. After controlling for select } \\
\text { demographic variables, what is the } \\
\text { impact of workplace incivility and } \\
\text { conflict styles on turnover intentions? }\end{array}$ & $\begin{array}{l}\text { Hierarchical regression } 1 . \\
\text { Dependent variable is turnover intention. } \\
\text { Independent variables are entered in this order. } \\
\text { 1. Age, sex, tenure, and } \\
\text { organizational rank } \\
\text { 2. } 5 \text { CMS variables } \\
\text { 3. WI scores (target) } \\
\text { Hierarchical regression } 2 \text {. } \\
\text { Dependent variable is turnover intention. } \\
\text { Independent variables are entered in this order. } \\
\text { 1. Age, sex, tenure, and } \\
\text { organizational rank } \\
\text { 2. } 5 \text { CMS variables } \\
\text { 3. WI scores (instigator) }\end{array}$ \\
\hline
\end{tabular}

\section{Limitations}

There are some limitations to this study. First, the correlational design of this study cannot establish a cause-effect relationship between the variables that are correlated (Pagano, 1998). Secondly, the data collection method is potentially limiting since it 
involves both electronic and hard copy surveys. Electronic surveys tend to produce lower response rates than mailed surveys, therefore any low response rates may result in a biased estimate of the characteristics of the population (Bean \& Roszkowski, 1995).

Thirdly, self-report measures raise the possibility of common-method bias producing spurious or inflated relationships among study variables (Crampton \& Wagner, 1994). Further, self-report measures limit the generalizability of results, especially when certain measures pertain to admission of wrong-doing such as instigating uncivil behaviors. Lee (1993) asserted that people tend to underreport negative or deviant workplace behaviors for fear of being caught or punished.

Summary

This chapter detailed the methods and procedures for the conduct of this study, which applied a non-experimental descriptive correlational design to examine relationships between variables. A mixed-mode survey methodology was utilized for data collection. Research instruments used to the measure each of the study variables were presented and the statistical procedures for exploring the relationships between the variables were discussed. 


\section{CHAPTER IV}

\section{RESULTS \\ Introduction}

This study explored the relationships between workplace incivility (from both target and instigator perspectives), conflict management styles and their influence on perceived job performance, organizational commitment and intent to turnover. This chapter presents a summary of the population and sample data obtained through survey questionnaires, as well as the results of correlational and hierarchical multiple regression analyses addressing each of the research questions.

The following research questions guided the exploration of the relationships between the variables:

1. What is the relationship between workplace incivility and conflict management styles of (a) dominating, (b) integrating, (c) compromising, (d) obliging, and (e) avoiding? 2. Are there differences between the relationships of conflict management style and workplace incivility from the perspectives of targets versus instigators of incivility? 3. Do conflict management styles affect the impact of workplace incivility on employee's job performance, commitment to their organization and turnover?

4. After controlling for select demographic variables, what is the relationship between workplace incivility, conflict management styles and perceived job performance? 
5. After controlling for select demographic variables, what is the relationship of workplace incivility and conflict styles on organizational commitment?

6. After controlling for select demographic variables, what is the impact of workplace incivility and conflict styles on turnover intentions?

Population and Sample

The participants in this exploratory study consisted of employees in three Midwestern private companies. The first of these was an organization in the field of long term healthcarc. The other two samples were divisions of two different manufacturing companies. The survey questionnaire was administered through hardcopies to the first two organizations while the third (and smallest sample) was via a Web-based survey. There were 289 returned surveys (with an overall return rate of $47 \%$ ), with 248 complete data sets. The largest organization had a return rate of $35.8 \%$ (143 of 400 surveys returned), the second organization had $68.6 \%$ (127 of 185 surveys) and the third with $63.3 \%$ (19 out of 30 emailed web-based survey invitations). With missing data on some variables, the $n$ used for some statistical analyses was smaller than 289 .

\section{Demographic variables}

Gender, Ethnicity, and Age

The descriptive statistics of the demographic variables are presented in Table 5. $51.6 \%$ of survey respondents identified themselves as males $(n=149)$, and $48.4 \%$ identified themselves as females $(n=140$ ). Interestingly, respondents from the first organization (healthcare) consisted of a majority of females $(81.1 \%$ ), while those from the second organization (manufacturing) consisted of mainly males $(89.8 \%)$. The third organization had an almost even split in gender ( female $=42.1 \%$, males $=57.9 \%$ ) 
Approximately $85.8 \%$ of the respondents were Caucasians $(n=248)$, with $8.3 \%$ African-Americans $(n=24)$, and 5.5\% identified themselves as "other" $(n=16)$. The majority of respondents (45.8\%) were between $31-44$ years of age, followed by those in the $45-55$ age range $(27.8 \%)$. Only $11.2 \%$ are in the age range of $18-30$, while $13 \%$ are in 56-65 age range. A small 2.2\% of respondents are 66 or above years of age.

Organizational Tenure, Hierarchical Rank

$43.4 \%$ of the respondents $(n-125)$ have worked in their organizations for nine or more years in contrast to $32.6 \%(94)$ having worked at their respective organization for two years or less. The others $(n=68)$ have worked in their organization for three to eight years.

Only $26.5 \%$ of respondents $(n=76)$ were in some sort of managerial position ranging from supervisor to executive manager. The majority of respondents, $54.5 \%(n=$ 160) were non-managerial employees (floor/ line workers and administrative/ clerical staff). The rest consisted of junior and middle-management level workers $(n=71)$. $16.9 \%(n=47)$ of the returns did not specify any organizational hierarchical rank. 
Table 5

Demographic Information

\begin{tabular}{lcccc}
\hline Demographic Categories & $N$ & Frequency & $\%$ of Total \\
\hline Gender & 289 & & \\
& Male & & 149 & $51.6 \%$ \\
& Female & 140 & $48.4 \%$
\end{tabular}

Age

277

$18-30$

31

$11.2 \%$

$31-44$

127

$45.8 \%$

45-55

77

$27.8 \%$

$56-65$

36

$13.0 \%$

$65+$

6

$2.2 \%$

Ethnicity

288

Caucasian

248

$86.1 \%$

African American

24

$8.3 \%$

Other

16

$5.6 \%$

Hierarchical position

289

Floor line

134

$46.4 \%$

Admin/clerical

26

$9.0 \%$

Supervisor

43

$14.9 \%$

Middle management

28

$9.7 \%$

Exec management

11

$3.8 \%$

Missing Info

47

$16.3 \%$ 
Table 5 (continued)

\begin{tabular}{cccc}
\hline Demographic Categories & $N$ & Frequency & $\%$ of Total \\
\hline Organizational Tenure & 288 & & \\
$0-2$ years & & 40 & $32.6 \%$ \\
$3-5$ years & 29 & $13.9 \%$ \\
$6-8$ years & 125 & $43.4 \%$ \\
9 or more ycars & & \\
\hline
\end{tabular}

\section{Descriptive Statistics}

The descriptive statistics for the study variables are reported in Table 6 . The DUTCH Conflict Handling scale (De Dreu et. al, 2001) consists of five subscales measuring various conflict management styles. For the purposes of this study, the mean scores of each conflict management style subscale were used for analyses. The highest mean of 3.80 was reported for the integrative conflict management style $(N=279, S D=$ $.59)$ while the lowest mean of 2.56 was for the dominating style $(N=283, S D=.78)$.

The range of the WIS scale (Cortina et. al, 2001) measuring workplace incivility from either the target or instigator perspective was between seven and 35 . The mean scores were utilized for all analyses in this study. The reported range of respondents experiencing incivility $(N=283)$ was between mean scores of 1 and 4.14 , with a mean of $1.96(S D=.77)$ while those who admitted to instigating incivility $(N=286)$ scored between 1.00 and 1.43 , with a mean of $1.82(S D=.62)$. Analyses revealed that $86 \%(N=$ 281) of the respondents have experienced some form of incivility in the workplace within the past ycar, $12 \%$ of whom reportedly experienced incivility on a "sometimes" to 
"always" level of frequency. Similarly, $90 \%(N=284)$ admitted to having engaged in some form of incivility within the past year although only $6 \%$ reportedly instigated such behavior on the level of frequency described in the scale as "sometimes", "often", or "always".

The scores for the dependent variables were all based on the raw scores on each of the relevant scales. The Job Performance Questionnaire asked respondents to rate their own perceived job performance in comparison with other individuals in the organization. The Job Performance task dimension had five questions with a score range of five to 25 , while the contextual dimension consisted of seven questions with a range of six to 30 . The mean score was $19.17(N=284, S D=3.46)$ for task performance, while contextual performance had a mean score of $24.74(N=283, S D=3.63)$.

Respondents appear to have differing levels of commitment to their organization based on the large standard deviation of their scores on the Organizational Commitment scale $(N=279, M=26.67, S D=6.60)$. The scores for this scale range from eight to 40 . The Intent to Turnover scale mean of $6.82(N=277, S D=3.13)$. This scale has a score range of three to 15 . 
Table 6

Descriptive Statistics

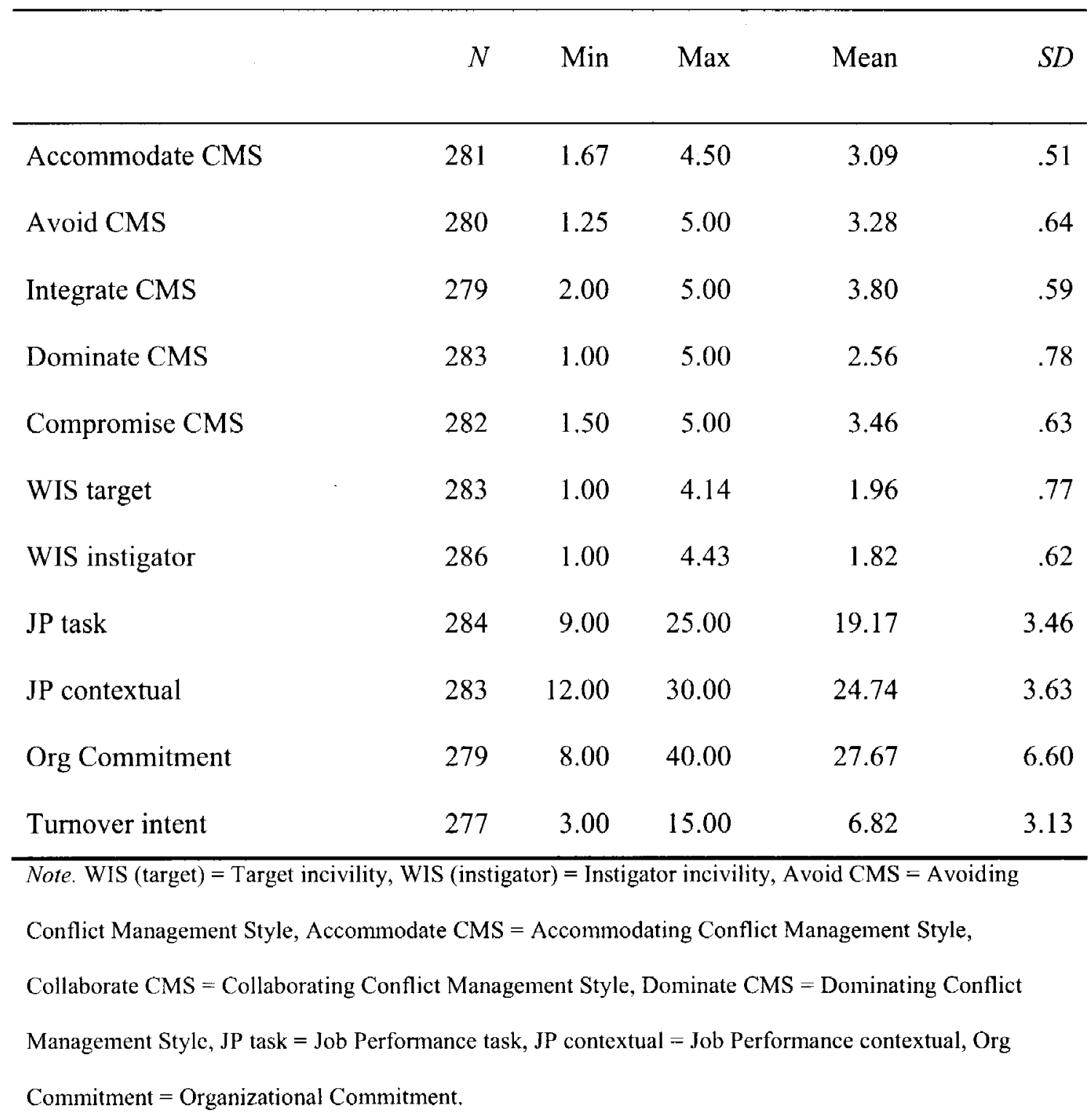

\section{Data Analysis}

Reliability Analysis

To ensure that the scales used in the study were reliable measures, the internal consistencies of each scale was examined. The internal consistencies (Cronbach's $\alpha$ ) of these measures are reported in Table 7 . They generally reflect the alphas reported by the 
other researchers (see Table 3). With the exceptions of the Conflict Management Styles (CMS) subscales of Avoid, Accommodate, and Compromise, the measures exceeded the criterion of .70 that is often used by researchers (Nunnally \& Bernstein, 1994). The Compromise subscale of the CMS measure had a Cronbach's $\alpha$ of .68, which exceeds that of from the study $(\alpha=.66)$ conducted by De Dreu et al. (2001). With Cronbach's $\alpha$ of .55 and .57 respectively, the reliabilities of both the Avoid and Accommodate CMS subscales were called into question. Consequently, the Accommodate subscale had to be removed from the analyses. A subsequent scan of the item analysis on the Avoid subscale indicated that removal of one of the itcms, Avoid minimize differences, increased alpha reliability from .57 to .62 , a more acceptable level. This item was then removed from further analyses. The correlation between the new 3-item scale and the original 4-item scale was .93 , indicating that there was little difference between the scales, thus verifying that the 3-item scale is appropriate for measuring the avoiding conflict management style. 
Table 7

Cronbach's a Reliability Coefficients for scale measures

\begin{tabular}{lll}
\hline Scale Measure & $\alpha$ & $N$
\end{tabular}

\begin{tabular}{lll}
\hline WIS (target) & .89 & 283
\end{tabular}

$\begin{array}{lll}\text { WIS (instigator) } & .87 & 286\end{array}$

$\begin{array}{lll}\text { Avoid CMS } & .57 & 280\end{array}$

$\begin{array}{lll}\text { Accommodate CMS } & .55 & 281\end{array}$

$\begin{array}{lll}\text { Collaborate CMS } & .71 & 279\end{array}$

$\begin{array}{lll}\text { Dominate CMS } & .76 & 283\end{array}$

$\begin{array}{lll}\text { Compromise CMS } & .68 & 282\end{array}$

$\begin{array}{lll}\text { JP task } & .76 & 284\end{array}$

$\begin{array}{lll}\text { JP contextual } & .85 & 283\end{array}$

$\begin{array}{lll}\text { Org Commitment } & .88 & 279\end{array}$

$\begin{array}{lll}\text { Turnover intent } & .87 & 277\end{array}$

$\overline{\text { Note. } \text { WIS }(\text { target })=\text { Target incivility, WIS (instigator) }=\text { Instigator incivility, Avoid CMS }=\text { Avoid Conflict }}$

Management Style, Accommodate CMS = Accommodating Conflict Management Style, Collaborate CMS

$=$ Collaborating Conflict Management Style, Dominate CMS $=$ Dominating Conflict Management Style, JP

task $=$ Job Performance task, JP contextual $=$ Job Performance contextual, Org Commitment $=$

Organizational Commitment.

Differences in Samples

A MANOVA was conducted on the three organizations to examine if there were any significant differences between them that may affect pooling the three samples.

Box's test was significant $(p<.001)$ : the covariance matrices were significantly different indicating a violation of the homogeneity of covariance matrices assumption. According 
to Field (2005), the effects of the violation of the assumption are unclcar. Further, the author asserted that the more number of dependent variables, and the greater the differences in sample sizes, the more distorted probability values produced.

The multivariate test statistics including Wilks' $\lambda(F=7.11, d f=20, p=.000)$ indicated that there were significant differences between organizations on the combination of variables. Levene's test was non-significant for all variables except for dominate CMS $(p<.05)$ and Job performance- task $(p<.05)$ confirming that the assumption of homogeneity of covariance was not met. Scheffe post hoc statistics showed that there were significant differences between the healthcare and first manufacturing organization in relation to the integrate, dominate and compromise CMS, incivility (target), both task and contextual dimensions of job performance, organizational commitment and intent to turnover; all at the $p<.01$ level. There were also significant differences between the health care organization and the second manufacturing organization on target incivility $(p<.01)$ and turnover intent $(p<.05)$ only. However, both manufacturing organizations significantly differed on contextual job performance only $(p<.01)$.

The differences between the three organizations lead to the decision to control for such differences in multiple regression analyses. Since the organization variable was a categorical variable (with three organizations), dummy coding was utilized to create two new variables, organizational effect code 1 (Org Effect 1), and organizational effect code 2 (Org Effect 2). These were entered into all the regression analyses as a first block. This method of control of organizational differences justifies the pooling of the three samples in order to conduct the regression analyses. 
Research Questions 1 and 2

Pearson Correlations were computed for each study variable to address Research Questions 1 and 2. In this study, the independent variables were workplace incivility target, workplace incivility instigator, and four conflict management styles: avoiding, integrating, dominating and compromising, while job task performance, job contextual performance, organizational commitment; and intent to turnover were the dependent variables. The correlation results are presented in Table 8 . An inspection of the correlation matrix indicates that a number of the independent variables were significantly correlated with each other. 
Table 8

Correlations between Variables

\begin{tabular}{lccccc}
\hline & WPI & WPI & Accommodate & Avoid & Integrate \\
& target & instigator & CMS & CMS & CMS \\
\hline WPI target & 1 & & & & \\
WPI instigator & $.56^{* *}$ & 1 & & & \\
Accommodate CMS & .04 & .02 & & & \\
Avoid CMS & -.02 & -.07 & $.29^{* *}$ & 1 & \\
Integrate CMS & $-.32^{* *}$ & $-.36^{* *}$ & $.17^{* *}$ & $.14^{*}$ & 1 \\
Dominate CMS & $.14^{*}$ & $.24^{* *}$ & .09 & .04 & -.04 \\
Compro CMS & $-.20^{* *}$ & $-.24^{* *}$ & $.14^{*}$ & $.23 * *$ & $.53^{* *}$ \\
JP task & $-.12^{*}$ & $-.15^{* *}$ & -.04 & -.01 & $.39^{* *}$ \\
JP context & $-.28^{* *}$ & $-.33^{* *}$ & .03 & $.12^{*}$ & $.46^{* *}$ \\
Org Commit & $-.57^{* *}$ & $-.36^{* *}$ & .06 & .04 & $.39^{* *}$ \\
Turnover intent & $.49^{* *}$ & $.28^{* *}$ & .00 & -.05 & $-.26^{* *}$ \\
\hline
\end{tabular}

Note. ${ }^{* *}$ Correlation is significant at the 0.01 level (2-tailed).

* Correlation is significant at the 0.05 level (2-tailed). 
Table 8 (continued)

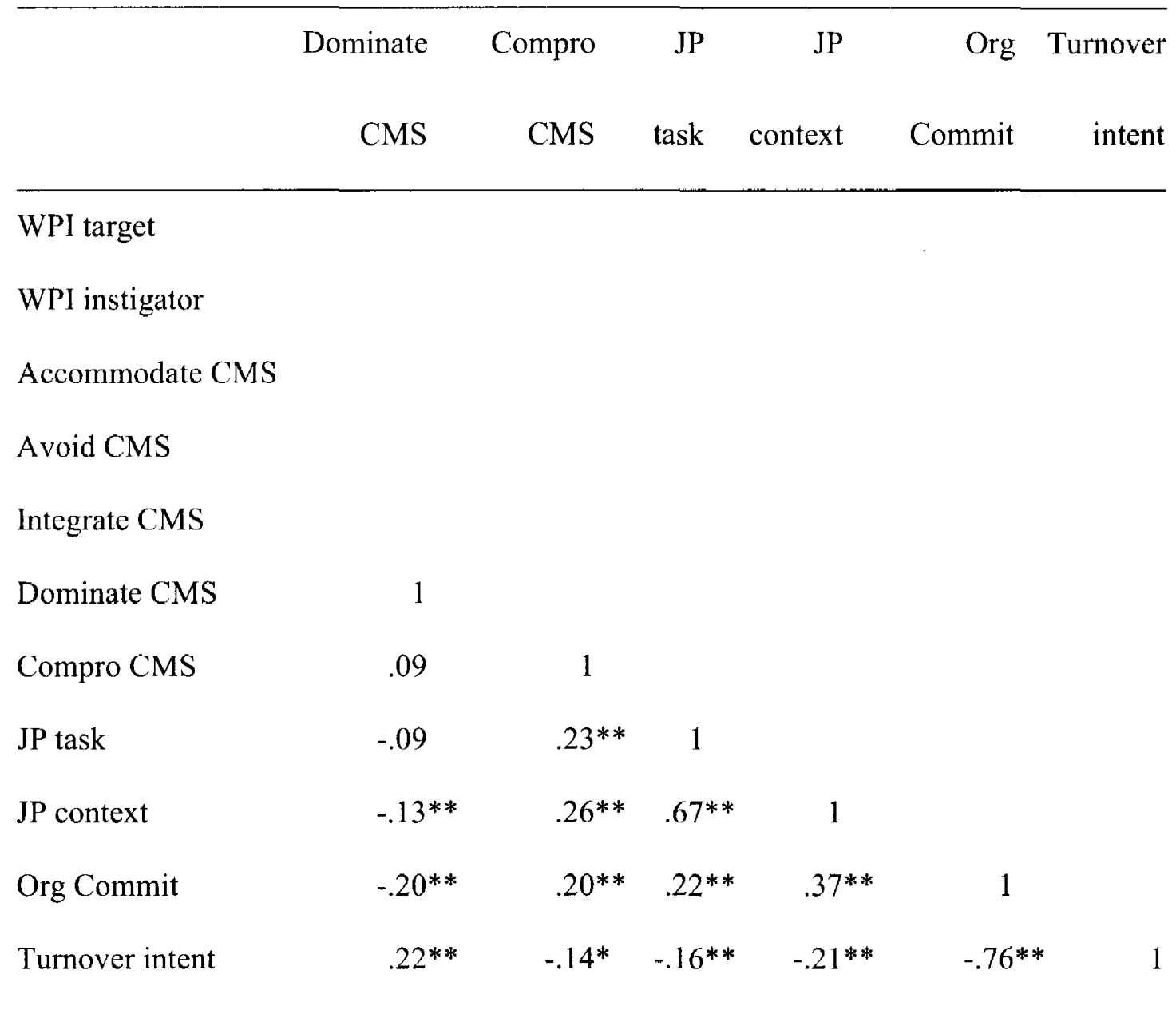

Note. ${ }^{* *}$ Correlation is significant at the 0.01 level (2-tailed).

* Correlation is significant at the 0.05 level (2-tailed).

Research Question 1 was addressed by examining the correlations between workplace incivility (both target and instigator variables) and the four conflict management styles. The relationships of these variables to the dependent variables of perceived job performance (both task and contextual dimensions), organizational commitment and turnover intentions were also considered.

From the target perspective, experiences of workplace incivility were significantly and positively correlated with the dominating style of conflict management (Dominate 
CMS), with $r=.137, p<.05$. The higher frequency of experienced incivility corresponded with more frequent use of the dominating conflict style. Significant negative correlations $(\mathrm{p}<.01)$ between incivility targets and both the integrating $(r=-$ $.32)$ and compromising $(r=-.20)$ conflict management styles were noted. These two conflict management styles corresponded with lower rates of experienced incivility. The avoiding conflict management style did not demonstrate a statistically significant relationship to experienced incivility.

Increased experiences of incivility as targets also correlated significantly to an increase in intent to quit $(r=.49, p<.01)$. Further, there was a significant negative correlation $(r=-.57, p<.01)$ between incivility targets and organizational commitment. The more incivility experienced by targets, the higher the level of turnover intentions and the lower the organizational commitment respectively. Both job performance dimensions, task $(r=-.12, p<.05)$ and contextual $(r=-.28, p<.01)$, were also negatively related to the incidents of experienced workplace incivility. This demonstrates that as frequency of incivility experiences increased, there was a corresponding decrease in perceived job performance, both on the task and contextual dimensions.

Table 8 also revealed that instigated incivility was significantly correlated ( $p<$ $.01)$ with three of the four conflict management styles: dominating (positive correlation), integrating (negative correlation) and compromising (negative correlation). Of the three, the integrating style was the most strongly correlated to instigated incivility $(r=-.36)$. The frequent use of dominating style corresponded with an increase in instigated uncivil behaviors. In contrast, use of either the integrating or compromising styles related to a decrease in instigating uncivil behaviors. Further, instigator scores were also negatively 
related at the $p<.01$ level to both dimensions of job performance $(r=-.15$ for task, $r=-$ .33 for contextual), and organizational commitment ( $r=-.36$ ). Turnover intentions, in contrast, increased along with instigated incivility $(r=.28, p<.01)$.

Research Question 2 addresses the differences, if any, between targets and instigators of incivility on the four conflict management styles. Likewise, such differences in relationships between incivility and the dependent variables of task and contextual job performance, organizational commitment and turnover intentions were also investigated. Target of workplace incivility scores (WPI target) were significantly and positively correlated with those of workplace incivility instigators (WPI instigator), $r=.56, p<.01$. This indicates that as the frequency level of experienced incivility increased, the frequency level of instigated uncivil behaviors also increased.

Workplace incivility instigator (WI instigator) scores were similarly related to the same three conflict management styles (integrating, dominating and compromising), as the workplace incivility target scores (WI target), differing only on the magnitude of correlations. Both target and instigator scores correlated negatively to the integrating and compromising conflict management styles. The higher the use of either of these styles, the lower the frequencies of uncivil behaviors, either as a target or instigator. A notable difference between target and instigator perspectives is the degree of correlation on the dominating style. Incivility instigators were more highly correlated to the dominating style $(r=.24, p<.01)$ as compared to incivility targets $(r=.14, p<.05)$. The use of a dominating conflict management style corresponded with an increase in uncivil behaviors. 
The magnitude of correlations indicated that incivility instigators had a slightly stronger relationship than targets with respect to both the task $(r=-.12, p<.05$ for targets, $r=-.15, p<.01$ for instigators) and contextual ( $r=-.28$ for target, $r=-.33$ for instigators, both at $p<.01$ ) dimensions of job performance. Further, although there was a difference between target $(r=-.57, p<.01)$ and instigator $(r=.-.36, p<.01)$ perspectives on organizational commitment, the correlation was higher for incivility targets.

The correlation between workplace incivility instigator and turnover intent was positive $(r=.28, p<.01)$ but at a lower value than that of targets $(r=.49, p<.01)$. This indicates that experienced incivility is more strongly correlated to turnover intentions than instigated incivility. The direction and magnitude of correlations on organizational commitment and turnover intentions for both forms of incivility appear to be consistent: incivility in either form, was related to decreased organizational commitment and increased intent to quit.

Because many of the variables were significantly correlated with each other, an assessment of the tolerance values and variance inflation factors (VIF) was warranted as multicollinearity may adversely affect regression statistics rendering misleading and imprecise estimates of regression coefficients (Pedhazur, 1997). According to Myers (1990), any VIF exceeding 10 would raise multicollinearity concerns. In addition, tolerance values below .1 indicate a serious problem (Field, 2005). The VIF values reported in this study for all the variables fall between 1.00 and 2.00 ; and tolerance values were at least .64. Consequently, multicollinearity was not an issue for regression analyses on the data. 


\section{Research Question 3}

Hierarchical regression analyses were used to determine the role of each conflict management style and form of incivility predicting perceived job performance (task and contextual), organizational commitment and intent to turnover. The required sample size for testing $B$ coefficients is $n>=104+\mathrm{m}$ (where $\mathrm{m}=$ number of independent variables) (Tabachnick \& Fidell, 2001), thus the minimum would be 115. Another rule of thumb is that there should be a minimum of 15 subjects per predictor variable in regression analyses (Stevens, 2002). In this study, the sample size was at least 227 subjects (varying between 227 and 282 subjects, depending on completed data sets for variables regressed), thus meeting the suggested minimum requirements for multiple regression analyses.

Hierarchical regression analyses were conducted between conflict management styles and workplace incivility (target and instigator perspectives separately) on each of the four dependent variables: job performance task, job performance contextual, organizational commitment and turnover intent. Entry of the variables into the regression equations were guided by the model presented in Chapter II. The first block consisted of the two organizational effect control variables, followed by the four conflict management styles (avoiding, integrating, compromising and dominating), and thirdly, either workplace incivility (target or instigator) on each of the dependent variables. The multiple correlation coefficients $\left(R^{2}\right)$ were reported as they represent the magnitude of relationship between independent and dependent variables (Cohen \& Cohen, 1983). Further, the coefficients for the models, $B$ and $\beta$ values, were also reported as indicators of the relative strength and importance of each independent variable in the prediction model. 
Task Job Performance. Table 9 presents the results of the first hierarchical regression analysis on both dimensions of job performance. This first regression analysis involved conflict management styles and target incivility on job performance (task dimension). After controlling for organizational effects represented by dummy coded variables (Org Effect 1 and Org Effect 2) (Block $1 ; R^{2}=.09, p<.01$ ), the integrating conflict management style $(\beta=.32, p<.01)$ was the only significant predictor variable of task job performance (Block $2 ; \Delta R^{2}=.11, p<.01$ ). The total variance accounted for by conflict management styles model was $20 \%$ indicating a medium to large effect size according to Cohen's (1988) standards. When target workplace incivility (WPI target) was entered as a third block, it did not turn out to be a significant predictor of task job performance. 
Table 9

Summary of Hierarchical Regression Analyses for Organizational Effects, Conflict

Management Styles and Target Incivility Predicting Job Performance (Task dimension)

\section{Total}

\begin{tabular}{lrrrrrr} 
& Variable & $B$ & $S E B$ & $\beta$ & $R^{2}$ & $\Delta R^{2}$ \\
\hline Step 1 & & & .09 & .09
\end{tabular}

Org Effect 1

Org Effect 2

Step 2

Org Effect 1

Org Effect 2

Avoid CMS

Integrate CMS

Dominate CMS

Compromise CMS

Step 3

Org Effect 1

Org Effect 2

Avoid CMS

Integrate CMS

Dominate CMS

Compromise CMS $\begin{array}{lll}.56 & .34 & .10\end{array}$

$-1.46 \quad .34 \quad-.25 * *$

$.20 \quad .11$

$\begin{array}{ccc}.38 & .33 & .07 \\ -.99 & .34 & -.17^{* *} \\ -.23 & .26 & -.05 \\ 1.86 & .39 & .32^{* *} \\ -.14 & .25 & -.03 \\ .19 & .36 & .04\end{array}$

$.20 \quad .00$

$\begin{array}{lll}.45 & .34 & .08\end{array}$

$\begin{array}{lll}-.99 & .34 & -.17 * *\end{array}$

$\begin{array}{lll}-.23 & .26 & -.05\end{array}$

$1.94 \quad .40 \quad .33^{* *}$

$\begin{array}{lll}-.16 & .25 & -.04\end{array}$

$\begin{array}{lll}.21 & .36 & .04\end{array}$ 
Table 9 (continued)

Total

\begin{tabular}{lrrrrr} 
Variable & $B$ & $S E B$ & $\beta$ & $R^{2}$ & $\Delta R^{2}$ \\
\hline TargetWI & .23 & .27 & .05 & & \\
\hline
\end{tabular}

Note. Dependent Variable: Job performance Task; Org Effect 1 = Organizational effect 1; Org Effect $2=$

Organizational effect 2; Avoid CMS $=$ Avoiding conflict management style, Integrate CMS $=$ Integrating conflict management style; Dominate CMS $=$ Dominating conflict management style; Target WI $=$ target workplace incivility.

${ }^{*} p<.05 .{ }^{* *} p<.01$.

The results of the second hierarchical regression analyses on task job performance with conflict management styles, instigated workplace incivility after organizational effects are controlled, are shown in Table 10. Like the previous regression with target incivility, only the integrating conflict management style was a significant predictor $(\beta=$ $.31, p<.01)$. An $R^{2}=.19$ (Block $\left.2 ; \Delta R^{2}=.10, p<.01\right)$ again indicated a medium to large effect size. Instigated workplace incivility, entered as the third block, did not significantly influence job performance on the task dimension: it was not a significant predictor. 
Table 10

Summary of Hierarchical Regression Analyses for Organizational Effects, Conflict

Management Styles and Instigator Incivility Predicting Job Performance (Task

dimension)

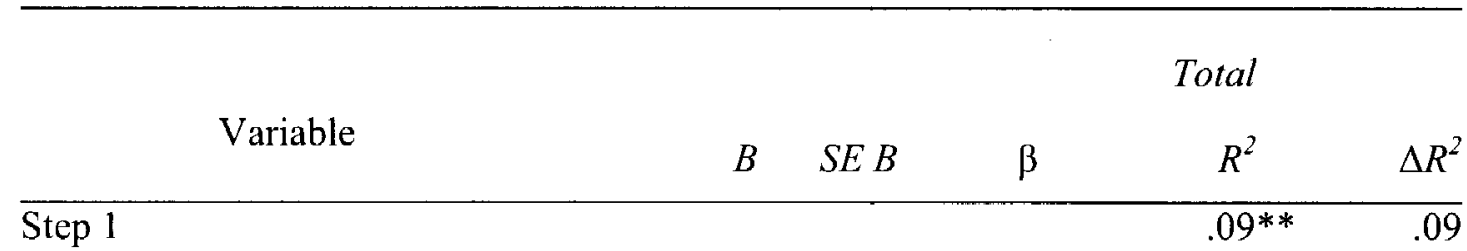

Org Effect 1

$.57 \quad .34 \quad .10$

Org Effect 2

$-1.47 \quad .34 \quad-.26^{* *}$

Step 2

Org Effect 1

$\begin{array}{lll}.38 & .33 \quad .07\end{array}$

Org Effect 2

$-.99 \quad .34-.17 * *$

Avoid CMS

$-.23 \quad .26 \quad-.05$

Integrate CMS

$\begin{array}{lll}1.86 & .40 & .31 * *\end{array}$

Dominate CMS

$\begin{array}{lll}-.14 & .25 & -.03\end{array}$

Compromise CMS

$.20 \quad .36 \quad .04$

Step 3

Org Effect 1

$\begin{array}{lll}.39 & .33 & .07\end{array}$

Org Effect 2

$-1.01 \quad .34 \quad-.18 * *$

Avoid CMS

$\begin{array}{lll}-.23 & .26 & -.05\end{array}$

Integrate CMS

$1.90 \quad .41 \quad .32 * *$

Dominate CMS

$\begin{array}{lll}-.17 & .26 & -.04\end{array}$ 
Table 10 (continued)

Total

\begin{tabular}{lccccc} 
Variable & $B$ & $S E B$ & $\beta$ & $R^{2}$ & $\Delta R^{2}$ \\
\hline Compromise CMS & .21 & .36 & .04 \\
InstigateWI & .16 & .34 & .03 \\
\hline
\end{tabular}

Note. Dependent Variable: Job performance (Task)

${ }^{*} p<.05 .{ }^{* *} p<.01$.

Contextual Job Performance. In the two regression analyses on contextual job

performance, with conflict management styles and separately with incivility targets and

then instigated incivility (controlling for organizational effects), the results were similar.

These results are presented in Tables 11 and 12 . 
Table 11

Summary of Hierarchical Regression Analyses for Organizational Effects, Conflict

Management Styles and Target Incivility Predicting Job Performance (contextual)

\begin{tabular}{|c|c|c|c|c|c|c|}
\hline & & & & & otal & \\
\hline & Variable & $B$ & $S E B$ & $\beta$ & $R^{2}$ & $\Delta R^{2}$ \\
\hline Step 1 & & & & & $.18^{* *}$ & .18 \\
\hline & Org Effect 1 & 1.39 & .33 & $.23 * *$ & & \\
\hline & Org Effect 2 & -1.83 & .34 & $-.30 * *$ & & \\
\hline Step 2 & & & & & $.32^{* *}$ & .14 \\
\hline & Org Effect 1 & 1.06 & .32 & $.18^{* *}$ & & \\
\hline & Org Effect 2 & -1.32 & .33 & $-.22 * *$ & & \\
\hline & Avoid CMS & .25 & .25 & .05 & & \\
\hline & Integrate CMS & 2.30 & .38 & $.37 * *$ & & \\
\hline & Dominate CMS & -.22 & .24 & -.05 & & \\
\hline & Compromise CMS & .06 & .35 & .01 & & \\
\hline Step 3 & & & & & .32 & .00 \\
\hline & Org Effect 1 & .96 & .33 & $.16^{* *}$ & & \\
\hline & Org Effect 2 & -1.31 & .33 & $-.22 * *$ & & \\
\hline & Avoid CMS & .26 & .25 & .05 & & \\
\hline & Integrate CMS & 2.20 & .39 & $.36^{* *}$ & & \\
\hline & Dominate CMS & -.19 & .24 & -.04 & & \\
\hline & Compromise CMS & .04 & .35 & .01 & & \\
\hline
\end{tabular}


Table 11 (continued)

\begin{tabular}{lrrrrrr}
\hline Variable & & & & & & \\
& & & & \\
& $B$ & $S E B$ & $\beta$ & $R^{2}$ & $\Delta R^{2}$ \\
\hline TargetWI & -.31 & .27 & -.06 & & \\
\hline
\end{tabular}

Note, Dependent Variable: Job performance (contextual).

${ }^{*} p<.05{ }^{* *} p<.01$. 
Table 12

Summary of Hierarchical Regression Analyses for Organizational Effects, Conflict

Management Styles and Instigated Incivility Predicting Job Performance (contextual)

\begin{tabular}{llrrc}
\hline & Variable & $B$ & $S E B$ & $\beta$ \\
\hline Step 1 & & & & \\
& Org Effect 1 & 1.39 & .34 & $.23^{* *}$ \\
& Org Effect 2 & -1.83 & .34 & $-.30^{* *}$ \\
Step 2 & & & & \\
& & & & \\
& Org Effect 1 & 1.03 & .32 & $.17^{* *}$ \\
& Org Effect 2 & -1.28 & .33 & $-.21^{* *}$ \\
& Avoid CMS & .27 & .25 & .05 \\
& Integrate CMS & 2.40 & .38 & $.39^{* *}$ \\
& Dominate CMS & -.26 & .24 & -.06 \\
& Compromise CMS & .02 & .35 & .00
\end{tabular}

Step 3

.34

.01

$\begin{array}{lrrl}\text { Org Effect 1 } & .97 & .32 & .16^{* *} \\ \text { Org Effect 2 } & -1.21 & .33 & -.20^{* *} \\ \text { Avoid CMS } & .25 & .25 & .05 \\ \text { Integrate CMS } & 2.22 & .39 & .36^{* *} \\ \text { Dominate CMS } & -.15 & .25 & -.03 \\ \text { Compromise CMS } & -.03 & .35 & -.01 \\ \text { InstigateWI } & -.64 & .33 & -.11\end{array}$

Note. Dependent Variable: Job performance (contextual)

${ }^{*} p<.05{ }^{* *} p<.01$. 
Out of the four conflict management styles, only the integrating style was a significant predictor. After controlling for organizational effects (Block $1 ; \Delta R^{2}=.18, p<$ $.01)$, the $\beta$ coefficient for the regression analyses with target incivility was .37 ( $p<.01)$ for the integrating conflict management style (Block $2 ; \Delta R^{2}=.14, p<.01$ ). The regression analyses with instigators revealed a $\beta$ of $.39(p<.01)$ for the integrating style. Further, $32.4 \%$ (Block $2 ; \Delta R^{2}=.14, p<.01$ ) of variance in contextual job performance was accounted for by the regression model, signifying a large effect. A similar result was obtained for the contextual job performance model with conflict management styles and instigated incivility, while controlling for organizational effects (Block $1 ; \Delta R^{2}=.18, p<$ $.01) .33 \%$ of variance in contextual job performance (Block $2 ; \Delta R^{2}=.14, p<.01$ ) was accounted for by conflict management styles, controlling for organizational differences, signifying a large effect. When either target or instigator incivility was entered into the regression analyses in the third step, neither were significant predictors of contextual job performance.

There were differences between the task and contextual dimensions of job performance models as conflict management styles explained more of the variance in contextual job performance (about $32.0 \%$ ) as compared to the variance in task job performance (about 19\%). Further, the integrating style of conflict management had a stronger influence on contextual job performance than on task performance. Organizational Commitment. Table 13 presents the summary of the regression analyses examining the predictability of conflict management styles and workplace incivility (target) on organizational commitment, while controlling for any differences in organizational effects $\left(\right.$ Block $\left.1 ; \Delta R^{2}=.08, p<.01\right)$. More than a third of variance $\left(R^{2}=\right.$ 
$.38, p<.01)$ in organizational commitment was explained by the independent variables, conflict management styles (Block $2 ; \Delta R^{2}=.13, p<.01$ ) and target incivility (Block 3; $\left.\Delta R^{2}=.17, p<.01\right)$. According to Cohen (1988), this constitutes a large effect size. The integrating $(\beta=0.22, N<.01)$ and dominating $(\beta=-.12 . p<.05)$ styles, as well as target incivility $(\beta=-.46, p<.01)$ were significant predictors of organizational commitment. These values reveal target incivility as the most important predictor in the regression model, followed by the integrating conflict management style, and then the dominating style. 
Table 13

Summary of Hierarchical Regression Analyses for Organizational Effects, Conflict

Management Styles and Target Incivility Predicting Organizational Commitment

\begin{tabular}{|c|c|c|c|c|c|c|}
\hline & Variable & & & & otal & \\
\hline & & $B$ & $S E B$ & $\beta$ & $R^{2}$ & $\Delta R^{2}$ \\
\hline Step 1 & & & & & $.08 * *$ & .08 \\
\hline & Org Effect 1 & 2.15 & .66 & $.20^{* *}$ & & \\
\hline & Org Effect 2 & -1.72 & .66 & $-.16^{* *}$ & & \\
\hline Step 2 & & & & & $.21 * *$ & .13 \\
\hline & Org Effect 1 & 1.59 & .63 & $.15^{*}$ & & \\
\hline & Org Effect 2 & -.56 & .65 & -.05 & & \\
\hline & Avoid CMS & .06 & .49 & .01 & & \\
\hline & Integrate CMS & 3.99 & .75 & $.35^{* *}$ & & \\
\hline & Dominate CMS & -1.38 & .48 & $-.16^{* *}$ & & \\
\hline & Compromise CMS & -.10 & .68 & -.01 & & \\
\hline Step 3 & & & & & $.38 * *$ & .17 \\
\hline & Org Effect 1 & .33 & .58 & .03 & & \\
\hline & Org Effect 2 & -.50 & .57 & -.05 & & \\
\hline & Avoid CMS & .17 & .44 & .02 & & \\
\hline & Integrate CMS & 2.50 & .69 & $.22 * *$ & & \\
\hline & Dominate CMS & -1.06 & .42 & $-.12 *$ & & \\
\hline & Compromise CMS & -.13 & .60 & .01 & & \\
\hline & TargetWI & -3.99 & .46 & $-.46^{* *}$ & & \\
\hline
\end{tabular}


Note. Dependent Variable: Organizational Commitment.

${ }^{*} p<.05{ }^{* *} p<.01$

The next regression analyses, controlling for organizational cffects (Block $1 ; \Delta R^{2}=.08, p<.01$ ), examined the relative predictability of conflict management styles (Block $\left.2 ; \Delta R^{2}=.13, p<.01\right)$ and instigated incivility (Block $3 ; \Delta R^{2}=.03, p<.01$ ) on organizational commitment. Table 14 details the results summary. The independent variables explained $24 \%$ of the variance in the model. The significance and strength of the predictors were similar to that of the previous model utilizing target incivility. In this regression model, the strongest ranked predictor was the integrating conflict management style $(\beta=.30, p<.01)$, followed by instigated incivility, $(\beta=-.19, p<.01)$ and thirdly, the dominating conflict management style $(\beta=-.13, p<.01)$. 
Table 14

Summary of Hierarchical Regression Analyses for Organizational Effects, Conflict

Management Styles and Instigated Incivility Predicting Organizational Commitment

\begin{tabular}{|c|c|c|c|c|c|c|}
\hline & & & & & otal & \\
\hline & Variable & $B$ & $S E B$ & $\beta$ & $R^{2}$ & $\Delta R^{2}$ \\
\hline$\overline{\text { Step } 1}$ & & & & & $.08^{* *}$ & .08 \\
\hline & Org Effect 1 & 2.15 & .66 & $.20 * *$ & & \\
\hline & Org Effect 2 & -1.72 & .66 & $-.16 * *$ & & \\
\hline Step 2 & & & & & $.21 * *$ & .13 \\
\hline & Org Effect 1 & 1.59 & .63 & $.15^{*}$ & & \\
\hline & Org Effect 2 & -.56 & .65 & -.05 & & \\
\hline & Avoid CMS & .06 & .49 & .01 & & \\
\hline & Integrate CMS & 3.99 & .75 & $.35^{* *}$ & & \\
\hline & Dominate CMS & -1.38 & .48 & $-.16^{* *}$ & & \\
\hline & Compromise CMS & -.10 & .68 & -.01 & & \\
\hline Step 3 & & & & & $.24 * *$ & .03 \\
\hline & Org Effect 1 & 1.38 & .62 & $.13^{*}$ & & \\
\hline & Org Effect 2 & -.36 & .64 & -.03 & & \\
\hline & Avoid CMS & .03 & .49 & .00 & & \\
\hline & Integrate CMS & 3.40 & .76 & $.30 * *$ & & \\
\hline & Dominate CMS & -1.06 & .48 & $-.13^{*}$ & & \\
\hline & Compromise CMS & -.24 & .67 & -.02 & & \\
\hline & InstigateWI & -2.01 & .65 & $-.19 * *$ & & \\
\hline
\end{tabular}


Note. Dependent Variable: Organizational Commitment.

${ }^{*} p<.05 .{ }^{* *} p<.01$.

Intent to turnover. Two sets of hierarchical regression analyses were conducted to examine the predictability of turnover intentions by conflict management styles and incivility, again controlling for organizational effects . In the first regression analysis (as summarized in Table 15), 32\% of variance in intent to turnover were explained by both conflict management styles (Block $2 ; \Delta R^{2}=.12, p<.01$ ) and target incivility (Block 3; $\Delta R^{2}=.17, p<.01$ ) controlling for organizational differences (Block $1 ; \Delta R^{2}=.02, p<$ $.01)$. This is considered as a large effect (Cohen, 1988). Out of the four conflict management styles, the integrating style $(\beta=-0.16 p<.05)$, and the dominating conflict management style, $(\beta=0.20, p<.01)$ proved to be significant predictors of turnover intentions. Further, target incivility, $(\beta=0.46, p<.01)$ was the strongest predictor. 
Table 15

Summary of Hierarchical Regression Analyses for Organizational Effects, Conflict

Management Styles and Target Incivility Predicting Turnover Intent

\begin{tabular}{rrrrrr}
\hline Variable & $B$ & $S E B$ & $\beta$ & Total $R^{2}$ & $\Delta R^{2}$ \\
\hline & & & $.02^{*}$ & .02
\end{tabular}

Step 1

$\begin{array}{llll}\text { Org Effect 1 } & -.81 & .32 & -.16^{*} \\ \text { Org Effect 2 } & -.43 & .33 & -.08\end{array}$

Step 2

$\begin{array}{lccc}\text { Org Effect 1 } & -.49 & .31 & -.09 \\ \text { Org Effect } 2 & -1.00 & .32 & -.19^{* *} \\ \text { Avoid CMS } & -.15 & .24 & -.04 \\ \text { Integrate CMS } & -.45 & .37 & -.27^{* *} \\ \text { Dominate CMS } & .97 & .23 & .24^{* *} \\ \text { Compromise CMS } & -.12 & .34 & -.02\end{array}$

Step 3

$\begin{array}{lccc}\text { Org Effect 1 } & .16 & .29 & .03 \\ \text { Org Effect 2 } & -1.07 & .29 & -.21^{* *} \\ \text { Avoid CMS } & -.19 & .22 & -.05 \\ \text { Integrate CMS } & -.82 & .34 & -.16^{*} \\ \text { Dominate CMS } & .81 & .21 & .20^{* *} \\ \text { Compromise CMS } & -.08 & .31 & -.02 \\ \text { TargetWI } & 1.88 & .23 & .46^{* *}\end{array}$

Note. Dependent variable: Turnover intent. ${ }^{*} p<.05 .{ }^{* *} p<.01$. 
In contrast, the second set of regression analyses on turnover intentions, controlling for organizational effects (Block $1 ; \Delta R^{2}=.02, p<.01$ ), with conflict management styles (Block 2; $\Delta R^{2}=.12, p<.01$ ) and instigated incivility (Block $3 ; \Delta R^{2}=$ $.03, p<.01)$, resulted in a significant but smaller $R^{2}$ of $.18(p<.01)$. This represents a medium to large effect size. Table 16 is a summary of the regression analysis. Two of the conflict management styles, the integrating style $(\beta=-0.22, p<.01)$, and the dominating style $(\beta=0.21, p<.01)$; as well as instigator incivility $(\beta=.19, p<.01)$ were significant predictors of turnover intentions.

Both types of incivility, the integrating and dominating conflict management styles predicted turnover intent. However, the combination of target incivility and conflict management styles resulted in a greater amount of variance explaining turnover intent, $32 \%$ in comparison to $18 \%$ for the regression model with instigator and conflict management styles. 
Table 16

Summary of Hierarchical Regression Analyses for Organizational Effects, Conflict

Management Styles and Instigated Incivility Predicting Turnover Intent

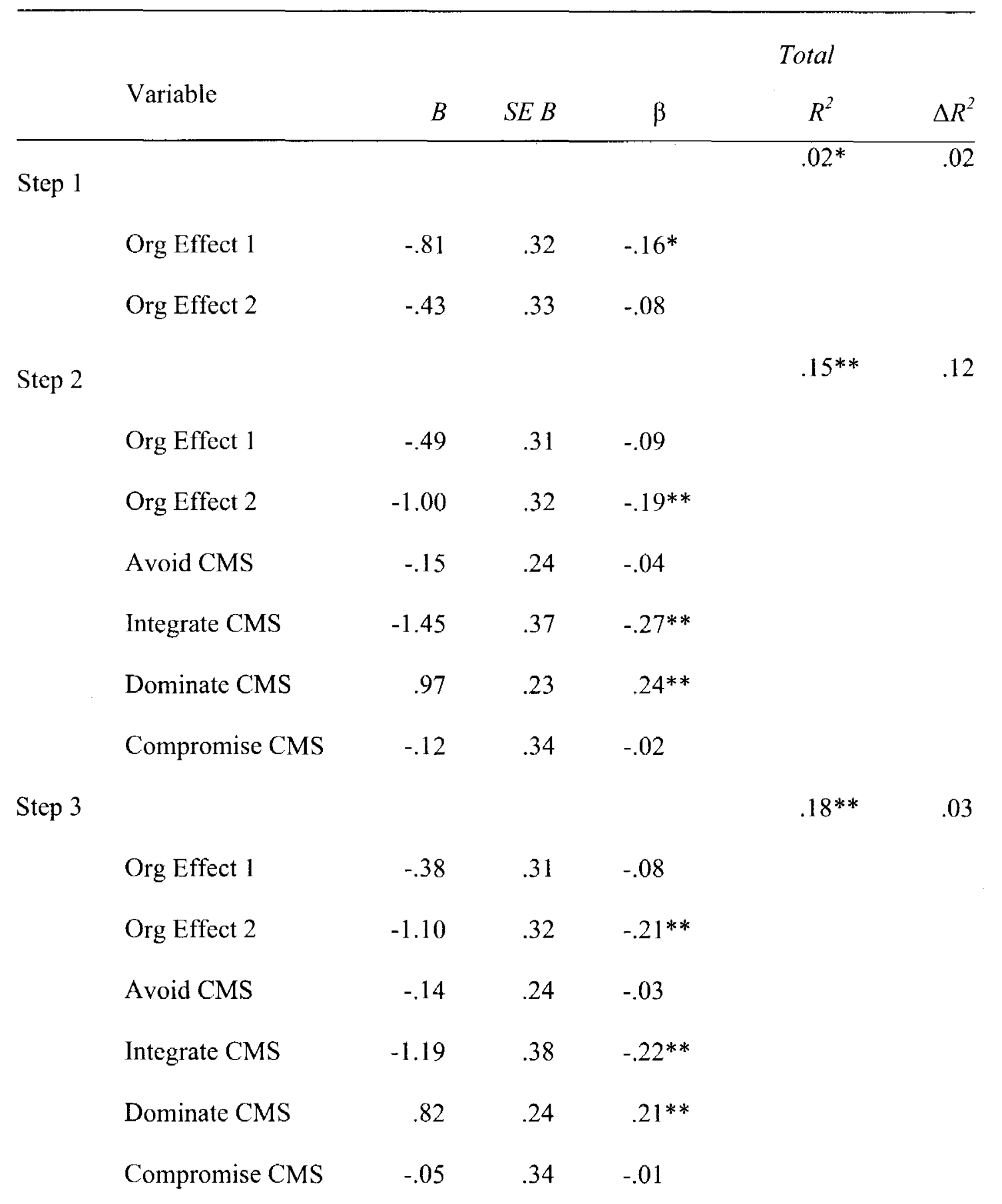


Table 16 (continued)

Total

\begin{tabular}{lrrrrr} 
Variable & $B$ & $S E B$ & $\beta$ & $R^{2}$ & $\Delta R^{2}$ \\
\hline InstigateWI & .93 & .31 & $.19^{* *}$ &
\end{tabular}

Note. Dependent variable: Turnover intent.

${ }^{*} p<.05{ }^{* *} p<.01$.

Research Question 4

Four sets of hierarchical regression analyses were conducted to examine the predictability of job performance (task and contextual dimensions) by conflict management styles and incivility (target and instigator), controlling for organizational effects and select demographic variables (gender, tenure, hierarchical rank and age). The first regression analysis (as summarized in Table 17), controlling for organizational effects (Block $1 ; \Delta R^{2}=.09, p<.01$ ), as well as demographic variables of gender, tenure, hierarchical rank and age (Block $2 ; \Delta R^{2}=.03$, non-significant), resulted in $22 \%$ of variance $(p<.01)$ in job performance (task) explained by conflict management styles (Block $\left.3 ; \Delta R^{2}=.10, p<.01\right)$. Hierarchical position $(\beta=.14, p<.05)$ and age $\beta=-.13, p$ $<.05)$ were significant predictors; as was the integrating style $(\beta=.37, p<.01)$. Those who held higher positions were more likely to perceive themselves as performing well on the task dimension of job performance. The younger the workers, the more likely they were to perceive themselves as high performers on the task dimension of job performance. Target incivility, when entered as the fourth block, was not a significant predictor in the model. 
Table 17

Summary of Hierarchical Regression Analyses for Organizational Effects, Demographic variables (Gender, Tenure, Hierarchical Rank, Age), Conflict Management Styles and Target Incivility Predicting Job Performance (Task)

Total

\begin{tabular}{lllll} 
& Variable & $B$ & $S E B$ & $\beta$ \\
\hline Step 1 & & & & \\
& Org Effect 1 & .57 & .41 & .10 \\
& Org Effect 2 & -1.38 & .40 & $-.24^{* *}$
\end{tabular}

Step 2

.12 .03

Org Effect 1

$\begin{array}{lll}.28 & .52 \quad .05\end{array}$

Org Effect 2

$-.74 \quad .53 \quad-.13$

Gender

$.81 \quad .61 \quad .12$

Tenure

$\begin{array}{lll}-.08 & .29 & -.03\end{array}$

Hierarchical position

$\begin{array}{lll}.34 & .19 & .12\end{array}$

Age

$-.37 \quad .25 \quad-.10$

Step 3

Org Effect 1

.18

.50

.03

Org Effect 2

$-.56 \quad .50 \quad-.10$

Gender

$\begin{array}{lll}.48 & .59 \quad .07\end{array}$

Tenure

$\begin{array}{lll}-.04 & .27 & -.02\end{array}$

Hierarchical position

$.38 \quad .18 \quad .14^{*}$

Age

$-.49 \quad .24 \quad-.13^{*}$


Table 17 (continued)

Total

\begin{tabular}{|c|c|c|c|c|}
\hline Variable & $B$ & $S E B$ & $\beta$ & $R^{2}$ \\
\hline Avoid CMS & -.02 & .31 & .00 & \\
\hline Integrate CMS & 2.24 & .46 & $.37 * *$ & \\
\hline Dominate CMS & .18 & .30 & .04 & \\
\hline Compromise CMS & -.46 & .43 & -.08 & \\
\hline
\end{tabular}

Step 4

.22

.00

\begin{tabular}{lccc} 
Org Effect 1 & .25 & .50 & .04 \\
Org Effect 2 & -.57 & .50 & -.10 \\
Gender & .41 & .60 & .06 \\
Tenure & -.06 & .27 & -.02 \\
Hierarchical position & .39 & .18 & $.15^{*}$ \\
Age & -.48 & .24 & $-.13^{*}$ \\
Avoid CMS & -.03 & .31 & -.01 \\
Integrate CMS & 2.35 & .47 & $.39 * *$ \\
Dominate CMS & .15 & .30 & .03 \\
Compromise CMS & -.43 & .43 & -.07 \\
Target incivility & .25 & .31 & .06 \\
\hline
\end{tabular}

Note. Dependent variable: Job performance (task).

$* p<.05 . * * p<.01$. 
The predictability of job performance (task) by conflict management styles and instigated incivility, controlling for organizational effects and select demographic variables (gender, tenure, hierarchical rank and age) was examined by a second regression analysis. The results are presented in Table 18. They reflect the same results as the previous regression analyses with target incivility (see Table 17). $22 \%$ of variance $(p<.01)$ in job performance (task) was explained by conflict management styles (Block $\left.3 ; \Delta R^{2}=.10, p<.01\right)$, controlling for organizational effects (Block $1 ; \Delta R^{2}=.09, p<.01$ ), demographic variables of gender, tenure, hicrarchical rank and age (Block $2 ; \Delta R^{2}=.03$, non-significant $)$. Hierarchical $\operatorname{rank}(\beta=.14, p<.05)$ and age $(\beta=-.13, p<.05)$ were significant predictors; as was the integrating style $(\beta=.37, p<.01)$. Those who held higher positions were more likely to perceive themselves as performing well on the contextual dimension of job performance. The younger the workers, the more likely they were to perceive themselves as high performers on the contextual dimension of job performance. Instigator incivility, when entered as the fourth block, did not result in a significant predictive model with the other variables. 
Table 18

Summary of Hierarchical Regression Analyses for Organizational Effects, Demographic variables (Gender, Tenure, Hierarchical Rank, Age), Conflict Management Styles and Instigated Incivility Predicting Job Performance (Task)

\begin{tabular}{|c|c|c|c|c|c|c|}
\hline & & & & & otal & \\
\hline & Variable & $B$ & $S E B$ & $\beta$ & $R^{2}$ & $\Delta R^{2}$ \\
\hline Step 1 & & & & & $.09 * *$ & .09 \\
\hline & Org Effect 1 & .57 & .41 & .10 & & \\
\hline & Org Effect 2 & -1.38 & .40 & $-.24 * *$ & & \\
\hline Step 2 & & & & & .12 & .03 \\
\hline & Org Effect 1 & .28 & .52 & .05 & & \\
\hline & Org Effect 2 & -.74 & .53 & -.13 & & \\
\hline & Gender & .81 & .61 & .12 & & \\
\hline & Tenure & -.08 & .29 & -.03 & & \\
\hline & Hierarchical position & .34 & .19 & .12 & & \\
\hline & Age & -.37 & .25 & -.10 & & \\
\hline Step 3 & & & & & $.22 * *$ & .10 \\
\hline & Org Effect 1 & .18 & .50 & .03 & & \\
\hline & Org Effect 2 & -.56 & .50 & -.10 & & \\
\hline & Gender & .48 & .59 & .07 & & \\
\hline & Tenure & -.04 & .27 & -.02 & & \\
\hline & Hierarchical position & .38 & .18 & $.14^{*}$ & & \\
\hline & Age & -.49 & .24 & $-.13^{*}$ & & \\
\hline
\end{tabular}


Table 18 (continued)

\begin{tabular}{|c|c|c|c|c|c|c|}
\hline & & & & & otal & \\
\hline & Variable & $B$ & $S E B$ & $\beta$ & $R^{2}$ & $\Delta R^{2}$ \\
\hline & Avoid CMS & -.02 & .31 & .00 & & \\
\hline & Integrate CMS & 2.24 & .46 & $.37 * *$ & & \\
\hline & Dominate CMS & .18 & .30 & .04 & & \\
\hline & Compromise CMS & -.46 & .43 & -.08 & & \\
\hline Step 4 & & & & & .22 & .00 \\
\hline & Org Effect 1 & .18 & .50 & .03 & & \\
\hline & Org Effect 2 & -.56 & .50 & -.10 & & \\
\hline & Gender & .48 & .59 & .07 & & \\
\hline & Tenure & -.05 & .28 & -.02 & & \\
\hline & Hierarchical position & .38 & .18 & $.14^{*}$ & & \\
\hline & Age & -.49 & .25 & $-.13 *$ & & \\
\hline & Avoid CMS & -.02 & .31 & .00 & & \\
\hline & Integrate CMS & 2.25 & .47 & $.37 * *$ & & \\
\hline & Dominate CMS & .17 & .30 & .04 & & \\
\hline & Compromise CMS & -.45 & .43 & -.08 & & \\
\hline & InstigateWI & .03 & .39 & .00 & & \\
\hline
\end{tabular}

Note. Dependent variable: Job performance (task).

${ }^{*} p<.05 . * * p<.01$. 
Table 19 sets out the results of the regression analyses examining the predictability of contextual job performance by conflict management styles and target workplace incivility, controlling for organizational effects, gender, tenure, hierarchical rank and age. $37 \%$ of variance in the contextual dimension of job performance is explained by conflict management styles (Block $3 ; \Delta R^{2}=.15, p<.01$ ), the demographic variables (Block 2; $\Delta R^{2}=.02$, non-significant) and the organizational effects (Block 1; $\left.\Delta R^{2}=.20, p<.01\right)$. Of the four conflict management styles, only the integrating conflict style was a significant predictor $(\beta=.43, p<.01)$. Target incivility was not a significant predictor when entered into the model as a fourth block.

When the demographic variables were added to the regression analyses, there was a small increase in the amount of variance explained in contextual job performance $(37 \%$ compared to $32 \%$ ). That is an indication that those variables, although non-significant, may have some influence on contextual job performance. 
Table 19

Summary of Hierarchical Regression Analyses for Organizational Effects, Demographic variables (Gender, Tenure, Hierarchical Rank, Age), Conflict Management Styles and Target Incivility Predicting Job Performance (Contextual)

\begin{tabular}{|c|c|c|c|c|c|c|}
\hline & & & & & Total & \\
\hline & Variable & $B$ & $S E B$ & $\beta$ & $R^{2}$ & $\Delta R^{2}$ \\
\hline Step 1 & & & & & $20^{* *}$ & .20 \\
\hline & Org Effect 1 & 1.33 & .41 & $.21 * *$ & & \\
\hline & Org Effect 2 & -2.00 & .41 & $-.32 * *$ & & \\
\hline Step 2 & & & & & .22 & .02 \\
\hline & Org Effect 1 & .86 & .53 & .14 & & \\
\hline & Org Effect 2 & -1.37 & .54 & $-.22 *$ & & \\
\hline & Gender & 1.41 & .62 & $.19^{*}$ & & \\
\hline & Tenure & -.06 & .30 & -.02 & & \\
\hline & Hierarchical position & .07 & .19 & .02 & & \\
\hline & Age & -.07 & .26 & -.02 & & \\
\hline Step 3 & & & & & $.37 * *$ & .15 \\
\hline & Org Effect 1 & .65 & .48 & .10 & & \\
\hline & Org Effect 2 & -1.12 & .49 & $-.18^{*}$ & & \\
\hline & Gender & .80 & .57 & .11 & & \\
\hline & Tenure & .01 & .27 & .01 & & \\
\hline & Hierarchical position & .17 & .18 & .06 & & \\
\hline & Age & -.31 & .24 & -.08 & & \\
\hline
\end{tabular}


Table 19 (continued)

\begin{tabular}{|c|c|c|c|c|c|c|}
\hline & & & & & otal & \\
\hline & Variable & $B$ & $S E B$ & $\beta$ & $R^{2}$ & $\Delta R^{2}$ \\
\hline & Avoid CMS & .37 & .30 & .07 & & \\
\hline & Integrate CMS & 2.79 & .44 & $.43^{* *}$ & & \\
\hline & Dominate CMS & -.19 & .30 & -.04 & & \\
\hline & Compromise CMS & -.19 & .42 & -.03 & & \\
\hline Step 4 & & & & & .38 & .00 \\
\hline & Org Effect 1 & .60 & .49 & .10 & & \\
\hline & Org Effect 2 & -1.11 & .49 & $-.18 *$ & & \\
\hline & Gender & .85 & .58 & .12 & & \\
\hline & Tenure & .03 & .27 & .01 & & \\
\hline & Hierarchical position & .16 & .18 & .06 & & \\
\hline & Age & -.31 & .24 & -.08 & & \\
\hline & Avoid CMS & .37 & .30 & .07 & & \\
\hline & Integrate CMS & 2.71 & .46 & $.42 * *$ & & \\
\hline & Dominate CMS & -.17 & .30 & -.03 & & \\
\hline & Compromise CMS & -.21 & .42 & -.03 & & \\
\hline & TargetWI & -.19 & .30 & -.04 & & \\
\hline
\end{tabular}

Note. Dependent variable: Job performance (contextual).

${ }^{*} p<.05{ }^{* *} p<.01$. 
The next regression analyses (as summarized in Table 20) examined the predictability of contextual job performance by conflict management styles and instigated workplace incivility, controlling for organizational effects, gender, tenure, hierarchical rank and age. None of the demographic variables were significant predictors when conflict management styles were entered into the regression equation. The same results were obtained as for target incivility previously: $37 \%(p<.01)$ of variance in the contextual dimension of job performance was explained by conflict management styles (Block $3 ; \Delta R^{2}=.15, p<.01$ ), the demographic variables (Block $2 ; \Delta R^{2}=.02$, nonsignificant) and the organizational effects (Block $1 ; \Delta R^{2}=.20, p<.01$ ). Of the four conflict management styles, only the integrating conflict style is a significant predictor $(\beta$ $=.43, p<.01)$. Like target incivility, instigated incivility was not a significant predictor of contextual job performance when entered into the model as a fourth block. 
Table 20

Summary of Hierarchical Regression Analyses for Organizational Effects, Demographic variables (Gender, Tenure, Hierarchical Rank, Age), Conflict Management Styles and Instigated Incivility Predicting Job Performance (Contextual)

\begin{tabular}{|c|c|c|c|c|c|c|}
\hline & & & & & otal & \\
\hline & Variable & $B$ & $S E B$ & $\beta$ & $R^{2}$ & $\Delta R^{2}$ \\
\hline$\overline{\text { Step } 1}$ & & & & & $.20^{* *}$ & .20 \\
\hline & Org Effect 1 & 1.33 & .41 & $.21 * *$ & & \\
\hline & Org Effect 2 & -2.00 & .41 & $-.32 * *$ & & \\
\hline Step 2 & & & & & .22 & .02 \\
\hline & Org Effect 1 & .86 & .53 & .14 & & \\
\hline & Org Effect 2 & -1.37 & .54 & $-.22 * *$ & & \\
\hline & Gender & 1.41 & .62 & $.19^{*}$ & & \\
\hline & Tenure & -.06 & .30 & -.02 & & \\
\hline & Hierarchical position & .07 & .19 & .02 & & \\
\hline & Age & -.07 & .26 & -.02 & & \\
\hline Step 3 & & & & & $.37 * *$ & .15 \\
\hline & Org Effect 1 & .65 & .48 & .10 & & \\
\hline & Org Effect 2 & -1.12 & .49 & $-.18^{*}$ & & \\
\hline & Gender & .80 & .57 & .11 & & \\
\hline & Tenure & .01 & .27 & .01 & & \\
\hline & Hierarchical position & .17 & .18 & .06 & & \\
\hline & Age & -.31 & .24 & -.08 & & \\
\hline
\end{tabular}


Table 20 (continued)

\begin{tabular}{|c|c|c|c|c|c|c|}
\hline & & & & & otal & \\
\hline & Variable & $B$ & $S E B$ & $\beta$ & $R^{2}$ & $\Delta R^{2}$ \\
\hline & Avoid CMS & .37 & .30 & .07 & & \\
\hline & Integrate CMS & 2.79 & .44 & $.43^{* *}$ & & \\
\hline & Dominate CMS & -.19 & .30 & -.04 & & \\
\hline & Compromise CMS & -.19 & .42 & -.03 & & \\
\hline Step 4 & & & & & .38 & .01 \\
\hline & Org Effect 1 & .71 & .48 & .11 & & \\
\hline & Org Effect 2 & -1.14 & .49 & $-.18 *$ & & \\
\hline & Gender & .81 & .57 & .11 & & \\
\hline & Tenure & .09 & .27 & .03 & & \\
\hline & Hierarchical position & .14 & .18 & .05 & & \\
\hline & Age & -.35 & .24 & -.09 & & \\
\hline & Avoid CMS & .33 & .30 & .06 & & \\
\hline & Integrate CMS & 2.59 & .46 & $.40 * *$ & & \\
\hline & Dominate CMS & -.13 & .30 & -.03 & & \\
\hline & Compromise CMS & -.24 & .42 & -.04 & & \\
\hline & InstigateWI & -.57 & .38 & -.10 & & \\
\hline
\end{tabular}

Note. Dependent variable: Job performance (contextual).

${ }^{*} p<.05 .{ }^{* *} p<.01$. 
Research Question 5

Two sets of hierarchical regression analyses were conducted to examine the predictability of organizational commitment by conflict management styles and incivility (target and instigator), controlling for organizational effects and select demographic variables (gender, tenure, hierarchical rank and age). In the first set of regression analyses (as summarized in Table 21), 39\% of variance $(p<.01)$ in organizational commitment, controlling for both organizational effects (Block $1 ; \Delta R^{2}=.12, p<.01$ ) and the demographic variables of gender, tenure, hierarchical rank and age (Block $2 ; \Delta R^{2}=.05, p$ $<.01$ ), was explained by conflict management styles (Block $3 ; \Delta R^{2}=.12, p<.01$ ) and target incivility (Block $4 ; \Delta R^{2}=.12, p<.01$ ). This constitutes a large effect (Cohen, 1988). Of all the control variables, age $(\beta=.14, p<.05)$ was the only significant predictor. The older the workers, the higher their scores on commitment to the organization. Target incivility was the strongest predictor of organizational commitment $(\beta=-.40, p<.01)$ followed by the integrating conflict management style $(\beta=.161 p<$ $.05)$ and lastly, the dominating style $(\beta=-.10, p<.05)$.

Controlling for demographic variables increased the variance explained from $38 \%$ (regression analyses without the demographic variables) to $39 \%$. This demonstrates that those variables, particularly the age of the employee, do have an influence on organizational commitment. 
Table 21

Summary of Hierarchical Regression Analyses for Organizational Effects, Demographic

variables (Gender, Tenure, Hierarchical Rank, Age), Conflict Management Styles and

Target Incivility Predicting Organizational Commitment

\section{Total}

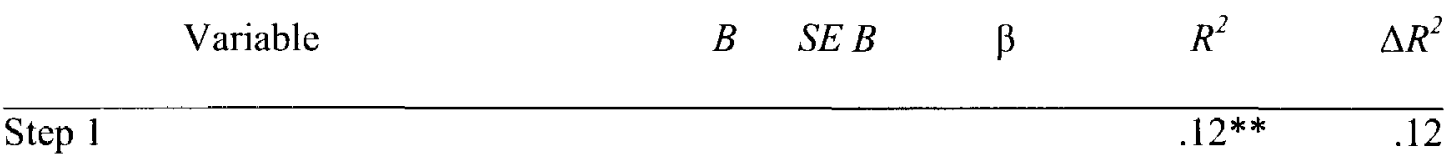

Org Effect 1

$2.97 \quad .76 \quad .27^{* *}$

Org Effect 2

$-1.41 \quad .75 \quad-.13$

Step 2

Org Effect 1

Org Effect 2

Gender

Tenure

Hierarchical position

Age

Step 3

$2.88 \quad .96 \quad .26^{* *}$

$\begin{array}{lll}-1.22 & .97 & -.11\end{array}$

$\begin{array}{lll}-.64 & 1.12 & -.05\end{array}$

$\begin{array}{lll}-.14 & .53 & -.03\end{array}$

$\begin{array}{lll}.26 & .35 & .05\end{array}$

$1.49 \quad .46 \quad .21^{* *}$
Org Effect 1

Org Effect 2

Gender

Tenure

Hierarchical position

Age
$2.56 \quad .90 \quad .23^{* *}$

$\begin{array}{lll}-.80 & .91 & -.07\end{array}$

$\begin{array}{lll}-1.81 & 1.07 & -.14\end{array}$

$-.03 \quad .50 \quad-.01$

$\begin{array}{lll}.33 & .33 & .07\end{array}$

$1.10 \quad .44 \quad .16^{*}$ 
Table 21 (continued)

\begin{tabular}{|c|c|c|c|c|c|c|}
\hline & & & & & otal & \\
\hline & Variable & $B$ & $S E B$ & $\beta$ & $R^{2}$ & $\Delta R^{2}$ \\
\hline & Avoid CMS & .08 & .56 & .01 & & \\
\hline & Integrate CMS & 3.37 & .83 & $.30 * *$ & & \\
\hline & Dominate CMS & -1.17 & .56 & $-.13 *$ & & \\
\hline & Compromise CMS & .85 & .78 & .08 & & \\
\hline Step 4 & & & & & $.39 * *$ & .12 \\
\hline & Org Effect 1 & 1.60 & .84 & .15 & & \\
\hline & Org Effect 2 & -.59 & .84 & -.05 & & \\
\hline & Gender & -.71 & 1.00 & -.06 & & \\
\hline & Tenure & .23 & .46 & .05 & & \\
\hline & Hierarchical position & .25 & .30 & .05 & & \\
\hline & Age & .99 & .41 & $.14^{*}$ & & \\
\hline & Avoid CMS & .18 & .51 & .02 & & \\
\hline & Integrate CMS & 1.83 & .80 & $.16^{*}$ & & \\
\hline & Dominate CMS & -.89 & .51 & $-.10^{*}$ & & \\
\hline & Compromise CMS & .53 & .72 & .05 & & \\
\hline & TargetWI & -3.39 & .54 & $-.40^{* *}$ & & \\
\hline
\end{tabular}

Note. Dependent variable: Organizational commitment.

${ }^{*} p<.05 .{ }^{* *} p<.01$.

The second regression analyses (summarized in Table 22) investigated the predictability of organizational commitment by conflict management styles (Block $3 ; \Delta R^{2}$ $=.12, p<.01$ ) and instigated incivility (Block $4 ; \Delta R^{2}=.03, p<.01$ ), controlling for 
organizational effects (Block $\left.1 ; \Delta R^{2}=.12, p<.01\right)$ and select demographic variables (gender, tenure, hierarchical rank and age; Block $2 ; \Delta R^{2}=.05, p<.05$ ). $31 \%$ of variance (Adjusted $R^{2}=.28, p<.01$ ) in organizational commitment, was explained by the model. Out of all the demographic variables, age $(\beta=.13, p<.05)$ was the only significant predictor. The strongest predictor of organizational commitment was the integrating conflict management style $(\beta=.23, p<.01)$, followed by instigated incivility $(\beta=-.21, p$ $<.01$ ). However, unlike the previous regression with target incivility (as one of the independent variables), the dominating style was not a significant predictor.

Controlling for demographic variables increased the variance explained from $24 \%$ (regression analyses without the demographic variables) to $31 \%$. This demonstrates that the demographic variables, when combined with conflict management styles and instigated incivility, did have an influence on organizational commitment, justifying controlling their effects on the regression equation. 
Table 22

Summary of Hierarchical Regression Analyses for Organizational Effects, Demographic variables (Gender, Tenure, Hierarchical Rank, Age), Conflict Management Styles and Instigated Incivility Predicting Organizational Commitment

\begin{tabular}{|c|c|c|c|c|c|c|}
\hline & & & & & otal & \\
\hline & Variable & $B$ & $S E B$ & $\beta$ & $R^{2}$ & $\Delta R^{2}$ \\
\hline$\overline{\text { Step } 1}$ & & & & & $.12^{* *}$ & .12 \\
\hline & Org Effect 1 & 2.97 & .76 & $.27 * *$ & & \\
\hline & Org Effect 2 & -1.41 & .75 & -.13 & & \\
\hline Step 2 & & & & & $.16^{*}$ & .05 \\
\hline & Org Effect 1 & 2.88 & .96 & $.26^{* *}$ & & \\
\hline & Org Effect 2 & -1.22 & .97 & -.11 & & \\
\hline & Gender & -.64 & 1.12 & -.05 & & \\
\hline & Tenure & -.14 & .53 & -.03 & & \\
\hline & Hierarchical position & .26 & .35 & .05 & & \\
\hline & Age & 1.49 & .46 & $.21 * *$ & & \\
\hline Step 3 & & & & & $.28 * *$ & .12 \\
\hline & Org Effect 1 & 2.56 & .90 & $.23^{* *}$ & & \\
\hline & Org Effect 2 & -.80 & .91 & -.07 & & \\
\hline & Gender & -1.81 & 1.07 & -.14 & & \\
\hline & Tenure & -.03 & .50 & -.01 & & \\
\hline & Hierarchical position & .33 & .33 & .07 & & \\
\hline & Age & 1.10 & .44 & $.16^{*}$ & & \\
\hline
\end{tabular}


Table 22 (continued)

\begin{tabular}{|c|c|c|c|c|c|c|}
\hline & & & & & otal & \\
\hline & Variable & $B$ & $S E B$ & $\beta$ & $R^{2}$ & $\Delta R^{2}$ \\
\hline & Avoid CMS & .08 & .56 & .01 & & \\
\hline & Integrate CMS & 3.37 & .83 & $.30^{* *}$ & & \\
\hline & Dominate CMS & -1.17 & .56 & $-.13 *$ & & \\
\hline & Compromise CMS & .85 & .78 & .08 & & \\
\hline Step 4 & & & & & $.31 * *$ & .03 \\
\hline & Org Effect 1 & 2.74 & .89 & $.25 * *$ & & \\
\hline & Org Effect 2 & -.85 & .90 & -.08 & & \\
\hline & Gender & -1.68 & 1.05 & -.13 & & \\
\hline & Tenure & .27 & .50 & .06 & & \\
\hline & Hierarchical position & .25 & .33 & .05 & & \\
\hline & Age & .93 & .44 & $.13^{*}$ & & \\
\hline & Avoid CMS & -.07 & .55 & -.01 & & \\
\hline & Integrate CMS & 2.56 & .85 & $.23^{* *}$ & & \\
\hline & Dominate CMS & -.96 & .55 & -.11 & & \\
\hline & Compromise CMS & .67 & .77 & .06 & & \\
\hline & InstigateWI & -2.27 & .73 & $-.21 * *$ & & \\
\hline
\end{tabular}

Note. Dependent variable: Organizational commitment.

${ }^{*} p<.05 .{ }^{* *} p<.01$. 
Research Question 6

The predictability of intent to turnover by conflict management styles and incivility (target and instigator), controlling for organizational effects (Block $1 ; \Delta R^{2}=$ $.05, p<.01$ ) and select demographic variables (gender, tenure, hierarchical rank and age; (Block $2 ; \Delta R^{2}=.03$, non-significant) was examined through two separate sets of hierarchical regression analyses. The first regression (as summarized in Table 23) with conflict management styles (Block $3 ; \Delta R^{2}=.10, p<.01$ ) target incivility (Block $4 ; \Delta R^{2}=$ $.16, p<.01)$ resulted in $R^{2}$ of .35 for the model. This is also another large effect size. Age $(\beta=-.11, p<.05)$ was a significant predictor. The younger the workers, the more likely they were to have turnover intentions. Target incivility was the strongest predictor of turnover $(\beta=.47, p<.01)$ followed by the dominating conflict management style $(\beta=$ $.16, p<.05)$.

Controlling for demographic variables increased the variance explained from $32 \%$ (regression analyses without the demographic variables) to $35 \%$. This demonstrates that those variables did have an influence on turnover intentions, in particular, the age of the employee. The older workers were less likely to score highly on intent to quit, while younger workers were more likely to want to turnover. 
Table 23

Summary of Hierarchical Regression Analyses for Organizational Effects, Demographic variables (Gender, Tenure, Hierarchical Rank, Age), Conflict Management Styles and Target Incivility Predicting Turnover Intent

\begin{tabular}{|c|c|c|c|c|c|c|}
\hline & & & & & otal & \\
\hline & Variable & $B$ & $S E B$ & $\beta$ & $R^{2}$ & $\Delta R^{2}$ \\
\hline Step 1 & & & & & $.05 * *$ & .05 \\
\hline & Org Effect 1 & -1.29 & .39 & $-.24 * *$ & & \\
\hline & Org Effect 2 & -.64 & .39 & -.12 & & \\
\hline Step 2 & & & & & .08 & .03 \\
\hline & Org Effect 1 & -1.10 & .50 & $-.20^{*}$ & & \\
\hline & Org Effect 2 & -.80 & .50 & -.15 & & \\
\hline & Gender & .30 & .57 & .05 & & \\
\hline & Tenure & .18 & .27 & .08 & & \\
\hline & Hierarchical position & -.09 & .18 & -.04 & & \\
\hline & Age & -.66 & .24 & $-.19 * *$ & & \\
\hline Step 3 & & & & & $.19 * *$ & .10 \\
\hline & Org Effect 1 & -.96 & .47 & $-.18^{*}$ & & \\
\hline & Org Effect 2 & -1.01 & .48 & $-.19 *$ & & \\
\hline & Gender & .84 & .55 & .13 & & \\
\hline & Tenure & .10 & .26 & .04 & & \\
\hline & Hierarchical position & -.11 & .17 & -.05 & & \\
\hline & Age & -.45 & .23 & -.13 & & \\
\hline
\end{tabular}


Table 23 (continued)

\begin{tabular}{|c|c|c|c|c|c|c|}
\hline & & & & & otal & \\
\hline & Variable & $B$ & $S E B$ & $\beta$ & $R^{2}$ & $\Delta R^{2}$ \\
\hline & Avoid CMS & -.15 & .29 & -.03 & & \\
\hline & Integrate CMS & -1.16 & .43 & $-.21 * *$ & & \\
\hline & Dominate CMS & .82 & .29 & $.19^{* *}$ & & \\
\hline & Compromise CMS & -.62 & .41 & -.12 & & \\
\hline Step 4 & & & & & $.35^{* *}$ & .16 \\
\hline & Org Effect 1 & -.46 & .43 & -.09 & & \\
\hline & Org Effect 2 & -1.20 & .43 & $-.22 * *$ & & \\
\hline & Gender & .21 & .50 & .03 & & \\
\hline & Tenure & -.07 & .23 & -.03 & & \\
\hline & Hierarchical position & -.04 & .16 & -.02 & & \\
\hline & Age & -.36 & .21 & $-.11 *$ & & \\
\hline & Avoid CMS & -.20 & .26 & -.05 & & \\
\hline & Integrate CMS & -.34 & .40 & -.06 & & \\
\hline & Dominate CMS & .66 & .26 & $.16^{*}$ & & \\
\hline & Compromise CMS & -.49 & .37 & -.09 & & \\
\hline & TargetWI & 1.93 & .27 & $.47 * *$ & & \\
\hline
\end{tabular}

Note. Dependent variable: Turnover intent.

${ }^{*} p<.05,{ }^{* *} p<.01$ 
The last regression analyses (as summarized in Table 24) examined the predictability of turnover intent with conflict managements styles and instigated incivility controlling for organizational effects and demographic variables (gender, tenure, hierarchical rank and age). Results demonstrate that $22 \%(p<.01)$ of variance in turnover was explained by the control variables of organizational effects (Block $1 ; \Delta R^{2}=$ $.05, p<.01$ ) and select demographic variables (gender, tenure, hierarchical rank and age (Block $2 ; \Delta R^{2}=.03$, non-significant), along with conflict management styles (Block 3; $\left.\Delta R^{2}=.10, p<.01\right)$ and instigated incivility (Block $\left.4 ; \Delta R^{2}=.03, p<.01\right)$. The demographic variables were not significant predictors of turnover. Instigated incivility was the strongest predictor of turnover $(\beta=.21, p<.01)$ followed by the dominating conflict management style $(\beta=.17, p<.05)$.

Controlling for demographic variables increased the variance explained from $18 \%$ (regression analyses without the demographic variables) to $22 \%$. This demonstrates that the demographic variables, do have an influence on turnover intentions in spite of nonsignificance. 
Table 24

Summary of Hierarchical Regression Analyses for Organizational Effects, Demographic variables (Gender, Tenure, Hierarchical Rank, Age), Conflict Management Styles and Instigated Incivility Predicting Turnover Intent

\section{Total}

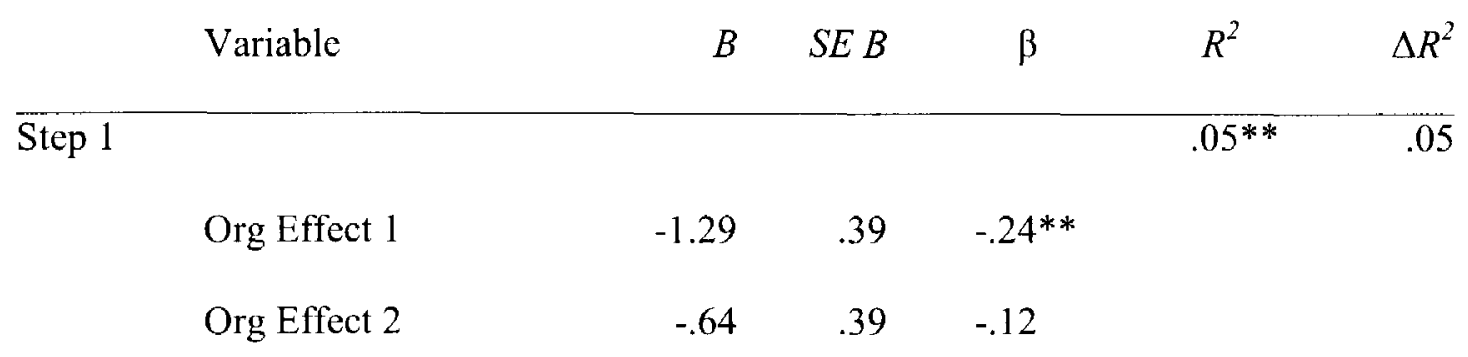

Step 2

$\begin{array}{lccc}\text { Org Effect 1 } & -1.10 & .50 & -.20^{*} \\ \text { Org Effect } 2 & -.80 & .50 & -.15 \\ \text { Gender } & .30 & .57 & .05 \\ \text { Tenure } & .18 & .27 & .08 \\ \text { Hierarchical position } & -.09 & .18 & -.04 \\ \text { Age } & -.66 & .24 & -.19^{* *}\end{array}$

Step 3

$\begin{array}{lrrr}\text { Org Effect 1 } & -.96 & .47 & -.18^{*} \\ \text { Org Effect 2 } & -1.01 & .48 & -.19^{*} \\ \text { Gender } & .84 & .55 & .13 \\ \text { Tenure } & .10 & .26 & .04 \\ \text { Hierarchical position } & -.11 & .17 & -.05 \\ \text { Age } & -.45 & .23 & -.13\end{array}$


Table 24 (continued)

\begin{tabular}{|c|c|c|c|c|c|c|}
\hline & & & & & otal & \\
\hline & Variable & $B$ & $S E B$ & $\beta$ & $R^{2}$ & $\Delta R^{2}$ \\
\hline & Avoid CMS & -.15 & .29 & -.03 & & \\
\hline & Integrate CMS & -1.16 & .43 & $-.21 * *$ & & \\
\hline & Dominate CMS & .82 & .29 & $.19 * *$ & & \\
\hline & Compromise CMS & -.62 & .41 & -.12 & & \\
\hline Step 4 & & & & & $.22 * *$ & .03 \\
\hline & Org Effect 1 & -1.06 & .47 & $-.20^{*}$ & & \\
\hline & Org Effect 2 & -1.01 & .47 & $-.19 *$ & & \\
\hline & Gender & .78 & .55 & .12 & & \\
\hline & Tenure & -.05 & .26 & -.02 & & \\
\hline & Hierarchical position & -.07 & .17 & -.03 & & \\
\hline & Age & -.36 & .23 & -.11 & & \\
\hline & Avoid CMS & -.08 & .28 & -.02 & & \\
\hline & Integrate CMS & -.80 & .44 & -.15 & & \\
\hline & Dominate CMS & .72 & .28 & $.17^{*}$ & & \\
\hline & Compromise CMS & -.54 & .40 & -.10 & & \\
\hline & InstigateWI & 1.07 & .36 & $.21 * *$ & & \\
\hline
\end{tabular}

Note. Dependent variable: Turnover intent.

${ }^{*} p<.05 .{ }^{* *} p<.01$. 
Additional Analyses

Conflict Management Styles and Workplace Incivility

One of the primary goals of this study is to explore the relationships between workplace incivility and conflict management styles; consequently, it was prudent to examine these relationships further. In that context, it was also useful to consider the role of demographic variables in predicting workplace incivility. Correlational analyses indicated that the workplace incivility (target and instigator) were related to conflict management styles. To further clarify the relationships, regression analyses were conducted to examine the predictability of conflict management styles (Block $1 ; R^{2}=.19$, $p<.01$ ), on target workplace incivility with demographic variables (gender, tenure, hicrarchical rank and age $)$ entered as a second block $\left(\Delta R^{2}=.05, p<.05\right) .23 \%$ of variance $(\mathrm{p}<.01)$ in target incivility was explained by the model. This is considered a large effect (Cohen, 1988). The integrating style $(\beta=-.31, p<.01)$ and tenure $(\beta=.27, p$ $<.05)$ were significant predictors of target workplace incivility.

In the second regression analyses, conflict management styles (Block $1 ; \Delta R^{2}=$ $.22, p<.01$ ), and demographic variables of gender, tenure, hierarchical rank and age (Block $\left.2 ; \Delta R^{2}=.05, p<.01\right)$ on instigated incivility, $27 \%(p<.01)$ of variance in instigated workplace incivility was explained by the model. The integrating style $(\beta=-$ $.30, p<.01)$, the dominating style $(\beta=-.12, p<.05)$ and tenure $(\beta=.22, p<.01)$ were significant predictors of instigated incivility. A summary of regression results are detailed in Appendices A, B and C.

Workplace Incivility, Conflict Management Styles and Perceived Job Performance. Hierarchical regression analyses did not reveal any significant relationships between 
workplace incivility and perceived job pcrformance, task and contextual dimensions. However, results of regression analyses on organizational commitment and turnover demonstrated that workplace incivility was a predictor of each of those outcomes. Organizational commitment and turnover intentions may be mediator variables between workplace incivility and perceived job performance. Consequently, regression analyses were conducted to explore the predictability of organizational commitment on task and contextual job performance. The model with organizational commitment (Block $2 ; \Delta R^{2}=$ $.02, p<.01$ ), controlling for organizational differences, (Block $1 ; \Delta R^{2}=.09, p<.01$ ) on task job performance established that organizational commitment $(\beta=.15, p<.05)$ did predict task job performance. Likewise, in regressing organizational commitment (Block $2 ; \Delta R^{2}=.06, p<.01$ ), controlling for organizational differences (Block $1 ; \Delta R^{2}=.19, p<$ $.01)$ on contextual job performance, organizational commitment $(\beta=.26, p<.01)$ predicted contextual job performance. The regression results are presented in Appendices $\mathrm{D}$ and $\mathrm{E}$.

Two other regression analyses were used to examine the predictability of turnover intentions, controlling for organizational differences, on job performance (task and contextual dimensions).. The first regression (as summarized in Appendix F) was with turnover intentions (Block $2 ; \Delta R^{2}=.03, p<.01$ ), controlling for organizational differences (Block $1 ; \Delta R^{2}=.08, p<.01$ ) on job performance (task dimension). Turnover intentions $(\beta=-.16, p<.01)$ significantly predicted task job performance. The second regression (as summarized in Appendix G) with turnover intentions (Block $2 ; \Delta R^{2}=.04$, $p<.01$ ), controlling for organizational differences (Block $1 ; \Delta R^{2}=.19, p<.01$ ) resulted in $R^{2}$ of .22 for the model. Turnover intentions $(\beta=-.19, p<.01)$ was a valid predictor of 
contextual job performance. The results of these additional regression analyses do clarify that workplace incivility is related to job performance, task and contextual dimensions.

\section{Summary}

Correlation and hierarchical regression analyses reveal relationships between variables in this study. Results of the analyses addressing each research question are summarized in Appendix H (Research Questions 1 and 2), Appendix I (Research Question 3), Appendix J (Research Question 4), Appendix K (Research Question 5) and Appendix L (Research Question 6). The integrating style is the only conflict management style that is a significant predictor of all four dependent variables of job performance (task and context), organizational commitment and turnover intent. Further, this integrating conflict management style is negatively correlated with both forms of incivility, target and instigator. The dominating style is the only other conflict management style that significantly predicted organizational commitment and turnover intent. It was also significantly correlated with both types of incivility.

Both target and instigator incivility were significantly correlated to job performance (task and contextual), organizational commitment and turnover intentions. However, neither forms of incivility were significant predictors of job performance (task nor contextual) although they did significantly predict organizational commitment and turnover intentions.

The following chapter will provide further discussion of the results and address the implications of the findings. The limitations of the study and directions for future research will also be detailed. 


\section{CHAPTER V}

\section{DISCUSSION}

\section{Introduction}

This chapter integrates the results reported in Chapter 4 with existing theory and research. Firstly, the rationale for the study is restated along with a review of the methodology used. An overview of the significant and unexpected findings; as well as consideration of these findings in light of existing research are presented. In addition, theoretical implications and limitations of the study that may affect the validity or generalizability of the results are examined. A discussion of the limitations and recommendations for future research closes the chapter.

The purpose of this study was to explore the relationship between workplace incivility and conflict management styles, as well as their impact on perceived job performance, organizational commitment and intent to turnover. Consequently, the following research questions were addressed:

1. What is the relationship between workplace incivility and conflict management styles of (a) dominating, (b) integrating, (c) compromising, (d) accommodating, and (e) avoiding?

2. Are there differences between the relationships of conflict management style and workplace incivility from the perspectives of targets versus instigators of incivility?

3. Do conflict management styles affect the impact of workplace incivility on employee's job performance, commitment to their organization and turnover? 
4. After controlling for select demographic variables, what is the relationship between workplace incivility, conflict management styles and perceived job performance?

5. After controlling for select demographic variables, what is the relationship of workplace incivility and conflict styles on organizational commitment?

6. After controlling for select demographic variables, what is the impact of workplace incivility and conflict styles on turnover intentions?

As explained in Chapter III, this quantitative study applied a non-experimental correlational design to explore and examine relationships between workplace incivility, conflict management styles, perceived job performance, organizational commitment and intent to turnover. Cross-sectional survey methodology was used to gather self-report data from workers in three Midwestern private organizations (one in long term healthcare and the other two in manufacturing) to study the relationships between the research variables. A self report questionnaire on employees' perceptions of their experiences of workplace incivility, their preferred conflict management styles, job performance as well as their commitment toward their organizations and turnover intent was administered via hard copy (for two organizations: one in healthcare, the other in manufacturing) or webbased survey link (from one manufacturing organization).

Workplace incivility was measured using the Workplace Incivility Scale (WIS) developed by Cortina, Magley, Williams and Langhout (2001). The original WIS was used to measure target incivility. A modified version reversing the perspective to instigator was used to measure frequency of instigated incivility. Further, conflict management styles (problem-solving, yielding, avoiding, compromising and forcing) were assessed with the 20-item DUTCH Test for Conflict Handling (De Dreu, Evers, 
Beersma, Kluwer, \& Nauta, 2001). A job performance (task and contextual dimensions) mcasure (Borman \& Motowidlo, 1993) was also used along with Meyer and Allen's (1997) organizational commitment scale (affective commitment and continuance commitment). The intent to turnover was assessed with a subscale from the Michigan Organizational Assessment Questionnaire (MOAQ) (Seashore, Lawler III, Mirvis, \& Camman, 1983). Lastly, demographic questions were also included to gather data about the sample population. Survey data obtained from 289 survey returns over a period of three weeks were analyzed through correlational and hierarchical regression analyses.

\section{Major Findings}

Much research in the past 10 years established many of the antecedents and outcomes of workplace incivility. However, this is the first study finding empirical support for linking workplace incivility with conflict management styles. Results from this exploratory study suggest that conflict management styles may play a role both as antecedent or potential way to manage workplace incivility. Previously, separate bodies of literature evolved around workplace incivility and conflict management styles.

Workplace incivility is a problem for organizations. Although $86 \%(N=281)$ of the sample reported having experienced some form of incivility in the workplace within the past year, only $12 \%$ experienced incivility on "sometimes" to "always" levels of frequency. This compares with $76 \%(N=1167)$ of public sector employees studied by Cortina et al. (2001) reportedly experiencing incivility. In a study investigating interpersonal and organizational incivility, Reio and Ghosh (in press) found that $54 \%$ of 402 respondents from 11 industries admitted to instigating incivility at least once a year, with $12 \%$ on a frequent basis. In contrast, $90 \%(N=284)$ of the present study sample 
admitted to having engaged in some form of incivility within the past year although only $6 \%$ reportedly instigated such behavior on the level of frequency described in the scale as "sometimes", "often", or "always".

The frequency of incivility from either a target or instigator perspective is a serious cause for concern in organizations, particularly in light of the negative effects on organizational outcomes. This study demonstrates that both workplace incivility and conflict management styles impact, through varying degrees of influence, organizational outcomes of perceived job performance, organizational commitment and turnover intentions.

\section{Workplace Incivility and Conflict Management Styles}

This study, in addressing Research Questions 1 and 2, revealed that how conflicts are managed (as determined through preferred conflict style) is related to, and determines the likelihood of incivility. Although the compromising, integrating and dominating styles were correlated to incivility, only the integrating and dominating styles significantly predicted incivility.

Target incivility and conflict management styles. Correlational analyses showed that individuals who used the integrating or compromising styles of conflict management tend to experience less incivility. Further, the integrating style decreased the likelihood of individuals experiencing incivility as targets. The use of integrating and compromise styles reflect individuals' concern for both self and other person's goals and a preference for joint problem-solving and mutual gain (Rahim, 1985). Such conflict oricntations are less adversarial and diffuse conflict. In contrast, those who use the dominating style reportedly experienced more incivility. The use of the dominating style increased the 
likelihood of individuals being targets of uncivil behaviors. This is substantiated in the literature on retaliatory actions from targets of negative behaviors (Lee \& Brotheridge, 2006; Bies \& Tripp, 2001; Greenberg \& Barling, 1999). Those who use the dominating style are more concerned about achieving personal goals and do so by ignoring the other person's needs (Rahim, 1985). It is conceivable then, that such incompatibility of concerns and goals relate to being uncivil or perceived to be uncivil by others, who then may retaliate in kind.

Instigated incivility and conflict management styles. Instigated incivility was more highly correlated than target incivility to the dominating style of managing conflict. Instigators are more likely to use the dominating style, reflecting a stronger concern with having their own needs met at the expense of others' needs, which may then result in less attention being paid to being "nice" or civil in interpersonal interactions in the workplace. In contrast, the use of either integrating or compromise conflict style was associated with lower levels of instigated uncivil behaviors. This is consistent with the literature on conflict management styles establishing that the integrative style reflects a win-win orientation that considers the needs of both self and others (Rahim, 1985). Such an orientation may be reflected in personal interactions that are more respectful of others.

Generally, individuals who manage conflicts in an integrative way experience fewer incidents of incivility and are less likely to engage in uncivil behaviors. In contrast, the dominating style is not only associated with more frequent instigated uncivil behaviors, but also predicts instigated incivility. The relationship between workplace incivility and conflict management styles supports Friedman's et al. (2000) finding that the conflict style used has a direct impact on the degree a person's work environment is 
affected by conflict. Prior research established that poorly managed conflict affects the level and frequency of future conflict (Meyer, 2004). This is consistent with Andersson and Pearson's (1999) incivility spiral of retaliatory uncivil behaviors which may then lead to more aggressive deviant behaviors. They also posit that individuals can and do make a choice to prevent or stop the situation from spiraling or escalating. This study demonstrates that the integrating and dominating styles predict incivility. However, neither the compromise nor the avoiding style influenced incivility. These findings are supported in part by previous research showing that integrative and compromising styles are correlated to lower frequency and intensity of conflicts while dominating, avoiding, and accommodating were associated with higher levels and frequency of conflict (Barki \& Hartwick, 2001).

In examining the relationship between target and instigator incivility, correlational analysis indicated a medium to high degree of association between targets and instigators $(r=.557)$. This implies that a proportion of those who experienced incivility also admit to being instigators of incivility. This finding appears to be consistent with Pearson and Porath's (1999) theory of an incivility spiral pointing to a reciprocating nature of incivility, which begins with a perceived incivility followed by a counter-incivility. However, although target and instigator incivility were correlated, the degree of correlation also indicated that there are differences between the two perspectives of incivility. This corroborates Blau and Andersson's (2005) exploratory findings that the two dimensions of target and instigator incivility were distinct from each other. Workplace Incivility, Conflict Management Styles (CMS) and Job Performance 
To date, this is the first empirical study exploring the relationship between workplace incivility and worker-perceived job performance. In addressing Research Question 3, findings extend previous research on workplace incivility and support extant literature on conflict management styles.

Target incivility, CMS and Job Performance. Both task and contextual dimensions of job performance were significantly and negatively associated with target incivility. The more workers perceived being incivility targets, the lower their perceived job performance, particularly on the contextual dimension. However, hierarchical regression results indicated that target incivility did not increase the likelihood of lower job performance on either the task or contextual dimension.

The integrating style increased the likelihood of better job performance, both on the task and contextual dimensions. This finding is consistent with previous empirical research establishing that the problem-solving style (which consist of either the integrating or compromise style) is positively related to job performance (Rahim et al., 2001). In a study on work teams in China, Tjosvold, Hui, and Yu (2003) found that a cooperative mode of conflict management is related to team task reflexivity, which in turn impacts team performance. The integrating style was more strongly correlated to contextual job performance than task job performance. Contrary to expectations, neither the dominating nor the avoiding style was a significant predictor of job performance. Again, this appears to support the findings from Rahim et al. (2001). Instigated Incivility, CMS and Job Performance. Those who instigated incivility more frequently reported lower perceived levels of task and contextual job performance. Similar to target incivility, this correlation is higher on the contextual dimension, which 
is focused on behaviors contributing to organizational effectiveness, but not on core job tasks (Motowidlo, 2003). Like targets of incivility, instigated incivility was not predictive of task or contextual job performance.

Both target and instigator incivility correlated to each of the two dimensions of job performance (task and contextual). There are differences in relationships to task and contextual performance. As expected, incivility (either target or instigator) is more strongly correlated to contextual job performance. These findings are consistent with prior research that counterproductive behaviors are related to both task and contextual performance (also defined as organizational citizenship behaviors); with a stronger correlation with contextual performance (Viswesvaran, Schmidt, \& Ones, 1999; Sackett, 2002). The unexpected finding of non significance of workplace incivility (target and instigator perspectives) as predictors of perceived job performance, particularly for the contextual dimension of job performance, may have been due to the self report measures where people have a tendency to see themselves in the best light by scoring themselves highly on perceived performance and under-reporting any negative self behaviors such as being uncivil to others. This social desirability bias and perhaps, fear of reprisal, may have affected the data (Donaldson \& Grant-Vallone, 2002). Workplace Incivility, Conflict Management Styles (CMS), Organizational Commitment and Intent to Turnover

Uncivil behaviors and conflict management styles (integrate and dominate styles) directly influenced both organizational commitment and turnover intentions. This indicates that incivility has deleterious effects, specifically lessening one's sense of commitment and belonging to an organization as well as increasing intentions to leave 
the organization. There is empirical evidence supporting the relationship between organizational commitment and turnover intentions, that the first is precursor to the other (Hom \& Griffith, 1995; Mowday et al., 1982).

Target incivility, CMS, Organizational Commitment and Intent to Turnover. Individuals who reported experiencing uncivil workplace behaviors considered quitting more often as well as feeling more detached from their organizations. This is consistent with past research showing that interpersonal conflict (including rudeness, disagreement and shouting) (Thomas et al., 2005), and workplace incivility related negatively to organizational commitment (Pearson et al., 2000). Use of the integrative conflict management style decreased the frequency of experienced incivility and increased the likelihood of having a stronger sense of attachment and belonging to the organization. Likewise, individuals using the integrative style were less inclined to have intentions to quit. In contrast, those using the dominating style tend to be targets of incivility, were more likely to want to quit and felt less attached to their organizations. The dominating style has been associated with higher levels of conflict and job stress (Friedman et al., 2000); job stress leads to increased turnover intentions (Giebels \& Janssen, 2005). Instigated Incivility, CMS, Organizational Commitment and Intent to Turnover. Individuals who instigated incivility tended to use the dominating conflict management style and were less committed to their organizations. They were also more likely to want to leave their organizations. However, the use of the integrative style reflected in lower levels of instigated incivility, thereby positively influencing organizational commitment as well as lowering turnover intentions. The finding that instigated incivility negatively impacts organizational commitment is a new contribution to the literature. A climate of 
incivility appears to affect the sense of attachment and belonging to an organization, not just for those who are targets of incivility but also for those who engage in incivility. These findings extend previous research documenting that incivility affects targets, witnesses and others in the organization (Montgomery, Kane, \& Vance, 2004; Lim et al., 2008; Miner-Rubino \& Cortina, 2007).

Study findings emphasize the importance of an integrative approach to conflict management in the workplace because of the influence on positive organizational outcomes. Empirical support was found for a significantly positive relationship between the integrative style and organizational commitment. Although this result was contrary to Munduate and Dorado's (1998) finding that the integrative style was not correlated to organizational commitment, other research established that cooperative and confirming approaches led to higher level of employee trust and commitment (Barker et al., 1988). In addition, the use of the dominating conflict management style predicted a lower level of organizational commitment. A collaborative approach at work influences perceptions of a sense of belonging to an organization. On the other hand, the implication is that a forceful and competitive approach focuses less on the organization and perhaps more on winning on a personal level.

Although both target and instigator incivility predict turnover, targets of incivility were much more likely to have higher turnover intentions than instigators. The growing literature on workplace incivility showed that the experience of incivility as a target is a strong predictor of turnover (Cortina et al., 2001; Lim \& Cortina, 2005). Interestingly, instigated incivility, to a lesser degree than target incivility, was also predictive of intentions to turnover. Blau and Andersson (2005) found that distributive justice, job 
dissatisfaction, and work exhaustion were antecedents of instigated incivility. It stands to reason that instigated incivility does influence turnover intentions.

The integrating and dominating conflict management styles significantly influence intent to turnover. The integrating style negatively predicts turnover intent. In contrast, the increased use of the dominating style corresponds with a higher intent to quit. These findings appear to be consistent with those of Meyer's (2004) study where the use of the dominating (forcing) style was related to negative work indicators (workplace accidents, absenteeism, and overtime).

Demographic variables, Workplace Incivility and Conflict Management styles on Work

\section{Outcomes}

Previous research on both incivility and conflict management styles have, to varying degrees, shown that demographic variables of gender, age, organizational rank and organizational tenure were influencing factors on either or both of these constructs. Further, these demographic variables have also been used in studies on the dependent variables of job performance, organizational commitment and turnover intentions. In the

present study, Research Questions 4, 5 and 6 considers the effect of gender, age, organizational rank and tenure by controlling their effects in subsequent regression analyses to determine their contributions in combination with workplace incivility and conflict management styles on each of the dependent variables. Gender and tenure were non-significant predictors in all the regression models with workplace incivility and conflict management styles on perceived job performance, organizational commitment and turnover intentions. 
Additional analyses involved examining the predictive relationships between the demographic variables of gender, tenure, hierarchical rank and age, with conflict management styles on incivility; only tenure was significant for both target and instigated incivility. It appears that the longer the length of time in an organization, the more likely individuals will experience incivility as well as engage in incivility. The lack of significance for gender and age is inconsistent with Reio and Ghosh's (in press) research establishing that younger Caucasian males were more likely to instigate incivility in the workplace. Others have also found that females were more likely than males to be targets of incivility (Cortina et al., 2001; Cortina et al., 2002; Young et al., 2007). Women in general, are more likely than men, to perceive certain behaviors as inappropriate or uncivil (Young et al., 2007). However, Porath and Pearson (2000) found that men and women were just as likely to be targets of incivility. The result of gender nonsignificance may be due to sampling error or bias, given that in one of the organizations; almost $90 \%$ of the respondents were male, while in the second organization, more than $80 \%$ of the respondents were female.

The finding that hierarchical rank was not a significant predictor of incivility was unsupported by literature. Men in higher organizational rank were more likely to be instigators of workplace incivility (Pearson et al., 2001). Hierarchical rank may have been an issue because there were missing values on a number of responses in the current study. Additionally, some organizational positions did not fit into the categories provided in the survey.

Job Performance. In controlling for demographic variables, age and hierarchical rank were significant predictors of the task dimension of job performance when regressed with 
incivility (either target or instigator) and conflict management styles. However, incivility (either target or instigator) remained a non significant predictor in the regression model. Inclusion of the demographic variables with conflict management styles increased the variance explained in task job performance. Specifically, age correlated negatively with the task dimension. Empirical research has produced mixed results with age as a predictor of task job performance (Shultz \& Adams, 2007). It is possible that given the industries from which the sample was collected, younger workers perceive themselves as being better at their tasks than older workers. As workers move up in their organizations, it appears that their perception is that they do well at their jobs.

However, neither age nor hierarchical rank was a significant predictor of contextual performance. The finding that age does not predict contextual performance (organizational citizenship behavior) is supported by previous research (Organ \& Konovsky, 1989).

Organizational Commitment. Age was the only demographic variable that significantly influenced organizational commitment from both instigated and target incivility perspectives. This positive correlation may indicate that older workers are more likely to have feelings of attachment or loyalty to their organization as they get more invested in the organization over time (retirement plans, benefits, position etc.) (Becker, 1960). Similar to the current study, McGhee and Satcher (1995) found that rank and tenure were not significant predictors of organizational commitment. However, in contrast to the present study's finding, the researchers did not find age to be a significant predictor. This is consistent with the findings in a longitudinal study conducted by Bateman and Strasser 
(1984). In contrast, other studies established age as a predictor of organizational commitment (Morris \& Sherman, 1981; Steers, 1977).

Turnover Intentions. Prior empirical research has shown that gender, age, and tenure were significant predictors of turnover intentions (Mobley, 1982; Mobley et al., 1978, 1979). In the present study, target and instigated incivility resulted in differing predictive values of the demographic variables on turnover intentions. Only age was a significant predictor for turnover intent when target incivility and conflict management styles, along with demographic variables were entered in a regression analysis. The negative predictive value of age indicated that the younger the worker, the higher the intent to leave. This finding seems to be consistent with established research (Lambert, Hogan \& Barton, 2001). In contrast, age did not appear to have a significant influence when instigated incivility and conflict management styles were regressed on turnover intent. Perhaps this is not unexpected since researchers noted that a study on a sample of technical professionals, age was so marginally significant a predictor of turnover, that it was considered of little practical significance (Finegold, Mohrman, \& Spreitzer, 2002). Unexpected findings

In investigating scale reliabilities, the discovery that the Accommodate and Avoid subscales for the DUTCH conflict management styles instrument had $\alpha$ reliabilities below the recommended .60 value was unexpected. These challenges were inconsistent with previous studies utilizing this instrument (De Dreu et al., 2001; Euwema \& Van Emmerik, 2007; Rizkalla et al., 2008). This resulted in the removal of the Accommodate subscale entirely, which may have impacted the subsequent analyses with conflict management styles. The modification of the Avoid subscale, by removing one of the 
items, improved reliability sufficiently to justify the inclusion of the subscale. Ultimately, the avoid conflict style did not turn out to be a significant predictor in any of the regression analyses.

Another unexpected finding relates to the non-significance of workplace incivility in predicting job performance, both task and contextual dimensions. Contextual job performance, which involves persistence and extra effort as well as cooperation with, and support of others in the workplace (Sackett, 2002) was not influenced by workplace incivility. Consequently, additional regression analyses were conducted to briefly explore the possibility that there may be intervening variables between incivility and job performance. The results indicated that organizational commitment and turnover were both mediators in the relationship between workplace incivility and perceived job performance.

\section{Theoretical Implications}

The results of this study suggest that how people treat each other and the manner in which incivility is managed in the workplace have a negative impact on organizational outcomes. Previously, conflict management styles have not been examined in connection with workplace incivility. This study builds on the extant literature and contributes toward a new framework for understanding workplace incivility. Conflict styles are considered to be both a behavioral approach and personal disposition (Ruble \& Schneer, 1994), and found to influence workplace incivility. This finding links two bodies of literature and provides a new theoretical framework for understanding workplace incivility and its effects on organizational outcomes. 
From another perspective, these exploratory findings demonstrate that conflict styles may be both an antecedent and antidote to workplace incivility. A dominating style of conflict predicts incivility while an integrative style reduces the likelihood of incivility. This study also clarifies that a more collaborative or integrative approach has a significant and positive impact on workplace relationships and organizational effectiveness. This is consistent with prior research establishing that a collaborative (integrative) conflict management style leads to more effective outcomes (Chusmir \& Mills, 1989; Meyer, 2004).

The current study also covered new ground in that workplace incivility was considered from both target and instigator perspectives together to explore if they are related to each other and in combination, if they have differing influence on work outcomes. Experiences of incivility lead to reciprocating uncivil behaviors, indicating the retaliatory nature of incivility. This finding substantiates the theoretical "tit for tat" model of incivility posited by Andersson and Pearson (1999). Further, the finding that target and instigated incivility are correlated is supported by empirical research that incivility exchange and escalation is attributed to retaliatory behavior tendencies of individuals against negative behaviors targeted at them (Bies \& Tripp, 2001; Greenberg \& Barling, 1999; Skarlicki \& Folger, 2004). The differing degree of relationships between incivility targets and instigators with conflict management styles, organizational commitment and turnover point to incivility consisting of two related, but separate constructs. Empirically, this corroborates Blau and Andersson's (2005) theory and exploratory findings on these constructs. Together, these findings substantiate and extend established theory and research. 
Relationships between incivility and perceived job performance, both task and contextual dimensions, through organizational commitment and turnover, provide new insight that incivility indirectly affects organizational effectiveness, and ultimately, the bottom line of organizations. This finding is supported by the associated finding that how conflict is managed does have a significant impact on perceived job performance, both task and contextual dimensions. Conflict, when managed ineffectively, poses a threat both on individual and organizational levels. Meyer (2004) found that poorly managed conflict in the workplace affects the level and frequency of future conflict and has a negative effect on productivity and work performance.

The combined effects of workplace incivility and conflict management styles on organizational commitment and turnover cover new ground in the literature. The results imply that the development of a new theory to help explain the antecedents and outcomes of workplace incivility is warranted.

\section{Limitations}

Several limitations in research study design are noted. The use of single-source, self-report methodology raises concerns of potential common method bias. However, as Spector (1987) demonstrated, properly developed and standardized instruments in research studies are resistant against method variance. All the scales used in this study have been used previously and have established reliability. Further studies on incivility and conflict management styles outcomes could incorporate objective data, for instance, organizational records pertaining to absenteeism to confirm turnover intent, or corroborating data from supervisors or co-workers in regard to job performance, conflict management styles and uncivil behaviors. 
A cross-sectional survey design with data collected at a single point in time precludes causal inferences. Longitudinal research is recommended to overcome this limitation. Examining the behaviors and responses of workers over time would improve validity. Experimental studies would be helpful in researching cause and effect between incivility, conflict management styles and work outcomes.

This study was performed in spring 2009 , during the most serious economic recession in the U.S. since the 1930's. How this might have affected respondents is unknown. However, responses to items making up certain variables (e.g., intent to turnover) could have been affected. Sampling bias may have occurred due to the voluntary nature of the data collection procedure in the three organizations. Employees were informed that participation was voluntary, leading to some opting out of the survey. The smallest sample consisted of 19 respondents who completed the survey on-line, which may also have introduced another source of bias as compared to the organizations that completed hard-copy surveys. This group was also a convenience sample; the online survey was available only to corporate employees with organizational email addresses. Further, the pooling of three different samples for analyses may have raised generalizability concerns. Investigating each sample separately was not practical because sample size would have been inadequate for statistical analyses. This issue was addressed by controlling for organizational differences.

Lastly, the low reliabilities of the two conflict management styles subscales of Accommodate and Avoid resulted in the removal of the former from analyses, and the modification of the latter. This may have impacted the outcomes of the regression 
analyses for the study. Repeating this study with different populations and samples may address this unexpected issue.

\section{Recommendations for further research}

This study addressed exploratory questions about the relationships between workplace incivility and conflict management styles in the context of organizational outcomes. While the study established a relationship between conflict management styles and workplace incivility, further research is necessary. New questions have also emerged from the results that bear further investigation. Consequently, there are a number of recommendations for future research.

Firstly, although this study identified relationships between the integrating and dominating styles with workplace incivility, two of the conflict management styles subscales (Avoid and Accommodate) could not be fully considered in the analyses. The psychometric properties of these two subscales warrant further investigation by using similar or different organizational samples. Other conflict management style instruments may also be used in future studies.

The current study revealed a correlation between workplace incivility and job performance, but no significant finding for workplace incivility predicting job performance. This is a previously unexplored connection that warrants further examination. Research established that job related outcomes are impacted negatively by workplace incivility. For instance, Pearson et al. (2000) found that targets disengaged or reduced organizational and helping activities, as well as reduced work efforts. These activities relate to job performance, particularly on the contextual dimension covering helping others and work effort (Borman \& Motowidlo, 1993). Additional analyses 
suggest that organizational commitment and turnover intentions may be mediators between workplace incivility and job performance. Future studies should examine the role of mediator variables in order to determine the relationship between incivility and job performance. Workplace incivility imposes costs on organizations. This explicates a need to concentrate on research focusing on work related outcomes.

As organizations are struggling to compete in a globally depressed economy, many have engaged in strategic HRD interventions of downsizing, outsourcing as well as cost reduction measures. The samples from the manufacturing sector had already experienced some organizational restructuring and layoffs. These are conditions and variables that need to be considered in future studies. The effects of such organizational change impact the occurrence of workplace incivility and job-related outcomes as well as how conflict is managed.

This exploratory study suggests that the dominating style could be a potential trigger for workplace incivility, whereas the integrating style may provide a means to curb or manage incivility. Further studies should examine this potential connection, perhaps by experimental studies or within training contexts. Researchers should systematically examine the efficacy of proposed interventions such as trainings since conflict management trainings have been shown to increase individuals' use of the integrative conflict management style (Johnson, 1991). An experimental or quasiexperimental design may be useful in determining any real effects of changes pre and post training. Further investigation is needed on antecedents to incivility that may be managed or controlled at the organizational level. These include job stressors and organizational justice variables. 
In addition, any changes in policies relating to incivility and leadership strategies should also be carefully monitored and studied. Future studies should examine the organizational culture and its effects on conflict management and incivility levels. Further, research on conflict styles of supervisors and managers with incivility both at peer and subordinate levels may yield pertinent information for organizational development. To date, there is no study on supervisory conflict styles and the influence on workplace incivility.

Empirical studies on instigated incivility are still limited since research has primarily focused on targets of incivility. Preliminary findings from the current study indicate that both perspectives are correlated yet distinct. Further research examining the antecedents and outcomes of instigated incivility is warranted. The current study gathered data on both target and instigator perspectives from the same subjects and correlational analysis indicated that target and instigator incivility are related. Qualitative studies will help clarify the nature of the relationship between target and instigator behaviors. The use of corroborating and objective data from supervisors or peers in evaluating or reporting of uncivil behaviors will also be beneficial.

This study was limited to three organizations in the Midwest, one in long term healthcare and the other two in manufacturing. Future studies could examine population samples from different industries and geographic regions, as well as organizations of varied sizes. Such organizations may include hospitals, or other types of service providers as well as other manufacturing organizations. Future studies should also examine the role of other demographic variables. For instance, although two manufacturing samples were 
used in this study, none of the respondents were unionized. Further research exploring the possible differences between unionized and non-unionized workplaces is needed.

The use of alternative research designs may provide more information and causal inferences regarding workplace incivility, conflict management styles and workplace outcomes. Qualitative and longitudinal studies will provide further insight as to the extent and nature of the relationship between incivility, conflict styles and workplace outcomes.

Implications for Human Resource Development

This study has practical implications from human resource management (HRM) and development (HRD) perspectives. The relationship between workplace incivility and conflict management styles, specifically, the integrating and dominating styles and their influence on organizational outcomes raise some major implications for human resource management and development at both individual and organizational levels.

Consequently, macro and micro level strategies are imperative to deal with the problem of incivility as well as improving organizational learning and effectiveness. Various recommendations are presented.

On an organizational level, HRD professionals may wish to consider macro level strategies to limit incivility and mitigate its effects by establishing policies and codes of conduct aimed specifically at encouraging respect and discouraging incivility (Pearson et al., 2000; Reio \& Ghosh, in press). According to Cortina (2008), the organizational environment may perpetuate or inhibit incivility. Because workplace norms also develop from traditions, culture as well as policies (Pearson et a1., 2000), organizational leaders need to be vigilant in modeling and establishing desired behavioral standards. Further, enforcement of these standards is critical in ensuring that the norms of civility are not 
eroded. Left unchecked, uncivil behaviors erode the norms of civility and become part of an organization's culture (Andersson \& Pearson, 1999; Pearson et al., 2000).

Organizational changes need to be managed carefully since major changes such as budget reductions, increased diversity of the workforce and changes in management, are associated with increased verbal and passive aggression (Baron \& Neuman, 1996). Such changes, if planned and executed carefully, will lead to a less traumatic transition time for employees, minimizing the potential for negative behaviors including incivility. The involvement of HRD professionals in change processes, both in the short term and long term, is essential. The adoption of a long term approach to organizational planning, strategies and operations will also limit interpersonal deviant behaviors (Jelinek \& Ahearne, 2006).

Given the increased use of virtual and other types of teams in organizations and attention on workforce diversity; HRM professionals may consider incorporating behavioral screening or assessment of conflict management styles in the recruitment and selection process in organizations. The use of such tools may assist in identifying appropriate skills for team based efforts. Further research into the use of these assessments would clarify their efficacy and role in the selection process. Reio and Ghosh (in press) suggest the use of role plays in interviews to help identify attitudes and behaviors that may be a liability to the organization. They assert that this technique will provide further information that may otherwise be circumvented by interviewees providing socially desirable responses in a regular interview. Pearson et al. (2000) recommend promoting civility throughout organizations through not only written 
policies, but at new hire orientations as well. The emphasis on respectful behavior needs to be evident at all levels of an organization.

HRD professionals may use the study results to explore, at both macro and micro levels, training interventions that will address gaps in individual and group interpersonal skills. HRD professionals should help organizations focus on training interventions to improve interpersonal skills, particularly conflict management or communication skills; focusing on training employees in behaviors consistent with the integrating conflict management style. Such trainings need to be part of an organization's overall learning strategy. If individuals or groups feel like they have been targeted for training because they were perceived as problematic, the training intervention will fail. Gross and Guerrero's (2000) finding that the integrate style is perceived as the most effective style has implications for organizational effectiveness. It supports the recommendation to equip and train employees to adopt this collaborative manner of managing organizational conflict, which includes workplace incivility. Maher (1986) found increased effectiveness in conflict management after conflict management training for a group of school directors. Johnson (1991), in a quasi-experimental study found that conflict management training improved conflict management skills of teachers. The researcher established that the teachers increased their use of integrative and compromising strategies, at the same time, decreased their use of dominating and avoiding strategies. Significant differences were found on pre and post tests as well as six months after the training. In another study using a quasi-experimental design on a sample of policemen, Zacker and Bard (1973) found that affective-behavioral oriented training to be superior in effectiveness to lecture 
format. Such studies provide a persuasive argument for organizations to train employees in conflict management skills.

Training interventions could also include mediation or conflict management trainings for supervisors, managers and other leaders. This may be considered a preventative strategy since management, once equipped, can identify and manage uncivil behaviors or conflicts before they escalate. Other human resource development interventions include mentoring and coaching of employees, particularly those in management positions, to improve performance and interpersonal skills, helping them model civility and building their skills in identifying incivility before it proliferates in the organization.

The results in this study may also inform HRD professionals in the field of career development. Because role-modeling is essential for promulgating civility in organizational culture (Pearson et al., 2000) and leadership effectiveness is related to the use of appropriate conflict management styles (Gross \& Guerrero, 2000), career development in organizations need to consider incorporating leadership programs that emphasize collaborative strategies and appropriate modeling behaviors.

Previous literature on incivility and conflict has remained separate. However, this study highlights a need for a multidisciplinary approach to theory building in order to bridge the gap between research and practice. Practical applications can be drawn from theoretical knowledge that can impact organizational efficiency and effectiveness.

\section{Conclusion}

The findings in this exploratory study contribute to the existing literature on workplace incivility and conflict management styles by linking the two constructs. This 
study establishes that conflict management styles are related to workplace incivility and in fact, conflict styles predict incivility. Findings suggest that incivility and conflict management styles together have varying degrees of impact on job performance, organizational commitment and turnover intentions. The study also substantiated Andersson and Pearson's (1999) theoretical model of an incivility spiral. The assumption made in this study is that incivility leads to, or is a part of, organizational conflict. The hypothesized conceptual link between workplace conflict and workplace incivility has some support in the literature. For instance, researchers and scholars such as Rahim (2002), Wall and Callister (1995) posited that amongst other factors, differences in values and perceptions of behaviors lead to conflict in the workplace. It follows that uncivil behaviors may lead to conflict or be an antecedent to conflict. This conceptual link requires further investigation.

This research indicates that more studies are needed to investigate ways and means of dealing with the pernicious problem of workplace incivility at both organizational and individual levels. The relationship between target and instigator incivility needs to be explored further as does the relationship between incivility and conflict management styles. The impact of incivility on organizational outcomes such as job performance and other workplace indicators also warrant further research. 


\section{REFERENCES}

Allen, N. J. (2003). Organizational commitment in the military: A discussion of theory and practice. Military Psychology, 15, 237-253.

Andersson, L. M., \& Pearson, C. M. (1999). Tit for tat? The spiraling effect of incivility in the workplace. Academy of Management Review, 24, 452-471.

Angle, H. L., \& Perry, J. (1981). An empirical assessment of organizational commitment and organizational effectiveness. Administrative Science Quarterly, 26, 1-14.

Antonioni, D. (1998). Relationship between the big five personality factors and conflict management styles. International Journal of Conflict Management, 9, 336-355.

Aquino, K., Galperin, B. L., \& Bennett, R. J. (2004). Social status and aggressiveness as moderators of the relationship between interactional justice and workplace deviance. Journal of Applied Social Psychology, 34, 126-138.

Aquino, K., Tripp, T. M., \& Bies, R. J. (2001). How employees respond to interpersonal offense: The effects of blame attribution, offender status, and victim status on revenge and reconciliation in the workplace. Journal of Applied Psychology, 86, $52-59$.

Aquino, K., Tripp, T. M., \& Bies, R. J. (2006). Getting even or moving on? Power, procedural justice and types of offense as predictors of revenge, forgiveness, reconciliation, and avoidance in organizations. Journal of Applied Psychology, $91,653-668$. 
Barbuto, J. E., Jr., \& Xu, Y. (2006). Sources of motivation, interpersonal conflict management styles, and leadership effectiveness: A structural model. Psychological Reports, 98, 3-20.

Barker, J., Tjosvold, D., \& Andrews, I. R. (1988). Conflict approaches of effective and ineffective managers: A field study in a matrix organization. Journal of Management Studies, 25, 167-178.

Barki, H., \& Hartwick, J. (2004). Conceptualizing the construct of interpersonal conflict. International Journal of Conflict Management, 15, 216-244.

Baron, R. A., \& Neuman, J. H. (1996). Workplace violence and workplace aggression: Evidence on their relative frequency and potential causes. Aggressive Behavior, $22,161-173$.

Baron, R. A., \& Neuman, J. H. (1998). Workplace violence and workplace aggression: Evidence concerning specific forms, potential causes, and preferred targets. Journal of Management, 24, 391-419.

Barrick, M. R., \& Mount, M. K. (1991). The big five personality dimensions and job performance: A meta-analysis. Personnel Psychology, 44, 1-26.

Barsky, A. E., \& Wood, L. (2005). Conflict avoidance in a university context, Higher Education Research \& Development, 24, 249-264.

Bateman, T. S., \& Strasser, S. (1984). A longitudinal analysis of the antecedents of organizational commitment. The Academy of Management Journal, 27, 95-112.

Bean, A. G., \& Roszkowski, M. J. (1995). The long and short of it. Marketing Research, 7, 20-26. 
Becker, H. (1960). Notes on the concept of commitment. American Journal of Sociology, $66,32-42$.

Bennett, R. J., \& Robinson, S. L. (2000). Development of a measure of workplace deviance. Journal of Applied Psychology, 85, 349-360.

Bennett, R. J., \& Robinson, S. L. (2003). The past, present and future of workplace deviance research. In R. A. Giacolone, \& J. Greenberg (Eds.), Organizational behavior: The state of the science (2nd ed., pp. 247-281). Mahwah, NJ: Erlbaum.

Berry, C. M., Ones, D. S., \& Sackett, P. R. (2007). Interpersonal deviance, organizational deviance, and their common correlates: A review and meta-analysis. Journal of Applied Psychology, 92, 410-424.

Bies, R. J., \& Tripp, T. M. (2001). A passion for justice: The rationality and morality of revenge. In R. Cropanzano (Ed.), Justice in the workplace: From theory to practice, Vol. 2. (pp. 197-208). Marwah, N.J.: Erlbaum.

Blake, R. R., \& Mouton, J. S. (1964). The managerial grid. Houston, TX: Gulf.

Blake, R. R., \& Mouton, J. S. (1970). The fifth achievement. Journal of Applied Behavioral Science, 6, 413-426.

Blake, R. R., \& Mouton, J. S. (1981). Management by grid principles or situationalism: Which? Group and Organization Studies, 6, 439-455.

Blau, G., \& Andersson, L. (2005). Testing a measure of instigated workplace incivility. Journal of Occupational and Organizational Psychology, 78, 595-614.

Borman, W. C., \& Motowidlo, S. J. (1993). Expanding the criterion domain to include elements of contextual performance. In N. Schmit \& W. C. Borman (Eds.), Personnel selection in organizations (pp. 71-98). San Francisco: Jossey-Bass. 
Brahnam, S. D., Margavio, T. M., Hignite, M. A., Barricr, T. B., \& Chin, J. M. (2005). A gender-based categorization for conflict resolution. The Journal of Management Development, 24, 197-208.

Brewer, N., Mitchell, P., \& Weber, N. (2002). Gender role, organizational status, and conflict management styles. Journal of Conflict Management, 13, 78-94.

Burke, R.J. (1970). Methods of resolving superior-subordinate conflict: The constructive use of subordinate differences and disagreements. Organizational Behavior and Human Performance, 5, 393-411.

Buss, A. H. (1961). The psychology of aggression. New York: Wiley.

Callanan, G. A., Benzing, C. D., \& Perri, D. F. (2006). Choice of conflict-handling strategy: A matter of context. The Journal of Psychology, 140, 269-288.

Canary, D. J., \& Spitzberg, B. H. (1987). Appropriateness and effectiveness perceptions of conflict strategies. Human Communication Research, 14, 93-118.

Canary, D. J., \& Spitzberg, B. H. (1989). A model of perceived competence of conflict strategies. Human Communication Research, 15, 630-649.

Carter, S. L. (1998). Civility: Manners, moral, and the etiquette of democracy. New York: Basic Books.

Cascio, W. F. (1991). Costing human resources: The financial impact of behavior in organizations. Boston: PWS-Kent.

Cattell, R.B. (1966). The meaning and strategic use of factor analysis. In R.B. Cattell (Ed.), Handbook of multivariate experimental psychology (pp. 174-243). Chicago, IL: Rand McNally. 
Cavanaugh, S. J. (1991). The conflict management style of staff nurses and nurse managers. Journal of Advanced Nursing, 16, 1254-1260.

Caza, B. B., \& Cortina, L. M. (2007). From insult to injury: Explaining the impact of incivility. Basic and Applied Social Psychology, 29, 335-350.

Chan, C. C. A., Monroe, G., Ng, J., \& Tan, R. (2006), Conflict management styles of male and female junior accountants. International Journal of Management, 23, 289-295.

Chiu, M.M., \& Khoo, L. (2003). Rudeness and status effects during group problem solving: Do they bias evaluations and reduce the likelihood of correct solutions? Journal of Educational Psychology, 95, 506-523.

Chusmir, L. H., \& Mills, J. (1989). Gender differences in conflict resolution styles of managers: At work and at home. Sex Roles, 20, 149-163.

Cohen, J. (1988). Statistical power for the behavioral sciences $\left(2^{\text {nd }}\right.$ ed.). Hillsdale, NJ: Erlbaum.

Colbert, A. E., Mount, M. K., Harter, J. K., Witt, L. A., \& Barrick, M. R. (2004). Interactive effects of personality and perceptions of the work situation on workplace deviance. Journal of Applied Psychology, 89, 599-609.

Cortina, L. M., Lonsway, K. A., \& Magley, V. J. (2004). Reconceptualizing workplace incivility through the lenses of gender and race. Paper presented at the annual meeting of the Society for Industrial-Organizational Psychology, Chicago.

Cortina, L. M., Magley, V. J., Williams, J. H., \& Langhout, R. D. (2001). Incivility in the workplace: Incidence and impact. Journal of Occupational Health Psychology, 6, 64-80. 
Cortina, L. M., \& Magley, V. J. (2003). Raising voice, risking retaliation: Events following interpersonal mistreatment in the workplace. Journal of Occupational Health Psychology, 8, 247-265.

Cortina, L. M., \& Magley, V. J. (2007). Patterns and profiles of response to incivility in. organizations. Working paper, University of Michigan, Ann Arbor.

Cortina, L. M. (2008). Unseen injustice: Incivility as modern discrimination in organizations. Academy of Management Review, 33(1), 55-75.

Cortina, L. M., Lonsway, K. A., Magley, V. J., Freeman, L. V., Collinsworth, L. L., Hunter, M., \& Fitzgerald, L.F. (2002). What's gender got to do with it? Incivility in the Federal Courts. Law \& Social Inquiry, 27, 235-270.

Crampton, S. M., \& Wagner, J. A. (1994). Percept-percept inflation in microorganizational research: An investigation of prevalence and effect. Journal of Applied Psychology, 79, 67-76.

Creswell, J. W. (2005). Educational research: Planning, conducting, and evaluating quantitative and qualitative research. Upper Saddle River, NJ: Pearson Education, Inc.

Cupach, W. R., \& Canary, D. J. (1997). Competence in interpersonal conflict. New York: McGraw-Hill.

De Dreu, C. K. W., Evers, A., Beersma, B., Kluwer, E., \& Nauta, A. (2001). A theory based measure of conflict management strategies in the workplace. Journal of Organizational Behavior, 22, 645-690. 
De Dreu, C. K. W., Giebels, E., \& Van de Vliert, E. (1998). Social motives and trust in integrative negotiation: The disruptive effects of punitive capability. Journal of Applied Psychology, 83, 408-422.

De Dreu, C. K. W., Harinck, F., \& Van Vianen, A. E. M. (1999). Conflict and performance in groups and organizations. In C. L. Cooper \& I. T. Robertson (Eds.), International review of industrial and organizational psychology, 14, 376 -405 .

De Dreu, C. K. W. (2008). The virtue and vice of workplace conflict: food for (pessimistic) thought. Journal of Organizational Behavior, 29, 5-18.

DeChurch, L. A., Haas, C., \& Hamilton, K. L. (2007). Effects of conflict management strategies on perceptions of intragroup conflict. Group Dynamics: Theory, Research, and Practice, 11, 66-78.

Deetz, S. A. (1992). Democracy in an age of corporate colonization: Developments in communication and the politics of everyday life. Albany, NY: State University of New York Press.

Deutsch, M. (1994). Constructive conflict resolution: Principles, training, and research. Journal of Social Issues, 50, 13-32.

Diefendorff, J. M., \& Mehta, K. (2007). The relations of motivational traits with workplace deviance. Journal of Applied Psychology, 92, 967-977.

Digman J. M. (1990). Personality structure: Emergence of the five-factor model. Annual Review of Psychology, 41,417-440. 
Dijkstra, M. T. M., Van Dierendonck, D., Evers, A., \& De Dreu, C. K. W. (2005). Conflict and wellbeing: The moderating role of personality. Journal of Managerial Psychology, 20, 87-104.

Dilchert, S., Ones, D. S., Davis, R. D., \& Rostow, C. D. (2007). Cognitive ability predicts objectively measured counterproductive work behaviors. Journal of Applied Psychology, 92, 616-627.

Dillman, D. A. (2000). Mail and Internet surveys: The tailored design method. New York: John Wiley and Sons.

Dillman, D. A. (2002). Presidential address: Navigating the rapids of change: Some observations on survey methodology in the early twenty-first century. Public Opinion Quarterly, 66, 473-494.

Dillman, D. A. (2007). Mail and internet surveys: The tailored design method (2nd ed.). Hoboken, NJ: John Wiley \& Sons.

Donaldson, S. I., \& Grant-Vallone, E. J. (2002). Understanding self-report bias in organizational behavior research. Journal of Business and Psychology, 17, 245260.

Donovan, M. A., Drasgow, F., \& Munson, L. J. (1998). The perceptions of fair interpersonal treatment scale: Development and validation of a measure of interpersonal treatment in the workplace. Journal of Applied Psychology, 83, 683692.

Douglas, S. C., \& Martinko, M. J. (2001). Exploring the role of individual differences in the prediction of workplace aggression. Journal of Applied Psychology, 86, 547559. 
Duffy, M. K., Ganster, D. C., \& Pagon, M. (2002). Social undermining in the workplace. Academy of Management Journal, 45, 331-351.

Duhart, D. T. (2001). Violence in the workplace, 1993-1999. U.S. Department of Justice, Bureau of Statistics Special Report (NCJ No. 190076).

Einarsen, S. (1999). The nature and causes of bullying at work. International Journal of Manpower, 20, 16-27.

Einarsen, S., Matthiesen, S., \& Skogstad, A. (1998). Bullying, burnout and well-being among assistant nurses. Occupational Health and Safety, 14, $563-568$.

Euwema, M. C., \& Van Emmerik, I. H. (2007). Intercultural competencies and conglomerated conflict behaviors in intercultural conflicts. International Journal of Intercultural Relations, 31, 427-441.

Fallon, J. D., Avis, J. M., Kudisch, J. D., Gornet, T. P., \& Frost, A. (2004). Conscientiousness as a predictor of productive and counterproductive behaviors. Journal of Business and Psychology, 15, 339-349.

Ferriss, A. L. (2002). Studying and measuring civility: A framework, trends, and scale. Sociological Inquiry, 72, 376-392.

Field, A. (2005). Discovering Statistics using SPSS (2 ${ }^{\text {nd }}$ ed.). Thousand Oaks, CA: Sage Publications.

Finegold, D., Mohrman, S. \& Spreitzer, G. M. (2002). Age effects on the predictors of technical workers' commitment and willingness to turnover. Journal of Organizational Behavior, 23, 655-674.

Fisher, R., Ury, W. L., \& Patton, B (1991). Getting to yes: Negotiating agreement without giving in (2nd ed.). Boston: Houghton Mifflin. 
Giacalone, R. A., \& Greenberg, J. (1997). Antisocial behavior in organizations. Thousand Oaks, CA: Sage.

Giebels, E., \& Janssen, O. (2005). Conflict stress and reduced well-being at work: The buffering effect of third-party help. European Journal of Work and Organizational Psychology, 14, $137-155$.

Glendinning, P. M. (2001). Workplace bullying: Curing the cancer of the American workplace. Public Personnel Management, 30(3), 269-285.

Glomb, T. M., \& Liao, H. (2003). Interpersonal aggression in work groups: Social influence, reciprocal, and individual effects. Academy of Management Journal, $46,486-496$.

Gonthier, G., \& Morrissey, K. (2002). Rude awakenings: Overcoming the civility crisis in the workplace. Chicago, IL: Dearborn Trade Publishing.

Graziano, W. G., Jensen-Campbell, L. A., \& Hair, E. (1996). Perceiving interpersonal conflict and reacting to it: The case for agreeableness. Journal of Personality and Social Psychology, 70, 820-835.

Greenberg, L., \& Barling, J. (1999). Predicting employee aggression against coworkers, subordinates, and supervisors: The roles of person behaviors and perceived workplace factors. Journal of Organizational Behavior, 20, 897-913.

Gross, M. A., \& Guerrero, L. K. (2000). Managing conflict appropriately and effectively: An application of the competence model to Rahim's organizational conflict styles. The International Journal of Conflict Management, 11, 200-226.

Guadagnoli, E., \& Velicer, W. (1988). Relation of sample size to the stability of component patterns. Psychological Bulletin, 103, 265-275. 
Hammock, G. S., Richardson, D. R., Pilkington, C. J., \& Utley, M. (1990). Measurement of conflict in social relationships. Personality and Individual Differences, 11, $577-83$.

Haraway, D. L., \& Haraway, W. M., III. (2005). Analysis of the effect of conflictmanagement and resolution training on employee stress at a healthcare organization. Hospital Topics: Research and Perspectives on Healthcare, 83, 11 17.

Henle, C. A. (2005). Predicting workplace deviance from the interaction between organizational justice and personality. Journal of Managerial Issues, 17, 247264.

Henle, C. A., Giacalone, R. A., \& Jurkiewicz, C. L. (2005). The role of ethical ideology in workplace deviance. Journal of Business Ethics, 56, 219-230.

Hepworth, W., \& Towler, A. (2004). The effects of individual differences and charismatic leadership on workplace aggression. Journal of Occupational Health Psychology, 9, 176-185.

Hershcovis, S., Turner, N., Barling, J., Arnold, L., Dupre, K., Inness, M., Leblanc, M., \& Sivanathan, N. (2007). Predicting workplace aggression: A meta-analysis approach. Journal of Applied Psychology, 92 , 228-238.

Hocker, J. L., \& Wilmot, W. W. (1998). Interpersonal conflict (5th ed.). Madison, WI: Brown \& Benchmark.

Hoel, H., \& Cooper, C. L. (2000). Destructive conflict and bullying at work. Manchester, UK: Manchester School of Management, University of Manchester Institute of Science and Technology. 
Hogan, J., \& Ones, D. S. (1997). Conscientiousness and integrity at work. In R. Hogan, J.A. Johnson, S.R. Briggs, (Eds.). Handbook of personality psychology. San Diego, CA: Academic Press, Inc.

Hollinger, R. C., Slora, K. B., \& Terris, W. (1992). Deviance in the fast-food restaurant: Correlates of employee theft, altruism, and counterproductivity. Deviant Behavior, 13, 155-184.

Horn, P. W., \& Griffeth, R. W. (1995). Employee turnover. Cincinnati, OH: South Western.

Hornstein, H. A. (1996). Brutal bosses and their prey. New York: Riverhead.

Isaac, S., \& Michacl, W. B. (1997). Handbook in research and evaluation: A collection of principles, methods, and strategies useful in the planning, design, and evaluation of studies in education and the behavioral sciences (3rd ed.). San Diego: Educational and Industrial Testing Services.

Jameson, J. K. (1999). Toward a comprehensive model for the assessment and management of intraorganizational conflict: Developing the framework. International Journal of Conflict Management 10, 268-294.

Jelinek, R., \& Ahearne, M. (2006). The enemy within: Examining salesperson deviance and its determinants. Journal of Personal and Sales Management, 26, 327-344.

Jensen-Campbell, L. A., \& Graziano,W. G. (2001). Agreeableness as a moderator of interpersonal conflict. Journal of Personality, 69, 323-361.

Johns, G. (1994). How often were you absent? A review of the use of self-reported absence data. Journal of Applied Psychology, 79, 574- 591. 
Johnson, L. W. (1991). The effects of conflict management training upon the conflict management styles of teachers. (Doctoral dissertation, Gonzaga University, 1990). Retrieved Junc 11, 2009, from Dissertations \& Theses: Full Text database. (Publication No. AAT 9133227).

Johnson, P. R., \& Indvik, J. (2001a). Rudeness at work: Impulse over restraint. Public Personnel Management, 30, 57-465.

Johnson, P. R., \& Indvik, J. (2001b). Slings and arrows of rudeness: incivility in the workplace. Journal of Management Development, 20, 705-713.

Judge, T. A., LcPinc, J. A., \& Rich, B. L. (2006). Loving yourself abundantly: Relationship of the narcissistic personality to self- and other perceptions of workplace deviance, leadership, and task and contextual performance. Journal of Applied Psychology, 91, 762-776.

Kaiser, H. F. (1960). The application of electronic computers to factor analysis. Educational and Psychological Measurement, 20, 141-151.

Kaiser, H.F. (1974). An index of factorial simplicity. Psychometrika, 39, 31-36.

Kaplowitz, M. D., Hadlock, T. D., \& Levine, R. (2004). A comparison of web and mail survey response rates. Public Opinion Quarterly, 68, 94-101.

Keashly, L. (1998). Emotional abuse in the workplace: Conceptual and empirical issues. Journal of Emotional Abuse, 1, 117-140.

Klenke, K. (2003). Gender influences in decision-making processes in top management teams. Management Decision, 41, 1024-1034. 
Korac-Kakabadse, A., Korac-Kakabadse, N., \& Myers, A. (1998). Demographics and leadership philosophy: Exploring gender differences. Joumal of Management Development, 17, 351-388.

Kowalski, R. M. (2003). Complaining, teasing and other annoying behaviors. New Haven, CT: Yale University Press.

Lambert, E. G., Hogan, N. L., \& Barton, S. M. (2001). The impact of job satisfaction on turnover intent: a test of a structural measurement model using a national sample of workers. The Social Science Journal, 38, 233-250.

Lau, E., Li, E., Mak, C., \& Chung, I.(2004).Effectiveness of conflict management training for traffic police officers in Hong Kong. International Journal of Police Science \& Management, 6, 97-109.

Leather, P., Lawrence, C., Beale, D., Cox, T., \& Dickson, R. (1998). Exposure to occupational violence and the buffering effects of intra-organizational support. Work and Stress, 12, $161-178$.

Lee, R. M. (1993). Doing research on sensitive topics. London: Sage.

Lee, K., Ashton, M. C., \& Shin, K. H. (2005). Personality correlates of workplace antisocial behavior. Applied Psychology: An International Review, 54, 81-98.

Lee, R. T., \& Brotheridge, C. M. (2006). When prey turns predatory: Workplace bullying as a predictor of counteraggression/ bullying, coping, and well-being. European Journal of Work and Organizational Psychology, 15, 352-377.

Lewicki, R. J., Weiss, S. E., \& Lewin, D. (1992). Models of conflict, negotiation, and third party intervention: A review and synthesis. Journal of Organizational Behavior, 13, 209-252. 
Leymann, H. (1996). The content and development of mobbing at work. European Journal of Work and Organizational Psychology, 5, 165-184.

Lim, S., \& Cortina, L. M. (2005). Interpersonal mistreatment in the workplace: The interface and impact of general incivility and sexual harassment. Journal of Applied Psychology, 90, 483-496.

Lim, S., Cortina, L. M., \& Magley, V. J. (2008). Personal and workgroup incivility: Impact on work and health outcomes. Journal of Applied Psychology, 93, 95-107.

Marcus, L. J., Dorn, B. C., Kritek, P. B., Miller, V. G., \& Wyatt, J. B. (1995). Renegotiating healthcare: Resolving conflict to build collaboration. San Francisco: Jossey-Bass.

Marriner, A. (1982). Managing conflict. Nursing Management, 13, 29-31.

Martin, R. J., \& Hine, D. W. (2005). Development and validatin of the uncivil workplace bchavior questionnaire. Journal of Occupational Health Psychology, 10, 477-490.

Martinko, M. J., Gundlach, M. J., \& Douglas, S. C. (2002). Toward an integrative theory of counterproductive workplace behavior: A causal reasoning perspective. International Journal of Selection and Assessment, 10, 36-50.

Mayhew, C., McCarthy, P., Chappell, D., Quinlan, M., Barker, M., \& Sheehan, M. (2004). Measuring the extent of occupational violence and bullying on traumatized workers. Employees Responsibilities and Rights Journal, 16, 117 132.

McCullough, M. E., Bellah, C. G., Kilpatrick, S. D., \& Johnson, J. L. (2001). Vengefulness: Relationships with forgiveness, rumination, well-being, and the Big Five. Personality and Social Psychology Bulletin, 27, 601-610. 
McGhee, M., \& Satcher, J. (1995). Predictors of organizational commitment and job satisfaction among state agency rehabilitation counselors. East Lansing, MU: National Center for Research on Teacher Learning.

McKenzie, C. (2002). Developing a CCO: Conflict competent organization. New Zealand Management, 49, 34-37.

Medina, F. J., Munduate, L., Dorado, M. A., Martinez, I., \& Guerra, J. M. (2005). Types of intragroup conflict and affective reactions. Journal of Managerial Psychology, $20,219-230$.

Mehta, R., \& Sivadas, E. (1995). Comparing response rates and response content in mail versus electronic mail surveys. Journal of the Market Research Society, 37, 429439.

Meyer, J. P., \& Allen, N. J. (1984). Testing the "side-bet theory" of organizational commitment: Some methodological considerations. Journal of Applied Psychology, 69, 372-378.

Meyer, J. P., \& Allen, N. J. (1991). A three-component conceptualization of organizational commitment. Human Resource Management Review, l, 61-89.

Meyer, J. P., Allen, N. J., \& Smith, C. A. (1993). Commitment to organizations and occupations: Extension and test of a three-component conceptualization. Journal of Applied Psychology, 78, 538-551.

Meyer, S. (2004). Organizational response to conflict: Future conflict and work outcomes. Social Work Research, 3, 183-190.

Miles, D. E., Borman, W. E., Spector, P. E., \& Fox, S. (2002). Building an integrative model of extra role work behaviors: A comparison of counterproductive work 
bchavior with organizational citizenship behavior. International Journal of Selection and Assessment, 10, 51-57.

Miner-Rubino, K., \& Cortina, L. M. (2007). Beyond targets: Consequences of vicarious exposure to misogyny at work. Journal of Applied Psychology, 92, 1254-1269.

Moberg, P. J. (1998). Predicting conflict strategy with personality traits: Incremental validity and the five factor model. International Journal of Conflict Management, $9,258-285$.

Moberg, P. J. (2001). Linking conflict strategy to the five-factor model: Theoretical and empirical foundations. International Journal of Conflict Management, 12, 47-68.

Mobley, W. H. (1997). Intermediate linkages in the relationship between job satisfaction and employee turnover. Journal of Applied Psychology, 62, 237-240.

Mobley, W.H. (1982), Employee turnover: Causes, consequences, and control. Reading, MA: Addison-Weslcy Publishing.

Mobley, W. H., Horner, S. O., \& Hollingsworth, A.T. (1978). An evaluation of precursors of hospital employee turnover. Journal of Applied Psychology, 63, 408-414.

Montgomery, K., Kane, K., \& Vance, C. M. (2004). Accounting for differences in norms of respect: A study of assessments of incivility through the lenses of race and gender. Group \& Organization Management, 29, 248-268.

Morris, J. H., \& Sherman, J. D. (1981). Generalizability of an organizational commitment model. The Academy of Management Journal, 24, 512-526.

Morris-Conley, C., \& Kern, R. (2003). The relationship between lifestyle and conflict resolution strategy. Journal of Individual Psychology, 59, 475-488. 
Morris-Rothschild, B. (2003). Teachers' use of conflict management styles: The role of attachment and efficacy. (Doctoral dissertation, Columbia University, 2003). Dissertation Abstracts International, 64, 1943.

Motowidlo, S. J. (2003). Job performance. In Borman, W. C., Ilgen, D. R., Klimoski, R. J., \& Weiner, I.B. (Eds.). Handbook of psychology, 12, 39-53.

Motowidlo, S. J., \& Van Scotter, J. R. (1994). Evidence that task performance should be distinguished from contextual performance. Journal of Applied Psychology, 79, 475-480.

Motowidlo, S. J., Borman, W. C., \& Schmit, M. J. (1997). A theory of individual differences in task and contextual performance. Human Performance, 10, 71-83.

Mowday, R. T., Porter, L. W., \& Steers, R. M. (1982). Employee-organizational linkages: The psychology of commitment, absenteeism, and turnover. New York, NY: Academic Press.

Munduate, L., \& Dorado, M. A. (1998). Supervisor power bases, co-operative behaviour, and organizational commitment. European Journal of Work \& Organizational Psychology, 7, 163-177.

Munduate, L., Ganaza, J., Peiro J. M., \& Euwema, M. (1999). Patterns of styles in conflict management and effectiveness. International Journal of Conflict Management, 10, 5-24.

Myers, R. (1990). Classical and modern regression with applications ( $2^{\text {nd }}$ ed.). Boston, MA: Duxbury Press.

Namic, G. (2003, November/ December). Workplace bullying: escalated incivility. Ivey Business Journal, 1-6. 
Neuman, J. H., \& Baron, R. A. (1997). Aggression in the workplace. In R.A Giacalone \& J. Greenberg (Eds.), Antisocial Behavior in Organizations (pp. 37-67). Thousand Oaks, CA: Sage.

Neuman, J. H., \& Baron, R. A. (1998). Workplace violence and workplace aggression: Evidence concerning specific forms, potential causes, and preferred targets. Journal of Management, 24, 391-419.

Neuman, J. H., \& Baron, R. A. (2005). Aggression in the workplace: A socialpsychological perspective. In S. Fox \& P. E. Spector (Eds.), Counterproductive work behavior: Investigations of actors and targets (pp. 13-40). Washington, DC: American Psychological Association.

Nicotera, A. M. (1997). Managing conflict communication in groups. In L. R. Frey \& J. K. Barge (Eds.), Managing group life: Communicating in decision-making groups (pp. 104-130). Boston: Houghton Mifflin.

Nunnally, J. C., \& Bernstein, I. H. (1994). Psychometric theory (3rd ed.). New York; McGraw-Hill.

O'Toole, J., \& Lawler, E. E. III. (2006). The new American workplace. New York: Palgrave Macmillan.

Olson-Buchanan, J. B., Drasgow, F., Moberg, P. J., Mead, A. D., Keenan, P. A., \& Donovan, M. A. (1998). An interactive video assessment of conflict resolution skills. Personnel Psychology, 51, 1-24.

Ones, D. S., Viswesvaran, C., \& Schmidt, F. L. (1993). Comprehensive meta-analysis of integrity test validities: Findings and implications for personnel selection and theories of job performance. Journal of Applied Psychology, 78, 679-703. 
Organ, D. W., \& Konovsky, M. (1989). Cognitive versus affective determinants of organizational citizenship behavior. Journal of Applied Psychology, 74, 157-164.

Organ, D. W., \& Ryan, K. (1995). A meta-analytic revicw of attitudinal and dispositional predictors of organizational citizenship behavior. Personnel Psychology, 48, 775802.

Pagano, R. R. (1998). Understanding statistics in the behavioral sciences ( $\left.5^{\text {th }} \mathrm{ed}.\right)$. Pacific Grove, CA: Brooks Cole.

Pearson, C. M., Andersson, L. M., \& Porath, C. L.(2000). Assessing and attacking workplace incivility. Organizational Dynamics, 29, 123-137.

Pearson, C. M, Andersson, L. M., \& Porath, C. L. (2005). Workplace incivility. In S. Fox, \& P. E. Spector (Eds.), Counterproductive work behavior: Investigations of actors and targets (pp. 177-200). Washington, DC, US: American Psychological Association.

Pearson, C. M., Andersson, L. M., \& Wegner, J. (2001). When workers flout convention: A study of workplace incivility. Human Relations, 54, 1387-1419.

Pearson, C. M., \& Porath, C. L. (2005), On the nature, consequences and remedies of workplace incivility: No time for "nice"? Think again. Academy of Management Executive, 19, 7-18.

Pedhazur, E. J. (1997). Multiple regression in behavioral research ( $3^{\text {rd }}$ ed.). Fort Worth, TX: Thomson Learning.

Pelled, L. H., Eisenhardt, K. M., \& Xin, K. R. (1999). Exploring the black box: An analysis of work group diversity, conflict, and performance. Administrative Science Quarterly, 44, 4-22. 
Penney, L. M., \& Spector, P. E. (2005). Job stress, incivility, and counterproductive work behavior (CWB): The moderating role of negative affectivity. Journal of Organizational Behavior. 26, 777-796.

Pondy, L. R. (1967). Organizational Conflict: Concepts and Models. Administrative Science Quarterly, 12, 296-320.

Pondy, L. R. (1992). Reflections on organizational conflict. Journal of Organizational Behavior, 13, 257-261.

Porath, C. L., \& Ercz, A. (2007). Does rudeness really matter? The effects of rudeness on task performance and helpfulness. Academy of Management Journal, 50, 11811197.

Porath, C. L., Overbeck, J. R., \& Pearson, C. (2008). Picking up the gauntlet: How individuals respond to status challenges. Journal of Applied Social Psychology, $38,1945-1980$

Porath, C. L., \& Pearson, C. M. (2000, August). Gender differences and the behavior of targets of workplace incivility: He "dukes" it out, she "disappears" herself. Paper presented at the annual meeting of the Academy of Management, Toronto, Ontario, Canada.

Portello, J. Y., \& Long, C. (1994). Gender role orientation, ethical and interpersonal conflicts, and conflict styles of female managers. Sex Roles, 31, 683-701.

Price, J. L. (1977). The study of turnover. Ames, IA: The Iowa State University Press.

Putnam, L. L., \& Poole, M. S. (1987). Conflict and negotiation. In F. M. Jablin, L. L. Putnam, K. Roberts, \& L. Porter (Eds.), Handbook of organizational communication. Beverly Hills, CA: Sage. 
Rahim, M. A. (1985). A strategy for managing conflict in complex organizations. Human Relations, 38, 81-89.

Rahim, M. A. (2002). Toward a theory of managing organizational conflict. International Journal of Conflict Management, 13, 206-235.

Rahim, M. A. (1983). A measure of styles of handling interpersonal conflict. Academy of Management Journal, 26, 368-376.

Rahim, M. A. (1986). Referent role and styles of handling interpersonal conflict. The Journal of Social Psychology, 126, 79-86.

Rahim, M. A. (2000). Managing Conflict in Organizations (3rd ed.). Westport, CT: Quorum Books.

Rahim, M. A. (2001). Managing organizational conflict: Challenges for organization development and change. In R.T. Golembiewski (2nd Ed.), Handbook of organizational behavior. New York, NY: Marcel Dekker.

Rahim, M. A. (2004). Rahim organizational conflict inventories: Professional manual. Bowling Green, KY: Center for Advanced Studies in Management.

Rahim, M. A., Antonioni, D., \& Psenicka, C. (2001). A structural equations model of leader powcr, subordinates' styles of handling conflict, and job performance. The International Journal of Conflict Management, 12, 191-211.

Rahim, M. A., \& Bonoma, T. V. (1979). Managing organizational conflict: A model for diagnosis and intervention. Psychological Reports, 44, 1323-1344.

Rahim, M. A., \& Buntzman, G. F. (1990). Supervisory power bases, styles of handling conflict with subordinates and subordinate compliance and satisfaction. Journal of Psychology, 123, 195-210. 
Rahim, M. A., Buntzman, G. F., \& White, D. (1999). An empirical study of the stages of moral development and conflict management styles. The International Journal of Conflict Management, 10, 154-171.

Rahim, M. A., Magner, N. R. (1995). Confirmatory factor analysis of the styles of handling interpersonal conflict: first order factor model and its invariance across groups. Journal of Applied Psychology, 80, 122-132.

Rayner, C. (1997). The incidence of workplace bullying. Journal of Community and Applied Social Psychology, 7, 199-208.

Rayner, C., Hocl, H., \& Cooper, C. L. (2002). Workplace bullying: What we know, who is to blame, and what can we do? New York: Taylor and Francis.

Reich, W. A., Wagner-Westbrook, B. J., \& Kressel, K. (2007). Actual and ideal conflict styles and job distress in a health care organization. The Journal of Psychology, $141,5-15$.

Reio, T. G., Jr., \& Callahan, J. (2004). Affect, curiosity, and socialization-related learning: A path analysis of antecedents to job performance. Journal of Business and Psychology, 19, 3-22.

Reio, T. G., Jr., \& Ghosh, R. (in press). Antecedents and outcomes of workplace incivility: Implications for human resource development research and practice. Human Resource Development Quarterly.

Rhodes, S. R. (1983). Age-related differences in work attitudes and behavior: A review and conceptual analysis. Psychological Bulletin, 93, 328-367.

Riketta, M. (2002). Attitudinal organizational commitment and job performance: A metaanalysis. Journal of Organizational Behavior, 23, 257-266. 
Rizkalla, L., Wertheim, E. H., \& Hodgson, L. K. (2008). The roles of cmotion management and perspective taking in individuals' conflict management styles and disposition to forgive. Journal of Research in Personality, 42, 1594-1601.

Robinson, S. L., \& Bennett, R. J. (1995). A typology of deviant workplace behaviors: A multidimensional scaling study. Academy of Management Journal, 38, 555-572.

Robinson, S. L. \& Grecnberg, J. (1999). Employees behaving badly: Dimensions, determinants and dilemmas in the study of workplace deviance. In D. M. Rousseau \& C. Cooper (Eds.), Trends in Organizational Behavior, Vol. 5 (pp. 123). New York: Wilcy.

Robinson, S. L., \& O'Leary-Kelly, A. M. (1998). Monkey sce, monkey do: The influence of work groups on the antisocial behavior of employees. Academy of Management Journal, 41, 658-672.

Rosenstein, A. H., \& O’Daniel, M. (2005). Disruptive behavior and clinical outcomes: Perceptions of nurses and physicians. American Journal of Nursing, 105, 54-64.

Ruble, T. L., \& Schneer, J. A. (1994). Gender differences in conflict-handling styles: Less than meets the eye? In A. Taylor \& J. B. Miller (Eds.), Conflict and gender (pp. 155-166). Cresskill, NJ: Hampton Press.

Ruble, T. L., \& Thomas, K. W. (1976). Support for a two-dimensional model for conflict bchavior. Organizational Behavior and Human Performance, 16, 143-155.

Sackett, P. R. (2002). The structure of counterproductive work behaviors: Dimensionality and relationships with facets of job performance. International Journal of Selection and Assessment, 10, 5-11. 
Sackett, P. R., \& DeVore, C. J. (2001). Counterproductive behaviors at work. In Anderson, N., Ones, D. S., Sinangil, H. K., \& Viswesvaran, V. (Eds), International Handbook of Work Psychology, 1, 145-164. London: Sage.

Salgado, J. F. (2002). The big five personality dimensions and counterproductive behaviors. International Journal of Selection and Assessment, 10(1/2), 117-125.

Salin, D. (2003). Ways of explaining workplace bullying: A review of enabling, motivating and precipitating structures and processes in the work environment. Human Relations, 56, 1213-1232.

Schat, A. \& Kelloway, E. K. (2005). Workplace Violence. In J. Barling, E. K. Kelloway, \& M. Frone, Handbook of Workplace Stress. Thousand Oaks, CA: Sage.

Schonlau, M., Fricker, R., \& Elliott, M. (2002). Conducting research surveys via email and the Web. Santa Monica, CA: Rand.

Seashore, S. E., Lawler III, E. E., Mirvis, P. H., \& Cammann, C. (Eds.). (1983). Assessing organizational change: A guide to methods, measures and practices. New York: John Wiley \& Sons.

Sexual harassment (2008). U.S. Equal Employment Opportunity Commission. Retrieved March 10, 2009 from http://www.eeoc.gov/types/sexual_harassment.html Shannon, D. M., \& Bradshaw, C. C. (2002). A comparison of response rate, response times, and costs of mail and electronic surveys. The Journal of Experimental Education, 70, 179-192.

Shaw, J. D., Duffy, M., Johnson, J., \& Lockhart, D. (2005). Turnover, social capital losses, and performance. Acadeny of Management Journal, 48, 594-606. 
Sheehan, E. P. (1993). The effects of turnover on the productivity of those who stay. Journal of Social Psychology, 133, 699-706.

Shell, G. R. (2001). Bargaining styles and negotiation: The Thomas-Kilmann Conflict Mode instrument in negotiation training. Negotiation Journal, 17, 155-172.

Sherif, M. (1936). The psychology of social norms. New York, NY: Harper.

Simsek, Z., \& Veiga, J. F. (2001). A primer on Internet organizational surveys. Organizational Research Methods, 4, 218-235.

Skarlicki, D. P., \& Folger, R. (2004). Broadening our understanding of organizational retaliatory behavior. In R. W. Griffin \& A. M. O’Leary-Kelly (Eds.), The dark side of organizational behavior. San Francisco: Jossey-Bass.

Skarlicki, D. P., Folger, R., \& Tesluk, P. (1999). Personality as moderator in the relationship between fairness and retaliation. The Academy of Management Journal, 42, 100-108.

Somers, M. J. (1995). Organizational commitment, turnover, and absenteeism: An examination of direct and interaction effects. Journal of Organizational Behavior, $15,535-547$.

Song, M, Dyer, B., \& Thicme, R. J. (2006). Conflict management and innovation performance: An integrated contingency perspective. Journal of the Academy of Marketing Science, 34, 341-356.

Spector, P. E. (1987). Method variance as an artifact in self-reported affect and perceptions at work: Myth or significant problem? Journal of Applied Psychology, 72, 438-443. 
Spector, P. E., \& Fox, S. (2005). A stressor-emotion model of counterproductive work behavior. In S. Fox \& P. E. Spector (Eds.), Counterproductive work behavior: Investigations of actors and targets (pp. 151-174). Washington, DC: American Psychological Association.

Speer, R. (1998, August). Can workplace violence be prevented. Occupational Hazard, 26-29.

Spreitzer, G. M. (1995). Pyschological empowerment in the workplace: Dimensions, measurement, and validation. Academy of Management Journal, 38, 1442-1465.

Steers, R. M. (1977). Antecedents and outcomes of organizational commitment. Administrative Science Quarterly, 22, 46-56.

Stcrnberg, R. J., \& Soriano, L. J. (1984). Styles of conflict resolution. Journal of Personality and Social Psychology, 47, 115-126.

Stevens, J. (2002). Applied multivariate statistics for the social sciences (4th ed.). Mahwah, NJ: Lawrence Erlbaum.

Survey of workplace violence prevention, 2005 (2006). News: United States Department of Labor. Washington, D.C.:Bureau of Labor Statistics. Retrieved March 10, 2009 from http://www.bls.gov/iif/oshwc/osnr0026.pdf

Tabachnick, B. G., \& Fidell, L. S. (2001). Using multivariate statistics (4th ed.). Boston: Allyn and Bacon.

Tedeschi, J. T., \& Fclson, R. B. (1994). Violence, aggresson, \& coercive actions. Washington, D.C.: American Psychological Association.

Tepper, B. J. (2000). Consequences of abusive supervision. Academy of Management Journal, 43, 178-191. 
Tepper, B. J., Duffy, M. K., \& Shaw, J. D. (2001). Personality moderators of the relationship between abusive supervision and subordinates' resistance. Journal of Applied Psychology, 86, 974-983.

Tepper, B. J., Duffy, M. K., Henle,C. A., \& Lambert,L. S. (2006). Procedural injustice, victim precipitation, and abusive supervision. Personnel Psychology, 59, 101-123.

Thau, S., Crossley, C., Bennett, R. J., \& Sczesny, S. (2007). The relationship between trust, attachment, and antisocial work behaviors. Human Relations, 60, $1155-$ 1179.

Thomas, J. L., Bliesc, P. D., \& Jex, S. M. (2005). Interpersonal conflict and organizational commitment: Examining two levels of supervisory support as multilevel moderators. Journal of Applied Psychology, 35, 2375-2398.

Thomas, K. W. (1976). Conflict and conflict management. In M.D. Dunnette (Ed.), Handbook of industrial and organizational psychology. Chicago, IL: Rand McNally.

Thomas, K. W. (1979). Conflict. In S. Kerr (Ed.), Organizational behavior (pp.151-181). Columbus, OH: Grid Publications.

Thomas, K. W. (1992). Conflict and negotiation processes in organizations. In M.D. Dunnette, \& L.M. Hough (Eds.), Handbook of industrial and organizational psychology (2nd ed., pp. 651-717). Palo Alto, CA: Consulting Psychologists Press, Inc.

Ting-Toomey, S., Gau, G., Trubisky, P., Yang, Z., Kim, H. S., Lin, S., \& Nishida, T. (1991). Culture, face maintenance, and styles of handling interpersonal conflict: A study in five cultures. International Journal of Conflict Management, 2, 275-296. 
Ting-Toomey, S., Octzel, J. G., \& Yec-Jung, K. (2001). Self-construal types and conflict management styles. Communication Reports, 14, 87-104.

Tjosvold, D. (1998). Cooperative and competitive goal approach to conflict: Accomplishments and challenges. Applied Psychology: An International Review, $47,285-342$.

Tjosvold, D., Hui, C., \& Yu, Z. (2003). Conflict management and task reflexivity for team in-role and extra-role performance in China. The International Journal of Conflict Management, 14, 141-163.

Tziner, A., \& Birati, A. (1996). Assessing employee turnover costs: A revised approach. Human Resource Management Review, 6, 113-122.

Van de Vlicrt, E. (1997). Complex interpersonal conflict behavior: Theoretical frontiers. Hove, UK: Psychology Press.

Van de Vliert, E., \& De Dreu, C. K. W. (1994). Optimizing performance by stimulating conflict. International Journal of Conflict Management, 5, 211-222.

Van de Vliert, E., \& Kabanoff, B. (1990). Toward theory-based measures of conflict management. Academy of Management Journal, 33, 199-209.

Van de Vliert, E., Nauta, A., Giebels, E., \& Janssen, O. (1999). Constructive conflict at work. Journal of Organizational Behavior, 20, 475-491.

Van Scotter, J. R., Motowidlo, S. J., \& Cross, T. C. (2000). Effects of task performance and contextual performance on systemic rewards. Journal of Applied Psychology, $85,526-535$. 
Vickers, M. H. (2006). Writing what's relevant: Workplace incivility in public administration- A wolf in sheep's clothing. Administrative Theory \& Praxis, 28, $69-88$.

Volkema, R. J., \& Bergmann, T. J. (1989). Interpersonal conflict at work: An analysis of behavioral responses. Human Relations, 42, 757-770.

Volkema, R. J., \& Bergmann, T. J. (1995). Conflict styles as indicators of behavioral patterns in interpersonal conflicts. The Journal of Social Psychology, 135, 5-15.

Wall, J. A., \& Callister, R. R. (1995). Conflict and its management. Journal of Management, 21, 515-558.

Weider-Hatfield, D., \& Hatfield, J. D. (1995). Relationship among conflict management styles, levels of conflict, and reactions to work. Journal of Social Psychology, $135,687-698$.

Whitener, E. M., \& Waltz, P. M. (1993). Exchange theory determinants of affective and continuance commitment and turnover. Journal of Vocational Behavior, 42, 265281.

Young, A.M., Vance, C. M., \& Harris, C. (2007). Moving beyond gender to discover differences in sensitivity to disempowering acts: An examination of the role of social context. Group \& Organization Management, 32, 598-620. 
APPENDIX A

Correlation table for Demographic Variables, Target and Instigated Incivility

Hierarchical

\begin{tabular}{lcccccc}
\hline & & & & & Hierarchical \\
& & & & & \\
& Target & Instigate & Gender & Tenure & Age \\
& 1.00 & & & & & \\
Target & $.56^{* *}$ & 1.00 & & & \\
Instigate & $-.14^{*}$ & $-.27^{* *}$ & 1.00 & & \\
Gender & $.27^{* *}$ & $.32^{* *}$ & $-.62^{* *}$ & 1.00 & \\
Tenure & -.11 & $-.13^{*}$ & $.26^{* *}$ & $-.23^{* *}$ & 1.00 \\
Hierarchical position & -.05 & -.11 & .01 & $.18^{* *}$ & -.01 & 1.00 \\
Age & & & & & & \\
\hline
\end{tabular}

Note. ${ }^{* *}$ Correlation is significant at the 0.01 level (2-tailed).

${ }^{*}$ Correlation is significant at the 0.05 level (2-tailed). 


\section{APPENDIX B}

Summary of Hierarchical Regression Analyses for Conflict Management Styles and

Demographic Variables Predicting Target Incivility

\begin{tabular}{|c|c|c|c|c|c|c|}
\hline & Variable & $B$ & $S E B$ & $\beta$ & $\begin{array}{r}\text { Total } \\
\qquad R^{2}\end{array}$ & $\Delta R^{2}$ \\
\hline Step 1 & & 3.76 & .44 & & $.19^{* *}$ & .19 \\
\hline & Compromise CMS & -.14 & .10 & -.11 & & \\
\hline & Dominate CMS & .14 & .06 & $.13^{*}$ & & \\
\hline & Integrate CMS & -.45 & .10 & $-.34 * *$ & & \\
\hline & Avoid CMS & .01 & .07 & .01 & & \\
\hline Step 2 & & & & & $.23^{*}$ & .05 \\
\hline & Compromise CMS & -.13 & .09 & -.10 & & \\
\hline & Dominate CMS & .10 & .07 & .10 & & \\
\hline & Integrate CMS & -.42 & .10 & $-.31 * *$ & & \\
\hline & Avoid CMS & .02 & .07 & .02 & & \\
\hline & Gender & .24 & .13 & .16 & & \\
\hline & Tenure & .16 & .05 & $.27^{* *}$ & & \\
\hline & Hierarchical position & -.03 & .04 & -.05 & & \\
\hline & Age & -.06 & .05 & -.07 & & \\
\hline
\end{tabular}




\begin{abstract}
APPENDIX C
Summary of Hierarchical Regression Analyses for Conflict Management Styles and

Demographic Variables Predicting Instigator Incivility
\end{abstract}

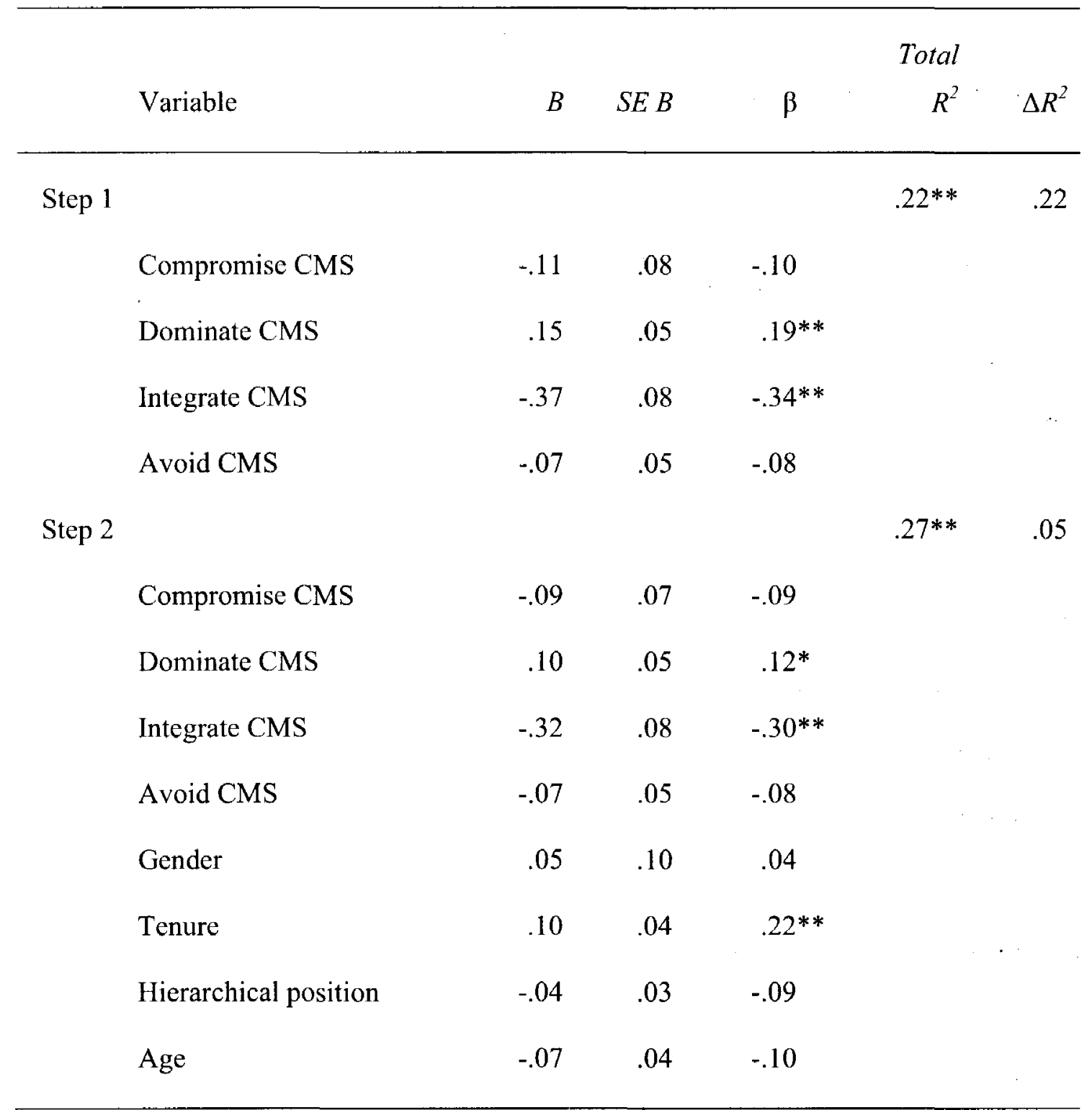

Note. Dependent Variable: Instigated incivility.

${ }^{*} p<.05 .{ }^{* *} p<.01$. 


\section{APPENDIX D}

Summary of Hierarchical Regression Analyses for Organizational Commitment

Predicting Task Job Performance

\begin{tabular}{|c|c|c|c|c|c|c|}
\hline & \multirow[b]{2}{*}{ Variable } & \multirow[b]{2}{*}{$B$} & \multirow[b]{2}{*}{$S E B$} & \multicolumn{3}{|c|}{ Total } \\
\hline & & & & $\beta$ & $R^{2}$ & $\Delta R^{2}$ \\
\hline Step 1 & & & & & $.09^{* * *}$ & .09 \\
\hline & Org Effect code 1 & .60 & .35 & .11 & & \\
\hline & Org Effect code 2 & -1.45 & .35 & $-.25 * *$ & & \\
\hline Step 2 & & & & & $.11^{* *}$ & .02 \\
\hline & Org Effect code 1 & .42 & .35 & .07 & & \\
\hline & Org Effect code 2 & -1.31 & .35 & $-.23 * *$ & & \\
\hline & Org Commitment & .08 & .03 & $.15^{*}$ & & \\
\hline
\end{tabular}

Note. Dependent Variable: JP task performance

${ }^{*} p<.05 .{ }^{* *} p<.01$ 


\section{APPENDIX E}

Summary of Hierarchical Regression Analyses for Organizational Commitment

Predicting Contextual Job Performance

\begin{tabular}{|c|c|c|c|c|c|c|}
\hline & \multirow[b]{2}{*}{ Variable } & \multirow[b]{2}{*}{$B$} & \multirow[b]{2}{*}{$S E B$} & \multicolumn{3}{|c|}{ Total } \\
\hline & & & & $\beta$ & $R^{2}$ & $\Delta R^{2}$ \\
\hline Step 1 & & & & & $.19^{* *}$ & .19 \\
\hline & Org Effect code 1 & 1.27 & .34 & $.21 * *$ & & \\
\hline & Org Effect code 2 & -1.94 & .34 & $-.32 * *$ & & \\
\hline Step 2 & & & & & $.25^{* *}$ & .06 \\
\hline & Org Effect code 1 & .94 & .33 & $.16^{* *}$ & & \\
\hline & Org Effect code 2 & -1.68 & .34 & $-.28 * *$ & & \\
\hline & Org Commitment & .15 & .03 & $.26^{* *}$ & & \\
\hline
\end{tabular}

Note. Dependent Variable: JP contextual performance

${ }^{*} p<.05{ }^{* *} p<.01$. 


\section{APPENDIX F}

Summary of Hierarchical Regression Analyses for Turnover Intentions Predicting Task

Job Performance

\begin{tabular}{|c|c|c|c|c|c|c|}
\hline & \multirow[b]{2}{*}{ Variable } & & & \multicolumn{3}{|c|}{ Total } \\
\hline & & $B$ & $S E B$ & $\beta$ & $R^{2}$ & $\Delta R^{2}$ \\
\hline Step 1 & & & & & $.08^{* *}$ & .08 \\
\hline & Org Effect code 1 & .54 & .34 & .10 & & \\
\hline & Org Effect code 2 & -1.34 & .35 & $-.24 * *$ & & \\
\hline Step 2 & & & & & $.10^{* *}$ & .03 \\
\hline & Org Effect code 1 & .40 & .34 & .07 & & \\
\hline & Org Effect code 2 & -1.42 & .34 & $-.25 * *$ & & \\
\hline & Turnover Intent & -.17 & .06 & $-.16^{* *}$ & & \\
\hline
\end{tabular}

Note. Dependent Variable: JP task performance

${ }^{*} p<.05 .{ }^{* *} p<.01$. 


\section{APPENDIX G}

Summary of Hierarchical Regression Analyses for Turnover Intentions Predicting Contextual Job Performance

\begin{tabular}{|c|c|c|c|c|c|c|}
\hline & \multirow[b]{2}{*}{ Variable } & \multirow[b]{2}{*}{$B$} & \multirow[b]{2}{*}{$S E B$} & \multicolumn{3}{|c|}{ Total } \\
\hline & & & & $\beta$ & $R^{2}$ & $\Delta R^{2}$ \\
\hline Step 1 & & & & & $.19^{* *}$ & .19 \\
\hline & Org Effect code 1 & 1.34 & .34 & $.22 * *$ & & \\
\hline & Org Effect code 2 & -1.89 & .35 & $-.31 * *$ & & \\
\hline Step 2 & & & & & $.22 * *$ & .04 \\
\hline & Org Effect code 1 & 1.17 & .34 & $.20 * *$ & & \\
\hline & Org Effect code 2 & -1.99 & .34 & $-.33^{* *}$ & & \\
\hline & Turnover Intent & -.22 & .06 & $-.19 * *$ & & \\
\hline
\end{tabular}




\section{APPENDIX H}

Summary of Results for Research Questions 1 and 2

\begin{tabular}{|c|c|}
\hline Research Question & Results of Analyses \\
\hline $\begin{array}{l}\text { 1. What is the relationship } \\
\text { between workplace incivility } \\
\text { (WI) and conflict management } \\
\text { styles (CMS) of: (a) } \\
\text { dominating, (b) integrating, (c) } \\
\text { compromising, (d) obliging, and } \\
\text { (e) avoiding? }\end{array}$ & $\begin{array}{lc}\text { Correlations between WI-target and CMS scores: } \\
\text { Accommodate CMS: } & .04 \\
\text { Avoid CMS: } & -.02 \\
\text { Integrate CMS: } & -.32^{* *} \\
\text { Dominate CMS: } & .14^{*} \\
\text { Compromise CMS: } & -.20^{* *} \\
\text { Correlations between WI-instigator and CMS scores: } \\
\text { Accommodate CMS: } & .02 \\
\text { Avoid CMS: } & -.07 \\
\text { Integrate CMS: } & -.36^{* *} \\
\text { Dominate CMS: } & .24^{* *} \\
\text { Compromise CMS: } & -.24 \\
* p<.05, * * p<.01 & \end{array}$ \\
\hline $\begin{array}{l}\text { 2. Are there differences between } \\
\text { the relationships of conflict } \\
\text { management style and } \\
\text { workplace incivility from the } \\
\text { perspectives of targets versus } \\
\text { instigators of incivility? }\end{array}$ & $\begin{array}{l}\text { The pattern of relationships between CMS scores and } \\
\text { WI-target scores was similar as that for CMS scores } \\
\text { and WI-instigator scores. } \\
\text { The higher the WI score (target or instigator) the } \\
\text { lower the CMS Integrate score. } \\
\text { The higher the WI score (target or instigator) the } \\
\text { higher the CMS Dominate score. } \\
\text { The higher the WI score (target or instigator) the } \\
\text { lower the CMS Compromise score. }\end{array}$ \\
\hline
\end{tabular}




\section{APPENDIX I}

Summary of Results for Research Question 3

\begin{tabular}{|c|c|}
\hline Research Question & Results of Analyses \\
\hline $\begin{array}{l}\text { 3. Do conflict management } \\
\text { styles affect the impact of } \\
\text { workplace incivility on } \\
\text { employee's job performance, } \\
\text { commitment to their } \\
\text { organization and turnover? }\end{array}$ & 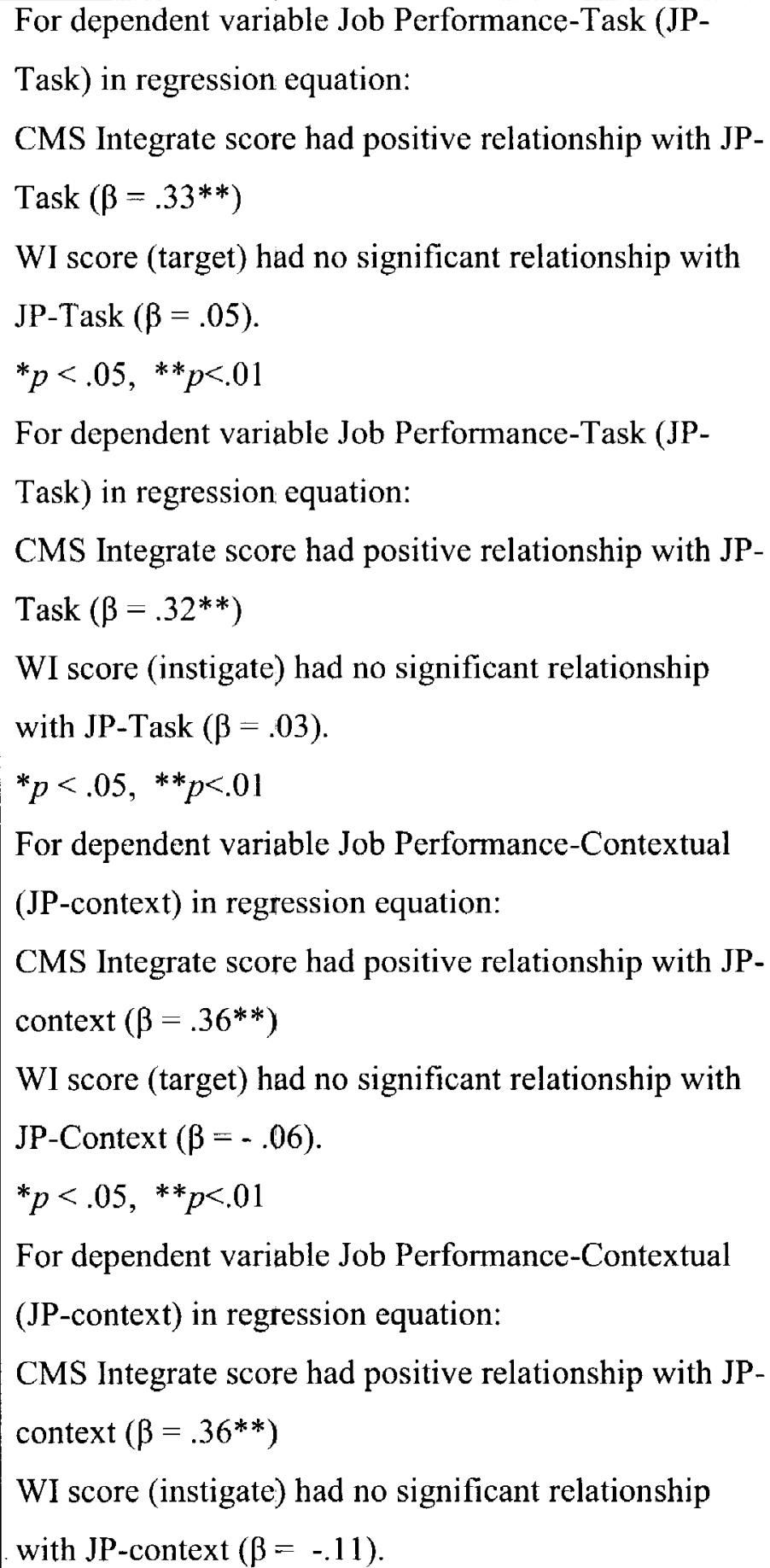 \\
\hline
\end{tabular}




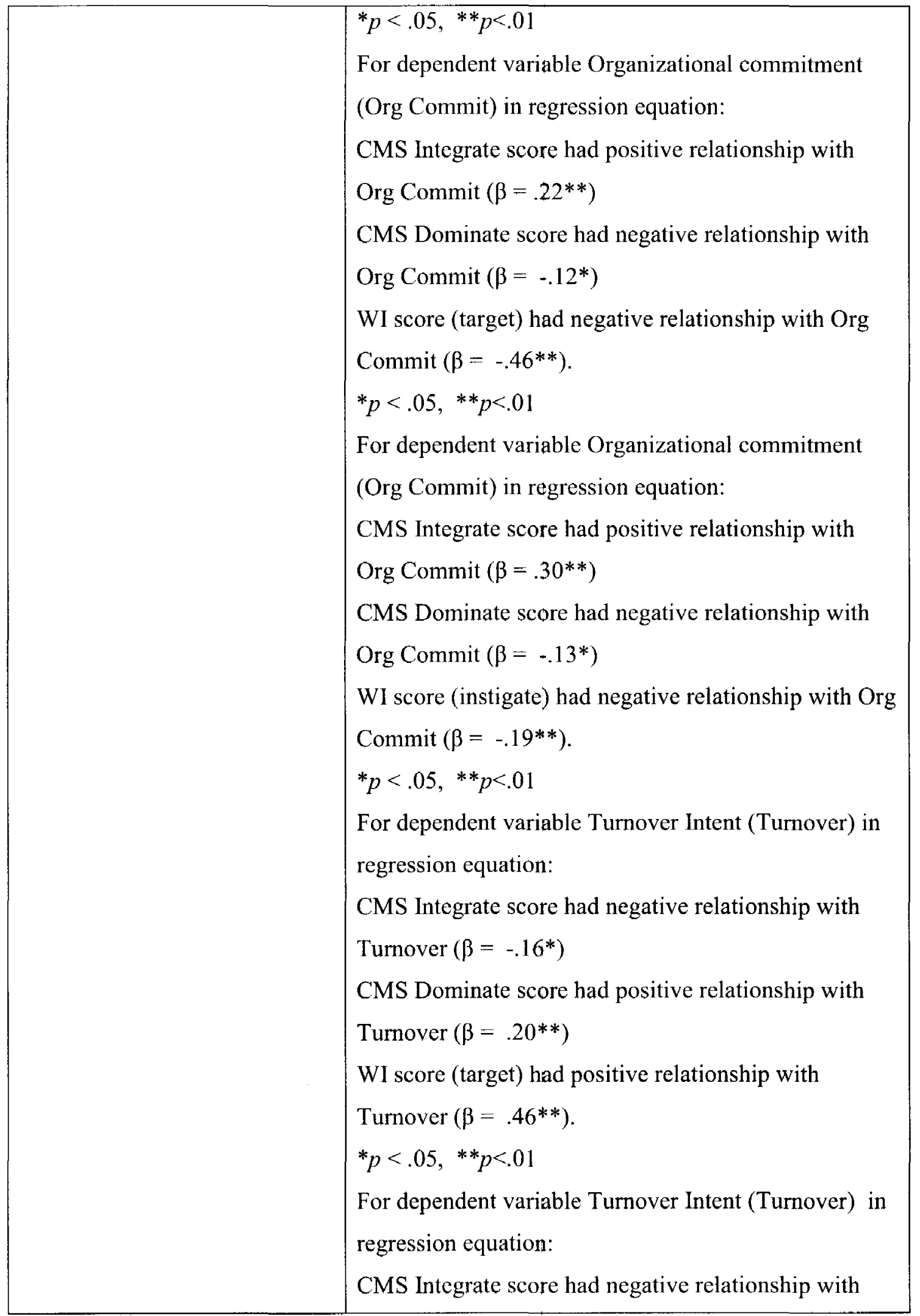




\begin{tabular}{|l|l|}
\hline Turnover $\left(\beta=-.22^{* *}\right)$ \\
CMS Dominate score had positive relationship with \\
Turnover $\left(\beta=.21^{* *}\right)$ \\
WI score $($ instigate $)$ had positive relationship with \\
Turnover $\left(\beta=.19^{* *}\right)$. \\
$* p<.05,{ }^{* *} p<.01$
\end{tabular}




\section{APPENDIX J}

Summary of Results for Research Question 4

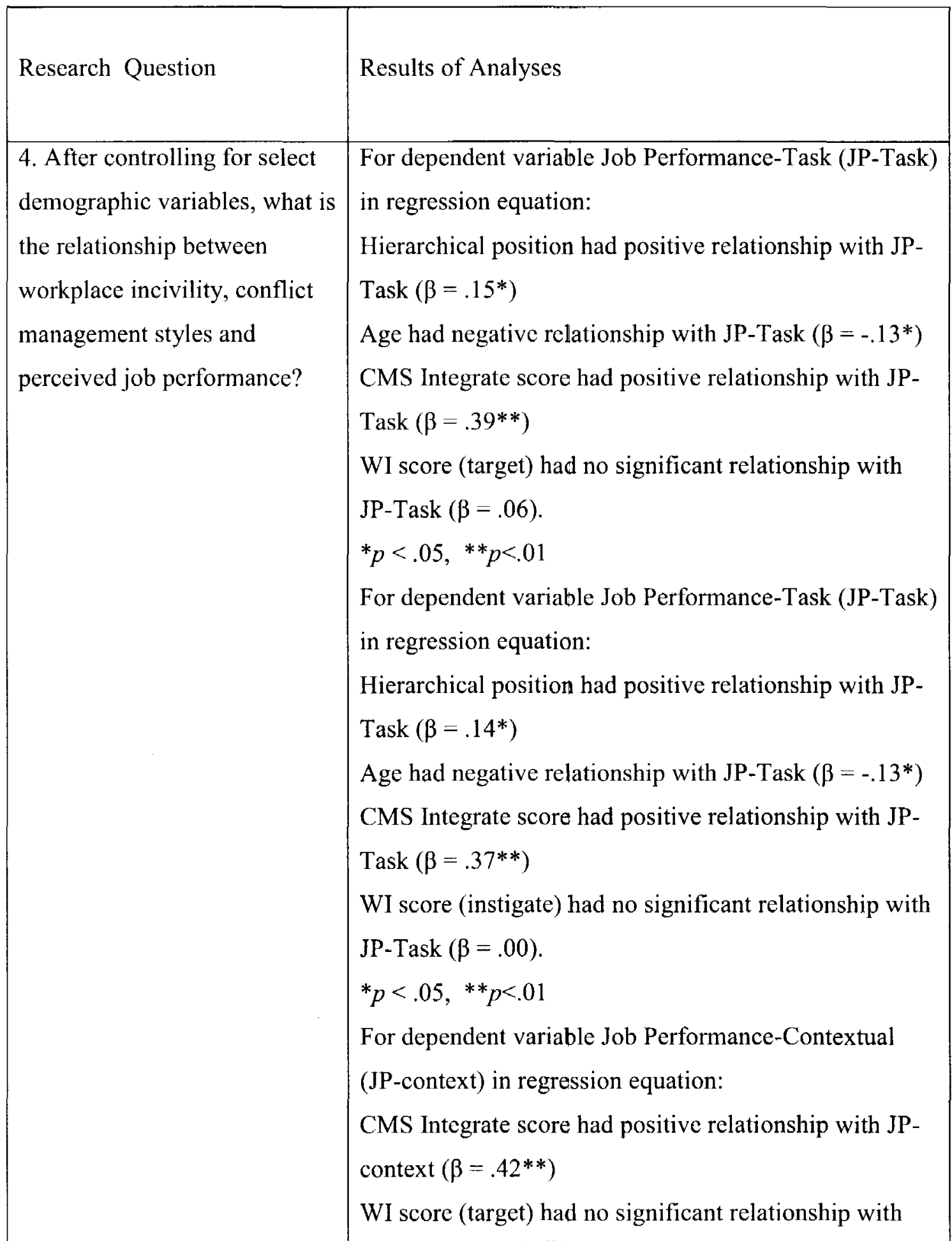




\begin{tabular}{|l|l|}
\hline & JP- context $(\beta=-.04)$ \\
$* p<.05, * * p<.01$ \\
For dependent variable Job Performance-Contextual \\
(JP-context) in regression equation: \\
CMS Integrate score had positive relationship with JP- \\
context $\left(\beta=.40^{* *}\right)$ \\
WI score (instigate) had no significant relationship with \\
JP- context $(\beta=-.10)$. \\
$* p<.05, * * p<.01$
\end{tabular}




\section{APPENDIX K}

Summary of Results for Research Question 5

\begin{tabular}{|c|c|}
\hline Research Question & Results of Analyses \\
\hline $\begin{array}{l}\text { 5. After controlling for select } \\
\text { demographic variables, what is } \\
\text { the relationship between } \\
\text { workplace incivility, conflict } \\
\text { management styles and } \\
\text { organizational commitment? }\end{array}$ & $\begin{array}{l}\text { For dependent variable Organizational Commitment } \\
\text { (Org Commit) in regression equation: } \\
\text { Age had positive relationship with Org Commit }(\beta= \\
\left..14^{*}\right) \\
\text { CMS Integrate score had positive relationship with Org } \\
\left.\text { Commit ( } \beta=.16^{*}\right) \\
\text { WI score (target) had negative relationship with Org } \\
\text { Commit }\left(\beta=-.40^{* *}\right) \text {. } \\
{ }^{*} p<.05, * * p<.01 \\
\text { For dependent variable Organizational Commitment } \\
\text { (Org Commit) in regression equation: } \\
\text { Age had positive relationship with Org Commit ( } \beta= \\
\left..13^{*}\right) \\
\text { CMS Integrate score had positive relationship with Org } \\
\text { Commit }\left(\beta=.23^{* *}\right) \\
\text { WI score }(\text { instigate) had negative relationship with Org } \\
\text { Commit }\left(\beta=-.21^{* *}\right) \text {. } \\
* p<.05, * * p<.01\end{array}$ \\
\hline
\end{tabular}




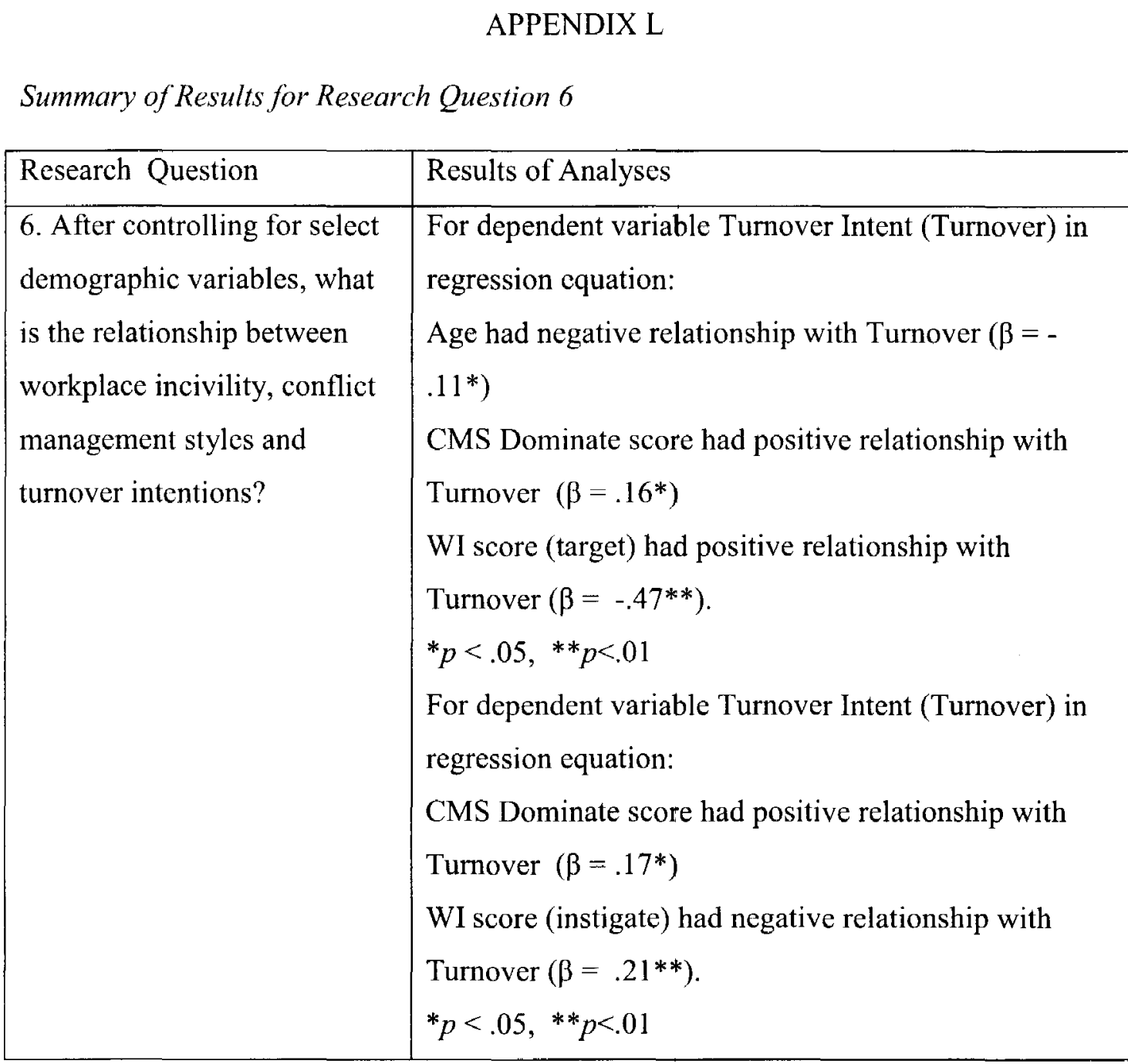




\section{WORKPLACE SURVEY}

Dear colleague,

You are being invited to participate in a research study. The purpose of this study is to learn about organizations and the process of conflict management. There are no known fisks foryour participation in this research study. This study is being conducted by Dr. Joe Petrosko and Jeannie Trudel, and is sponsored by the Leadership, Foundations and Human Resource Education (ELFH) department at Univers ity of Louisville. The information collected may not benefit you directly. The information leamed in this study may be helpful to others.

Your participation in this study is voluntary. By completing this survey you agree to take part in this research study. If you agree to participate, you will complete this survey questionnaire. The survey should take approximately $10-15$ minutes to complete. Youmay dedine to answer any questions that make you feel uncomfortable You may refuse to participate without being subject to any penalty of losing any benefits to which you are otherwise entitled.

Your completed survey will be stored within the ELFH department at the University of Louisville Individuals from the Department of Leadership, Foundations, and Hum an Resource Education, the University Human Studies Committee, the Institutional Review Board (IRB), the Human Subjects Protection Program Office (HSPPO), and other regulatory agencies may inspect these records. In al other respects, however, the data will be held in confidence to the extent permitted by law. Should the data be published, your identity and the identity of your organization would not be disclosed.

If you have any questions, concerns, or complaints about the research study, please contact: Dr. Joe Petrosko by phone at 502-852-0617 or by email at jpetro@louisville.edu or contact Jeannie Trudel by phone at 502-345 6737 or by email at Jeannie.trudel@indwes.edu.

If you have any questions about your rights a.s a research subject, you may call the University Human Studies Committees at (502) 852-5188. You can discuss any questions about your rights as a research subject, in confidence, with member of the committees. These are independent committees composed of people from the University community, staff of the institutions, as well as lay members of the community not connected with these institutions. The committees have reviewed this research study.

If you have concens or complaints about the research or research staff and you do not wish to give your name you may call 1-877-852-1167. This is a 24 hour hot line answered by people who do not work at the University of Louisville.

Sincerely,

Joe Petrosko

Seannie Trudel 


\section{WORKPLACE SURVEY}

OVERVIEW

Purpose of the Survey: The purpose of this survey is to leam about onganizations and the prosess of contikt management. Your as 5 ;stance in this project is kindly requested. Your participation is strictly voluntary and all responses will be keptconfidential.

Instructions: Please follow the instructions in each section. Upon completion. place the completed starvey in the self-adiresed, siamped ervelope prowded wht the surey and place it in the maxt

Thark you in advance for your time and panticipation.

Section 1: General Inomation

OHRECTIONS: Fiease check one box for each of the guestions below or complete the bilis where appropriate:

1. What is you gerder?

I Female

口 Ma垟

2. What is your ethricty? plesse seiect on one

a White American

] Aftican American

I Other

3. How kng have you been working at this current company?

D $0-2$ years

D $3-5$ years

D 6-8years

$\square$ or more years

4. What is your position in the company? (Check ondy one)

I] Foor/ hine worker

a Asministrative/derikal

I Supervicor/ junior management

I. Middie management

9 Executive management

$\square$ Other. Please specify

5. Are you loheck all those that apply)

I) union

a. Mon-union

$\square$ Hourly

a sataried

1 
6. What is you age?

$\square 18-30$

כ 31.44

0 45-55

$956-65$

a 56 and above

\section{Section 2 , Your Experienees of Workalace incivility}

DIRECTIONS: For each statement below; circle the one number on the scales that best represents your level of frequency of experiencing each of the stated incidents. The scales range from a low of 1 (Mever) to a high of 5 [Akways].

During the past year while employed at your current organization, have you been in a situation where any of your superiors or coworkers:

7 Put you down of was condescending to you?

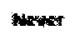

S Paid fittle attention to your statement or showed litte interest in your opinion?

9. Made demeaning or derogatory remarks about you?

10 Addressed you in ungrofessional terms, Either publich or priwately?

11 Ignored or exduded you from professiona camaraderie?

12 Doubted your judgment on a matter over which you have tespondibility?

13 Made thwanted attempts to draw you into a discussion of personal matters?

\begin{tabular}{|c|c|c|c|c|}
\hline wert & semsty & $\begin{array}{l}\text { some } \\
\text { nonns }\end{array}$ & orten & Anwars \\
\hline 1 & 2 & 3 & 4 & 5 \\
\hline 1 & $z$ & 3 & 4 & 5 \\
\hline 1 & 2 & 3 & 4 & 5 \\
\hline 1 & 2 & 3 & 4 & 5 \\
\hline 1 & 2 & 3 & 4 & 5 \\
\hline 1 & 2 & 3 & 4 & 5 \\
\hline & 2 & 3 & 4 & 5 \\
\hline
\end{tabular}




\section{Section 3. Contict Management Styles}

DIRECTIONS: For each statement below, circle the one number on the scales that best represents your level of frequency of using the response. The calks range from a low of 1 (Newer) to a high of 5 (Ahways).

When I have had conflicts at work, I respond most frequently in the following way:

\begin{tabular}{|c|c|c|c|c|c|c|}
\hline & & Never & marer & 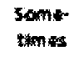 & ortan & Anews \\
\hline 14 & I give in to the wishes of the otrec party. & 1 & 2 & 3 & 4 & 5 \\
\hline 15 & Ity to mininuze the differences. & $\mathbf{1}$ & $z$ & 3 & 4 & 5 \\
\hline 16 & I work out a mutustly beneficial solution. & 1 & 2 & 3 & 4 & 5 \\
\hline 17 & ido ekerything to wirk. & $\mathbf{I}$ & 2 & 3 & 4 & 5 \\
\hline $1 E$ & I adapt to the other persari's goats and interests. & 1 & 2 & 3 & 4 & 5 \\
\hline 19 & 1 insist that we both give in a litte. & 1 & 2 & 3 & 4 & 5 \\
\hline 20 & I push for my own point of wiew. & 1 & 2 & 3 & 4 & $\mathbf{5}$ \\
\hline 21 & I avoid a confrontation about our differences. & 1 & 2 & 3 & 4 & 5 \\
\hline 22 & $\begin{array}{l}\text { 1 stand for my own and the other's gouls and } \\
\text { interest. }\end{array}$ & 1 & 2 & 3 & 4 & 5 \\
\hline 23 & it try to obtain a midde-of-the-ros a solution. & 1 & 2 & 3 & 4 & 5 \\
\hline 24 & i egres with the other person. & 1 & 2 & 3 & 4 & 5 \\
\hline 25 & $\begin{array}{l}\text { lexamine ideas from both sides to find a mutually } \\
\text { optimal solution. }\end{array}$ & 1 & $z$ & $\mathbf{3}$ & 4 & 5 \\
\hline 26 & I try to work out a fifty-fifty compromise. & $\mathbf{I}$ & 2 & 3 & 4 & 5 \\
\hline 27 & If fight for a good outcome for myself. & 1 & 2 & 3 & 4 & $\mathbf{s}$ \\
\hline
\end{tabular}

3 


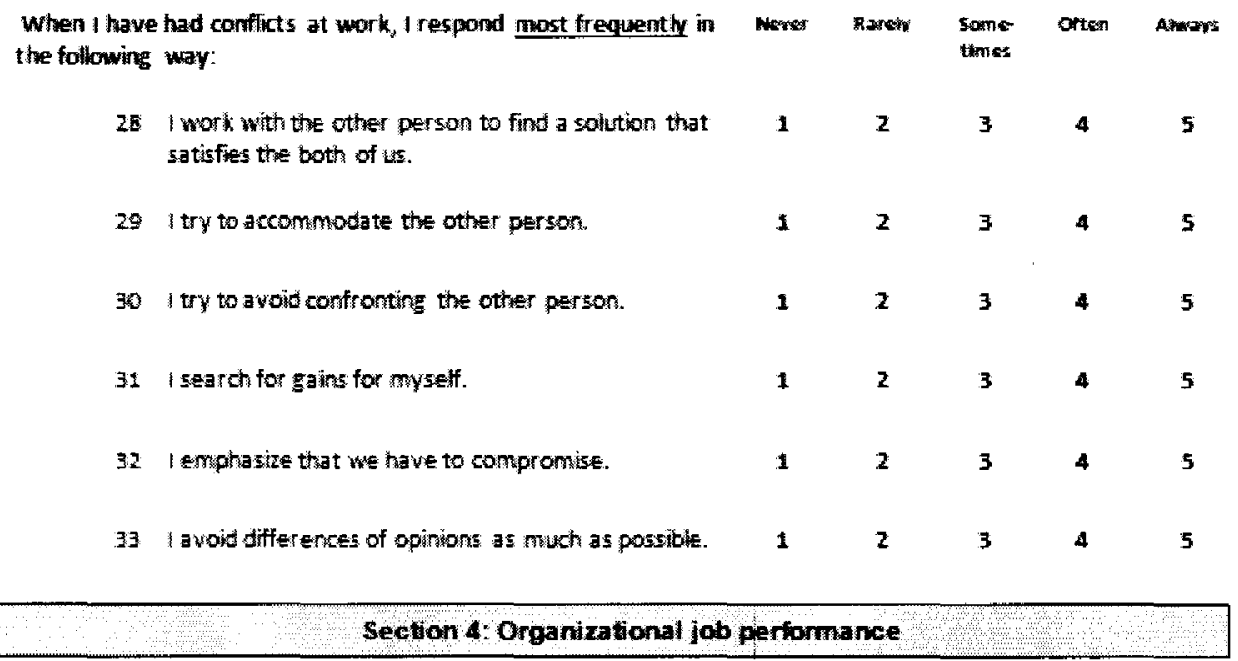

DARECIONS: For each statement beikw, cir de the one number on the scales that best represente your bevel of agresnent. The scakes range from a bw of 1 (Not at all Gehy) to a high of 5 (Extremehy tikely).

In responding to eash statement, think about your job, workplace or office in which you are presentw involwed:

In comparison to other individuals in your organization, how likely it is that you:

34 Hse probiem sovire skills.

35 Perform administrative tasks.

35 Have 3 good overall tectrical performanke.

37 Plan your work.

38 Organize your work.

39 cooperate with others in a team.

40 Persist in overcoming obstackes to compiete a task

41 Look for a ctallering assignment/task

\begin{tabular}{|c|c|c|c|c|}
\hline Wat at a & $\begin{array}{l}\text { Somenthat } \\
\text { seacerar }\end{array}$ & Whety & Very & $\begin{array}{c}\text { Entremer } \\
\text { tukery }\end{array}$ \\
\hline 1 & 2 & 3 & 4 & 5 \\
\hline 1 & $z$ & 3 & 4 & 5 \\
\hline 1 & 2 & 3 & 4 & 5 \\
\hline 1 & 2 & 3 & 4 & 5 \\
\hline 1 & 2 & 3 & 4 & 5 \\
\hline 1 & 2 & 3 & 4 & 5 \\
\hline 1 & $z$ & 3 & 4 & 5 \\
\hline 1 & 2 & 3 & 4 & 5 \\
\hline
\end{tabular}

4 
In comparison to ot her individuals in your organization, how likely it is that you:

42 Pay attention to important detalis.

43. Support and encourage a coworker with a problem.

44 Work well with others.

\begin{tabular}{|c|c|c|c|c|}
\hline 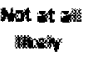 & Samewat & Muxir & Ver & Extrem \\
\hline $\mathbf{I}$ & 2 & 3 & 4 & 5 \\
\hline 1 & 2 & 3 & 4 & 5 \\
\hline 1 & 2 & 3 & 4 & 5 \\
\hline
\end{tabular}

\section{Section 5. Perceptions of Organization}

DRECTION5: For each statement below, cirche the one number on the scales that best represents your kvel of agreement. The scakes fange from a low of 1 (stronghy Disagree) to a bigh of 5 (Strongk Agree).

My perceptions of my organization and job:

45 I would be very happy to spend the rest of my career in this organization.

46. I enjoy discussing my organization with people outcide

47 I realy feel as it this arganiza tion's probleme are my own.

45. I think 1 could easily become as attached to another organization as 1 am to this one. $[\mathrm{R}\}$

49 I do not feel tike "part of the family" at my organization. $|R|$

501 do not feel emotionaly attacted to this organization. I $R$

51 This organization has a great deal of persond meaning for me.

52 I do not feel a strong sence of belonging to my organization. (R)

53 I often thing of heaving the orgarization.

54 It ie very possible that 1 look for new job next year.

55 If I may choose again, I will choose to work for the exrent organization. $[R$ )

\begin{tabular}{|c|c|c|c|c|}
\hline $\begin{array}{l}\text { Stronat } \\
\text { oxsacter }\end{array}$ & Drestres & 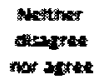 & Adres & $\begin{array}{l}\text { Strongh } \\
\text { Aares }\end{array}$ \\
\hline 1 & 2 & 3 & 4 & 5 \\
\hline 1 & $z$ & 3 & 4 & 5 \\
\hline 1 & 2 & 3 & 4 & 5 \\
\hline 1 & 2 & 3 & 4 & 5 \\
\hline $\mathbf{1}$ & 2 & 3 & 4 & 5 \\
\hline 1 & 2 & 3 & 4 & 5 \\
\hline 1 & $z$ & 3 & 4 & 5 \\
\hline 1 & $\mathbf{z}$ & 3 & 4 & 5 \\
\hline 1 & $z$ & $\mathbf{3}$ & 4 & 5 \\
\hline 1 & 2 & 3 & 4 & 5 \\
\hline 1 & 2 & 3 & 4 & 5 \\
\hline
\end{tabular}


CIRECTIONS: for sach statement below, circle the one number on the scakes that best represents your level of frequency of engaging in each of the stated behaviors. The scales range from a low of 1 (Never) to a high of 5 [Ahways].

How often you have exhibited the following behaviors in the past year to someone at work:

56 Put someone down or was condescending to thin or her?

57 Paid littic attention to a statement made by someane or showed litte intereat in his or her opinon?

59 Made demeanirg, rude or derogatory remarhs about someone?

59 Add essed someone in unprofe5sonal terme, either publicty or privatey?

60 Igwored or excluded someone from profescional camaraderie [E.g. social conwer sationl?

61 Doubted somedon's jutgment on a matter gver which he or she has resporsibility?

62 Made unwanted attempte to draw someone his a discussion of personal patters?

\begin{tabular}{|c|c|c|c|c|}
\hline Newer & naredr & $\begin{array}{l}\text { Soms } \\
\text { tomser }\end{array}$ & onth & Mwar \\
\hline 1 & 2 & 3 & 4 & 5 \\
\hline 1 & 2 & 3 & 4 & 5 \\
\hline 1 & 2 & 3 & 4 & 5 \\
\hline 1 & 2 & 3 & 4 & 5 \\
\hline 1 & 2 & 3 & 4 & 5 \\
\hline $\mathbf{1}$ & 2 & 3 & 4 & 5 \\
\hline 1 & 2 & 3 & 4 & 5 \\
\hline
\end{tabular}

-Thank you for participating in this surver 


\section{CURRICULUM VITAE}

NAME: Jeannie Trudel

ADDRESS: Indiana Wesleyan University

Merrillville Education Center

8415 Georgia St.

Merrillville, IN 46410

DOB: $\quad$ Malaysia, January 14, 1964

EDUCATION \& TRAINING:

B.Ec., Economics

Monash University, Australia

1987

LLB, Law

Monash University, Australia

1989

M.A., Conflict Management \& Negotiation

California State University at Dominguez Hills

2002

AWARDS: Outstanding Graduate Student award, 2002, California State University Dominguez Hills

PROFESSIONAL SOCIETIES:

American Evaluation Association

Association of Conflict Resolution

PRESENTATIONS:

Evaluation of an Adjunct Faculty Development Program - American Evaluation Association Conference, Denver 2008

Conflict Management in the Workplace- Conference for KY State Health Department workers, Louisville, 2006

Workplace Issues- "Dealing with Difficult People", Statewide Regional Family Court Conferences, Administrative Office of Courts, KY, 2004 